\title{
A Study of Additives for Aquagel/Bentonite Based Drilling Fluids in Relation to Filtration and Rheological Properties, Smectite Inhibition and Their Application to Marcellus Shale
}

Ike Eleanya O. Onuoha

West Virginia University

Follow this and additional works at: https://researchrepository.wvu.edu/etd

\section{Recommended Citation}

Onuoha, Ike Eleanya O., "A Study of Additives for Aquagel/Bentonite Based Drilling Fluids in Relation to Filtration and Rheological Properties, Smectite Inhibition and Their Application to Marcellus Shale" (2011). Graduate Theses, Dissertations, and Problem Reports. 2224.

https://researchrepository.wvu.edu/etd/2224

This Thesis is protected by copyright and/or related rights. It has been brought to you by the The Research Repository @ WVU with permission from the rights-holder(s). You are free to use this Thesis in any way that is permitted by the copyright and related rights legislation that applies to your use. For other uses you must obtain permission from the rights-holder(s) directly, unless additional rights are indicated by a Creative Commons license in the record and/ or on the work itself. This Thesis has been accepted for inclusion in WVU Graduate Theses, Dissertations, and Problem Reports collection by an authorized administrator of The Research Repository @ WVU. For more information, please contact researchrepository@mail.wvu.edu. 
A Study of Additives for Aquagel/Bentonite Based Drilling Fluids in

Relation to Filtration and Rheological Properties, Smectite Inhibition and Their Application to Marcellus Shale

\title{
Ike Eleanya O. Onuoha
}

Thesis Submitted to the College of Engineering and Mineral Resources at West Virginia University in partial fulfillment of the requirements for the degree of

\author{
Master of Science \\ In \\ Petroleum and Natural Gas Engineering
}

Ilkin Bilgesu, PhD., Chair

Sam Ameri, M.S.

Tom Mroz, M.S.

Kashy Aminian, PhD.

Department of Petroleum and Natural Gas Engineering

Morgantown, West Virginia

2011

Keywords: Marcellus Shale, Diamino Alkanes, Inhibition, Swelling, Bentonite, Chlorides, Hydroxides, Alkali Metals, Alkaline Earth Metals, Transition Metals, Smectite Clay, Rheology, Filtration, Drilling Fluids, Mud

Copyright 2011 Ike Eleanya O. Onuoha 


\section{Abstract \\ A Study of Additives for Aquagel/Bentonite Based Drilling Fluids in Relation to Filtration and Rheological Properties, Smectite Inhibition and Their Application to Marcellus Shale}

\section{Ike Eleanya O. Onuoha}

Since the dawn of rotary drilling, engineers and scholars have persevered, through study and research, to formulate an optimum inhibitive drilling fluid for the shale formations. Although fluids with acceptable performance in shale have been formulated, one only needs to examine the word "acceptable" in the context above to realize that the industry has ongoing activities to formulate an optimum inhibitive fluid for the Marcellus Shale. In accordance, this research seeks to fabricate a means of reducing formation damage (permeability reduction), stuck pipe incidences, heaving, sloughing and caving which are all due to the swelling of Smectite clay and shale. The ultimate achievement in reducing formation damage would consequently lead to an augmentation in oil and natural gas production from the Marcellus Shale.

This research paper, in its infinite practicality, illustrates the problems associated with swelling and dispersion of shale. The chemistry behind the swelling/dispersion of shale validates this research with respect to inhibition/swelling. Also, presented are the experimental procedures performed in the formulation of an optimum inhibitive drilling fluid such as rheological, filtration and linear swelling experiments. 
Most importantly, this paper introduces a novel approach and experiment towards the development of an optimum inhibitive drilling fluid. The study utilizes a novel chemical in the industry: $\alpha-\omega$ Diamino Alkanes (Diamino Butane and Diamino Hexane) as well as comparing the inhibitive capability of two familiar chemicals in conjunction with Chlorides and Hydroxides of Alkali metals, Alkaline earth metals and Transition metals $\left(\mathrm{K}^{+}, \mathrm{Na}^{+}, \mathrm{Zn}^{+}, \mathrm{Ca}^{2+}, \mathrm{Mg}^{2+}, \mathrm{Li}^{+}\right.$etc $)$in various concentrations.

The rheological, shale inhibition and filtration effects of the aforementioned Hydroxide and Chloride chemicals were tested and examined which led to the subsequent elimination and selection of certain fluids which this research has recommended for testing in Marcellus Shale in West Virginia and similar shale formations throughout the globe. Universally acceptable filtrate loss correlations have been formulated, during the course of this research, for various base drilling fluids.

API standard procedures were utilized in the evaluation of rheological and filtration properties of base drilling fluids and the results obtained from the rheological and filtration experiments are independent of shale formation characteristics. However, the inhibition/Swelling test was limited to the Marcellus Shale formation in the State of West Virginia and the results obtained for inhibition/swelling may not be universally acceptable in the evaluation of other shale formations. 


\section{Acknowledgement}

I would like to express my gratitude and special thanks to Dr. Ilkin Bilgesu for his unwavering commitment to my research, his omnipresence which allowed for easy access to vital information, his passion and infinite interest in my research topic. In addition, I would like to extend my acknowledgement to Professor Sam Ameri for his generous contributions in the form of tuition waivers and exceptional teaching methods.

Additionally, I thank Tom Mroz of the US Department of Energy for his remarkable contribution, in the form of crucial Shale samples and equipments, towards the accomplishment of this research. In accordance, some of the experiments conducted during my research would not have been possible without his generosity. Furthermore, I thank my parents for their unfaltering commitment to my life-long education, in the form of financial assistance, love, affection, encouragement and praise.

Also, my appreciation propagates and extends to all my friends and professors at WVU who motivated me throughout my MS program as well as transferred technical knowledge, in the areas of drilling, production and reservoir engineering, to me.

More so, I thank Dr. Kashy Aminian for the efficacy of his teaching method via in-class software, for agreeing to be a member of my committee and for his efficacious teaching methods in reservoir engineering. Furthermore, this research is dedicated to solving the Marcellus and Gulf of Mexico Shale swelling predicaments of the Oil and Gas Industry.

Finally, my special thanks extends to Dr. John Quaranta of the Civil Engineering Department at West Virginia University for providing a sophisticated and sensitive Linear Swell Meter. 


\section{Table of Contents}

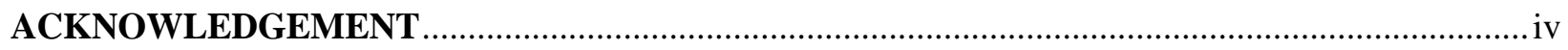

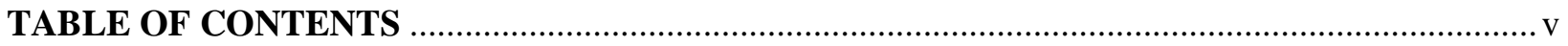

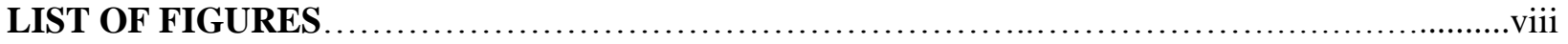

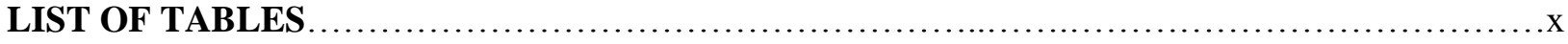

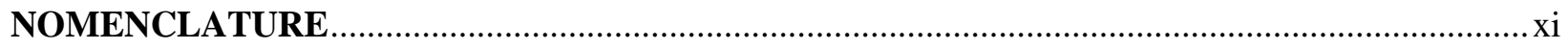

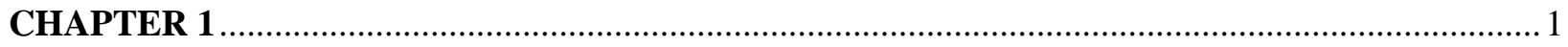

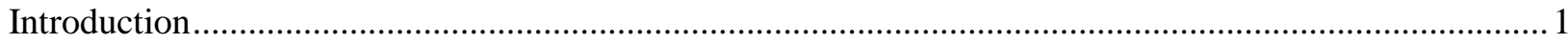

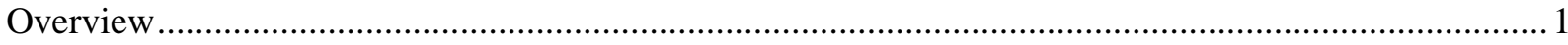

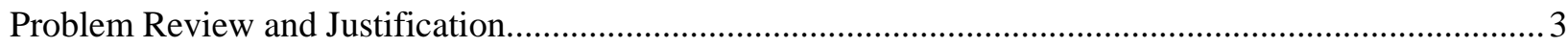

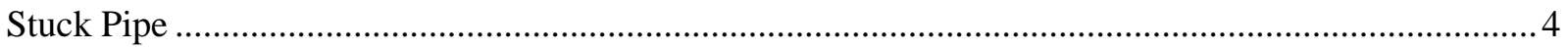

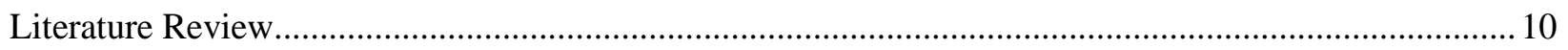

Comparison of Previous Research to this Research........................................................................ 10

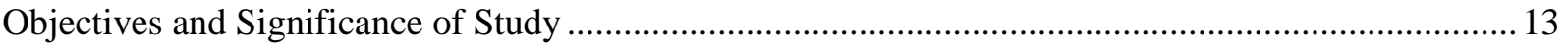

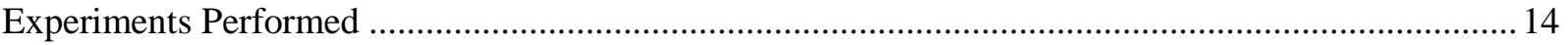

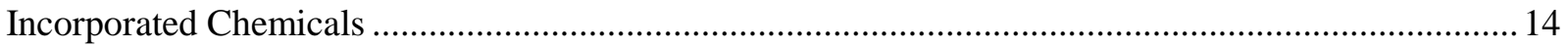

CHAPTER 2

Fundamentals of Drilling Fluids, Shale and Shale \& Drilling Fluid Interactions.................................. 15

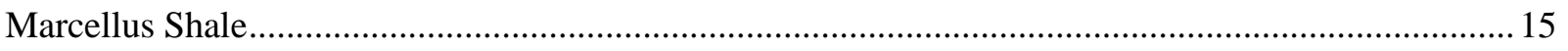

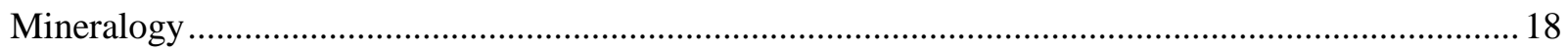

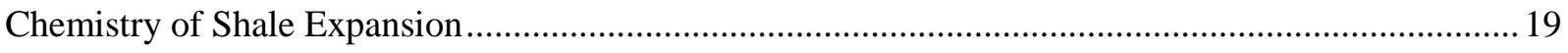

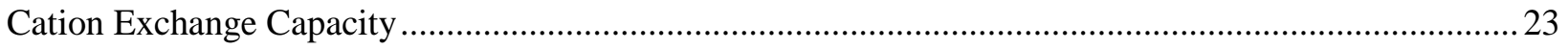

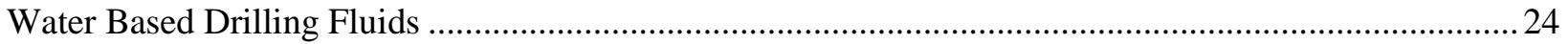

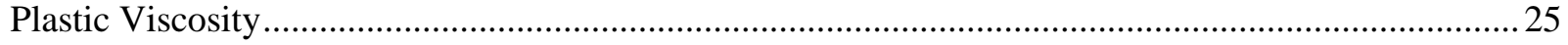

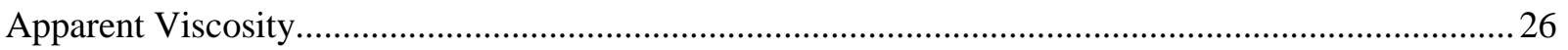

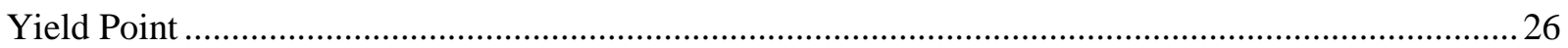

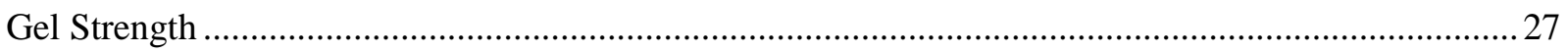

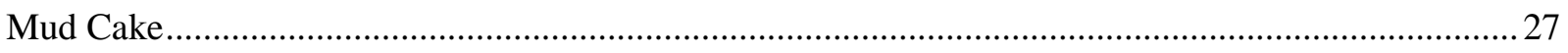

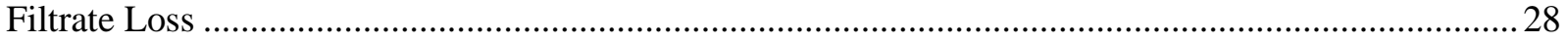

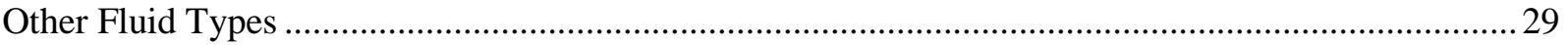




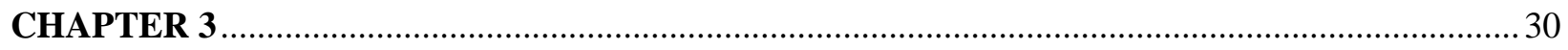

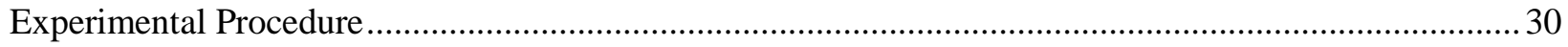

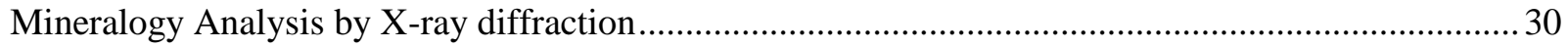

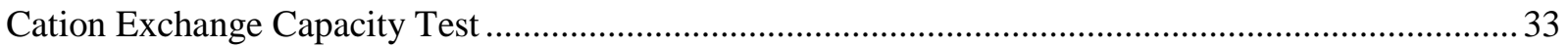

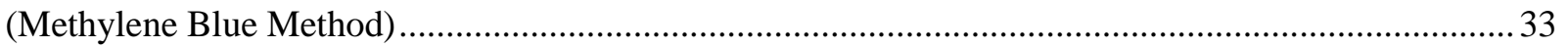

Spot-test for Endpoint determination of Methylene blue titration ................................................... 35

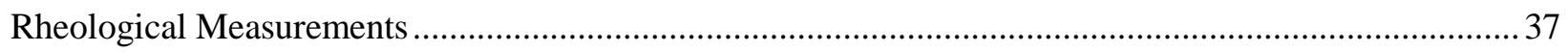

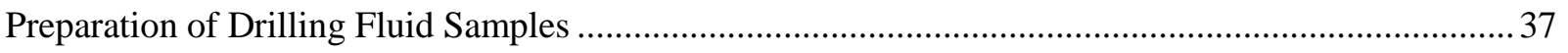

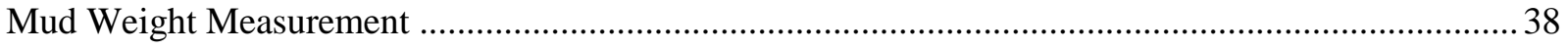

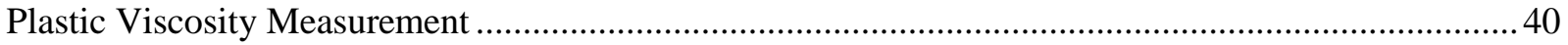

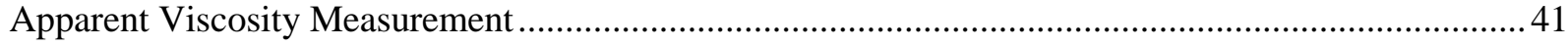

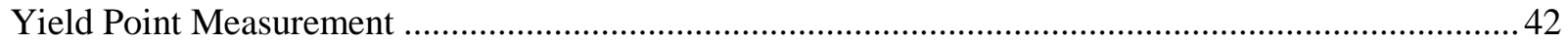

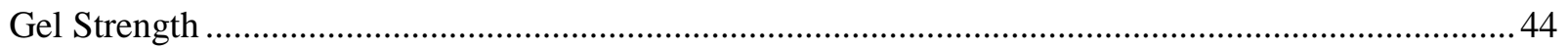

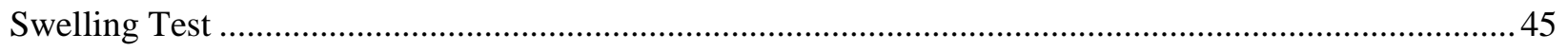

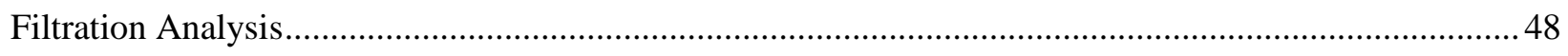

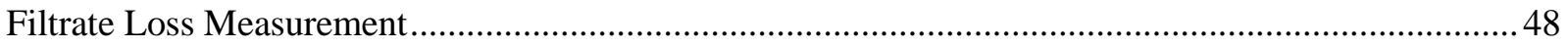

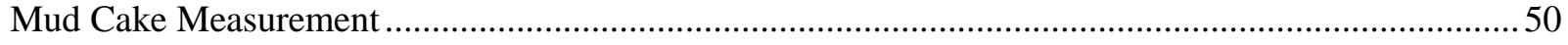

CHAPTER 4

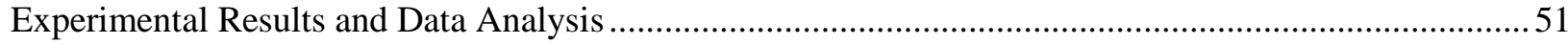

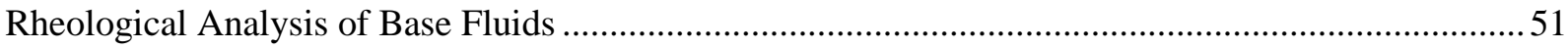

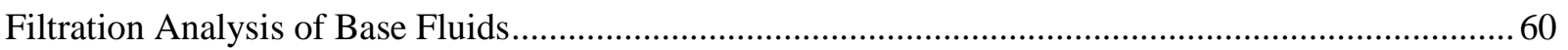

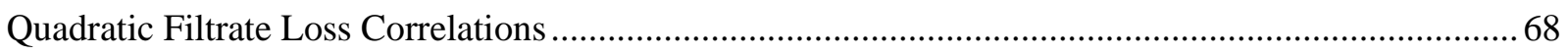

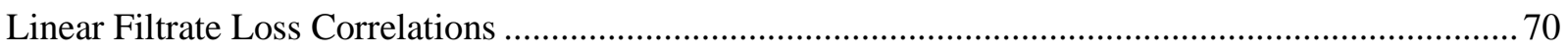

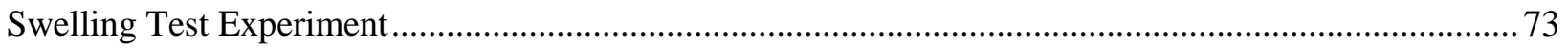

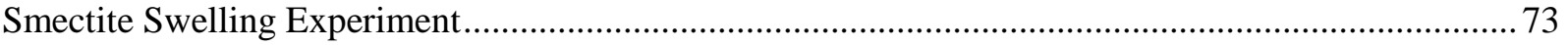

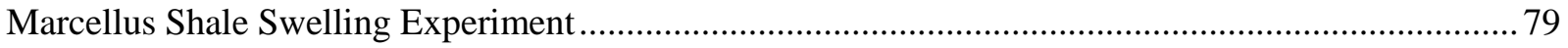

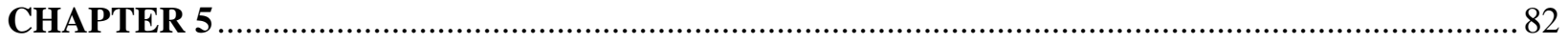

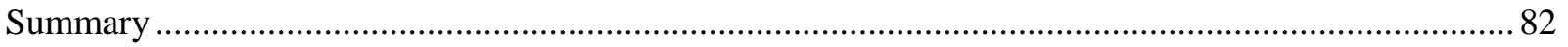

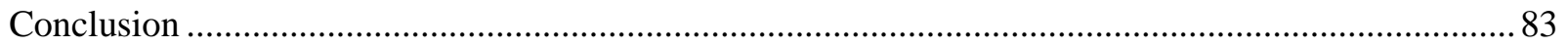

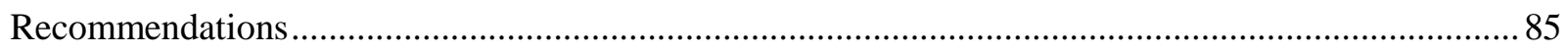

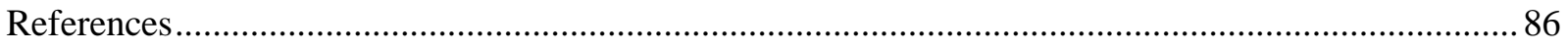

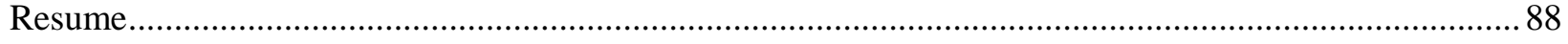

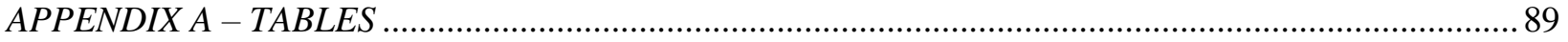




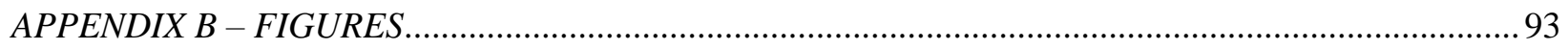

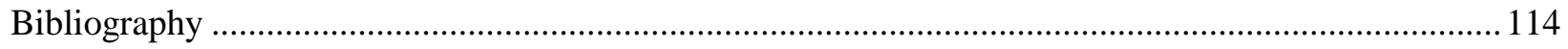




\section{$\underline{\text { List of Figures }}$}

Figure 1.1: Migration of water into the formation, causing the swelled shale to collapse and accumulate around the BHA .5

Figure 1.2: Insufficient mud weight to keep the hole from contracting ................................................ 6

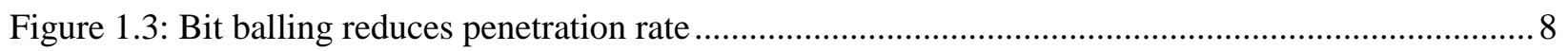

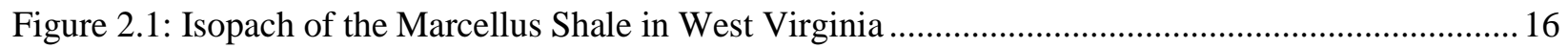

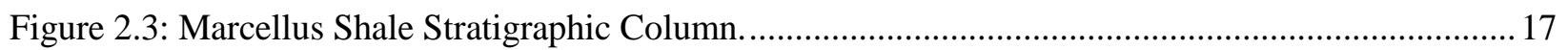

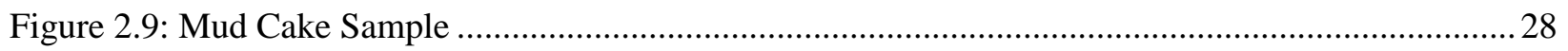

Figure 3.2: Rhomaa Umaa Plot compared with XRD results from single shale sample of the Marcellus

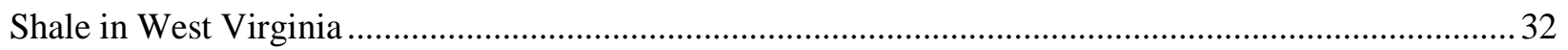

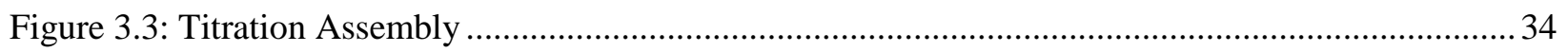

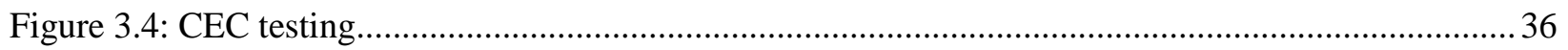

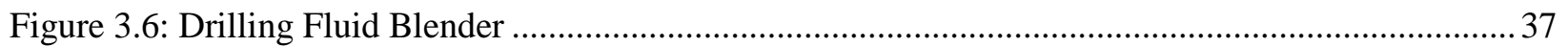

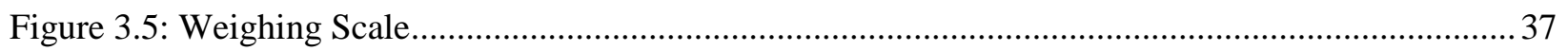

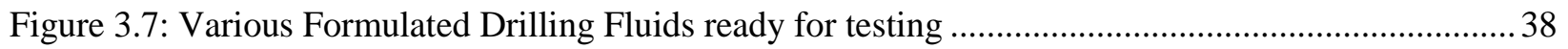

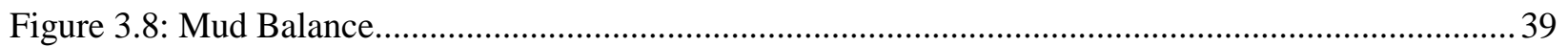

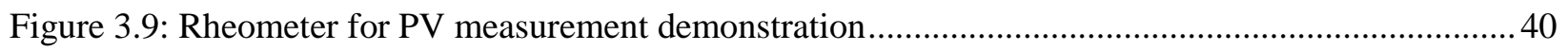

Figure 3.10: Rheometer for AV measurement demonstration ................................................................. 41

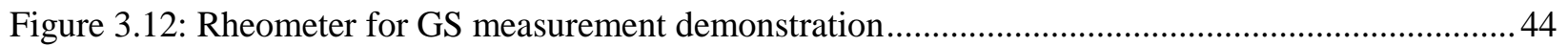

Figure 3.13: Uncrushed Marcellus Shale samples from WV\#6 well in West Virginia. $4737 \mathrm{ft}$ (Courtesy of

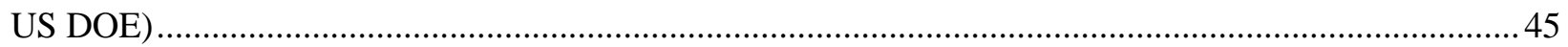

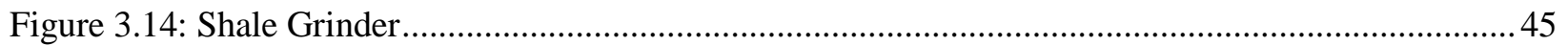

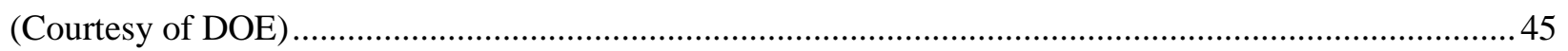

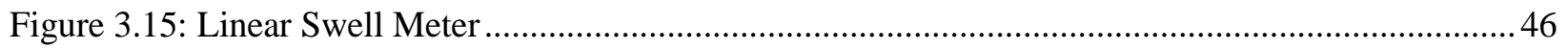

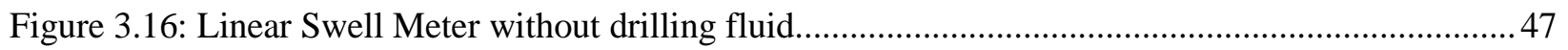

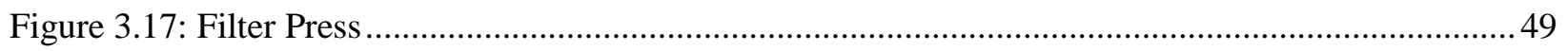

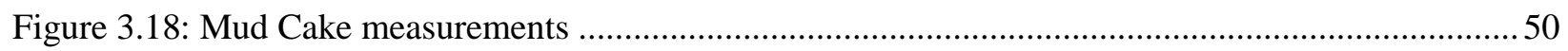

Figure 4.2: Variation of Apparent Viscosity of Base Fluids with Hydroxide and Chloride concentrations.

Figure 4.3 Variation of Gel Strength of Base Fluids with Hydroxide and Chloride concentrations. ..........56

Figure 4.4 Variation of Yield Point of Base Fluids with Hydroxide and Chloride concentrations. ...........57

Figure 4.6:Variation of Filtrate loss with square root of time for Low Loss Systems............................. 64

Figure 4.7: Variation of Filtrate loss with square root of time for MgCL-Aquagel systems.....................65

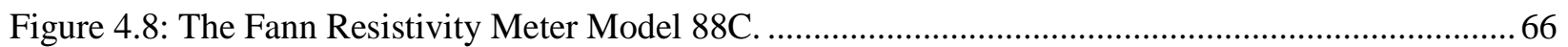

Figure 4.9: Variation of mud cake thickness with concentration for Base Drilling Fluids.........................67

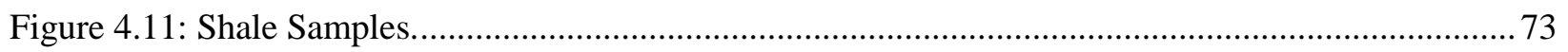

Figure 4.12: \%Linear Swelling of Smectite Caused by Several Fluid Candidates (1\% of Chloride or

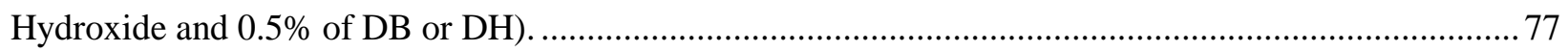

Figure 4.13: \%Linear Swelling of Fluid-contacted Smectite after Exposure to NaCL (1\% of Chloride or

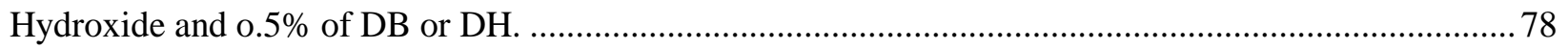

Figure 4.14: Bar Chart for Percentage Linear Swelling of Fluid-contacted Shale ................................... 81

Figure B.1: Variation of Yield Point with Hydroxide concentration for Base Drilling Fluids.................. 94

Figure B.2: Variation of Gel Strength with Hydroxide concentration for Base Drilling Fluids................95 
Figure B.3: Variation of Apparent Viscosity with Hydroxide concentration for Base Drilling Fluids. .....96

Figure B.4: Variation of Plastic Viscosity with Hydroxide concentration for Base Drilling Fluids. .........97

Figure B.5: Variation of Yield Point with Chloride concentration for Base Drilling Fluids.....................98

Figure B.6: Variation of Gel Strength with Chloride concentration for Base Drilling Fluids...................99

Figure B.7: Variation of Apparent Viscosity with Chloride concentration for Base Drilling Fluids. ...... 100

Figure B.8: Variation of Plastic Viscosity with Chloride concentration for Base Drilling Fluids............ 101

Figure B9: Variation of Filtrate loss with square root of time for $\mathrm{CaCl}_{2}$-Aquagel systems. .................. 102

Figure B10: Variation of Filtrate loss with square root of time for LiCl-Aquagel systems..................... 103

Figure B11: Variation of Filtrate loss with square root of time for $\mathrm{MgOH}_{2}$-Aquagel systems. .............. 104

Figure B12: Variation of Filtrate loss with square root of time for $\mathrm{LiOH}-A q$ quagel systems.................... 105

Figure B13: Variation of Filtrate loss with square root of time for Extreme high loss systems.............. 106

Figure B14: Variation of Filtrate loss with square root of time for High and Low systems.................... 107

Figure B15: Variation of Filtrate loss with square root of time for High Loss systems. ......................... 108

Figure B16: Variation of Filtrate loss with square root of time for ZnCl-Aquagel systems.................... 109

Figure B17: Variation of Filtrate loss with square root of time for KCl-Aquagel systems. .................... 110

Figure B18: Variation of Filtrate loss with square root of time for $\mathrm{CaOH}_{2}$-Aquagel systems. ...............111

Figure B19: Variation of Filtrate loss with square root of time for $\mathrm{NaCl}$-Aquagel systems. ................... 112

Figure B20: Variation of Filtrate loss with square root of time for $\mathrm{MgCl}_{2}$-Aquagel systems. ................ 113 


\section{$\underline{\text { List of Tables }}$}

Table 1.1: Base Drilling Fluid Systems and their compositions ......................................................... 12

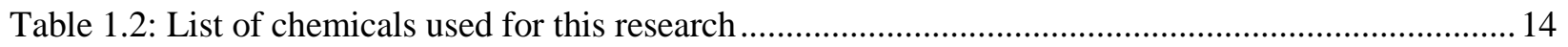

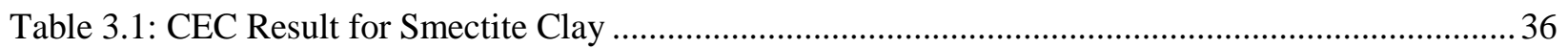

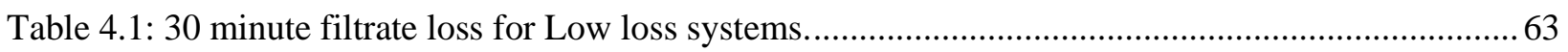

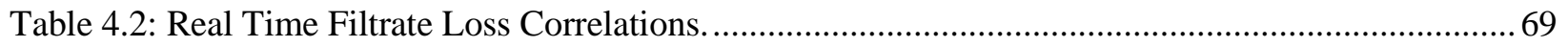

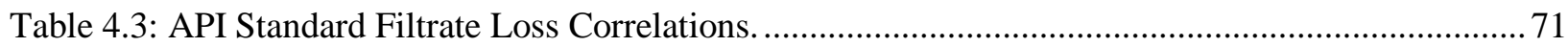

Table 4.4: Results of Inhibition Test on Smectite Montmorillonite Clays. ............................................. 76

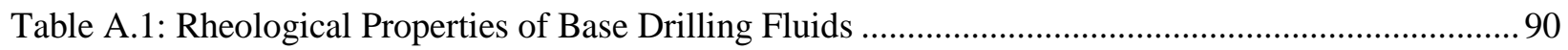

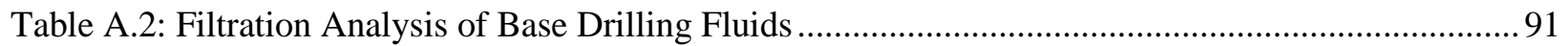

Table A.3: Classification of Base Drilling Fluids with respect to Filtrate loss.......................................92 


\section{Nomenclature}

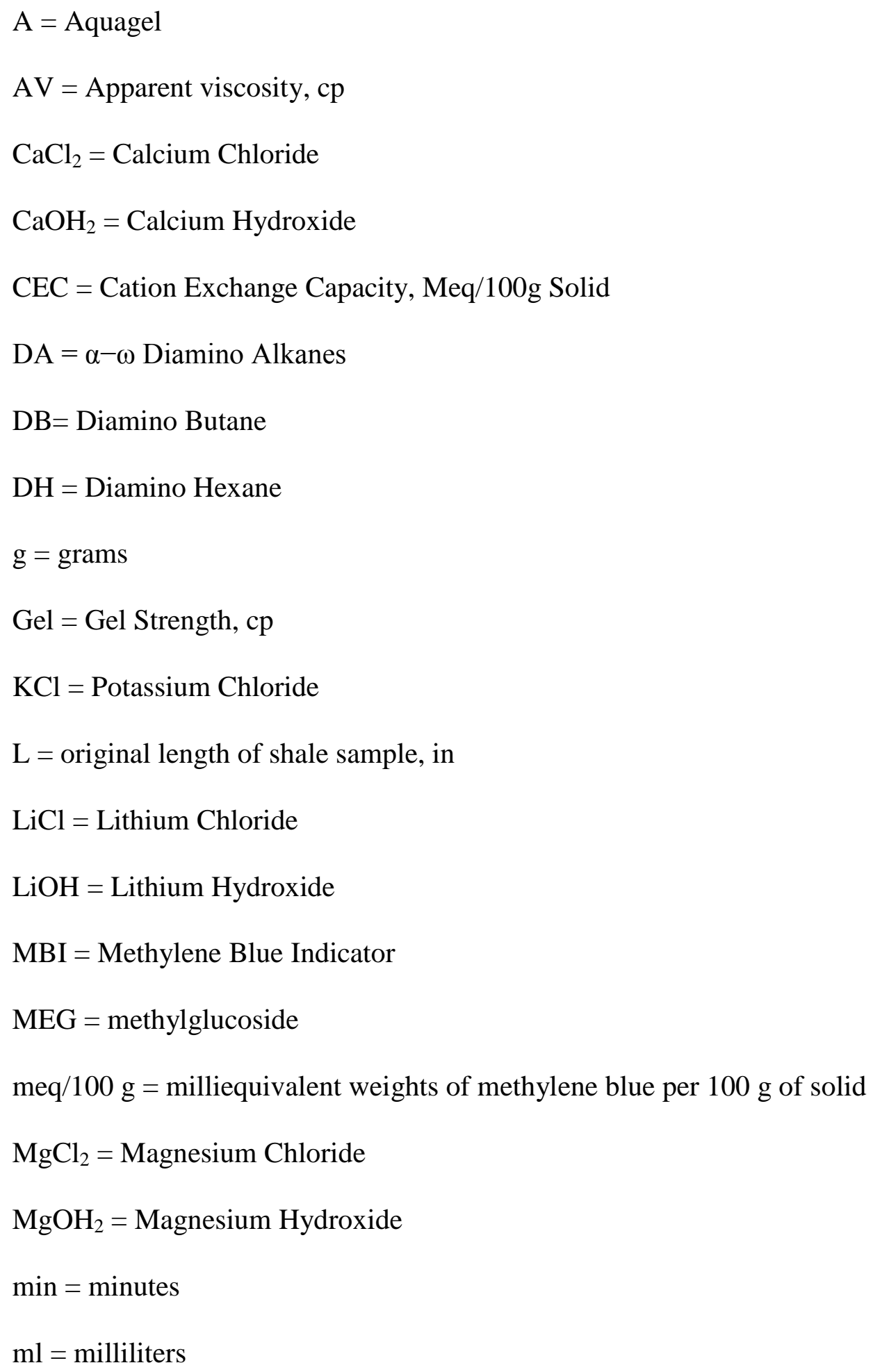




$$
\begin{aligned}
& \mathrm{N}=\text { spring factor } \\
& \mathrm{NaCl}=\text { Sodium Chloride } \\
& \mathrm{OBM}=\text { Oil-Based Mud } \\
& \mathrm{PHPA}=\text { partially hydrolyzed polyacrylamide } \\
& \mathrm{PV}=\text { plastic viscosity, cp } \\
& \mathrm{T}=\text { temperature, } \mathrm{K} \\
& \mathrm{WBM}=\text { Water-Based Mud } \\
& \mathrm{XRD}=\mathrm{X}-\mathrm{Ray} \text { Diffraction Analysis } \\
& \mathrm{YP}=\text { yield stress, lbf } / 100 \mathrm{ft} 2 \\
& \mathrm{ZnCl}=\text { Zinc Chloride } \\
& \theta_{600}=\text { dial reading at } 600 \mathrm{rpm} \\
& \theta_{300}=\text { dial reading at } 300 \mathrm{rpm} \\
& \Delta \mathrm{L}=\text { change in shale length, in } \\
& { }^{\circ} \mathrm{F}=\text { degrees Fahrenheit }
\end{aligned}
$$




\section{Chapter 1}

\section{Introduction}

\section{Overview}

Scholars, engineers and scientists have substantiated and proved that swelling clays in hydrocarbon reservoirs are one of the major causes of formation damage (John 1998). This damage to the formation mostly occurs due to the contact and interactions of incompatible fluids with swelling-susceptible clays in the shale formations. It is the aforementioned interaction between swelling-susceptible clays and incompatible fluids that primarily instigates the swelling of shale. Incompatible fluids which may provoke clay swelling include drilling fluids, completion fluids, fracturing fluids and injection fluids or steam used in EOR (Enhanced Oil Recovery) operations.

Smectite clay mineral constitutes the majority of swelling clays in shale hydrocarbon reservoirs, even though it only represents a few percentage of the shale. This is apparently due to the large surface area and continuity of the Smectite clay throughout the shale reservoir as a result of the thin sheet of Smectite clay covering the shale surface like a blanket.

Subsequently, the problems associated with shale instability are numerous and necessitate a solution in the formulation of an optimum inhibitive drilling fluid which can adequately abate shale swelling or possibly extinguish shale instability while simultaneously maintaining essential 
filtration and rheological properties such as plastic viscosity, apparent viscosity, gel strength, yield point, filter cake formation and the abatement of filter loss.

More so, problems associated with the swelling and dispersion of shale include caving, sloughing, stuck pipe, bit balling, excessive torque $\&$ drag, heaving, suspended drilling activity and lost revenue (Rabia 1985). It is the aforementioned inadequacies that have led to this vital research.

The experiments which were performed in an effort to formulate an inhibitive fluid began by testing the rheological, filtration and swelling properties of base fluids which consisted of $5 \%$ Aquagel clay as the viscosifier and low-gravity solid in addition to $0.5 \%, 1 \%, 2 \%$ or $3 \%$ of a Chloride or Hydroxide of an Alkali metal, Alkaline earth metal or transition metal. An example of such a base fluid was $5 \%$ Aquagel $+1 \% \mathrm{MgCl}_{2}$. Aquagel is a finely ground, premium-grade Wyoming sodium Bentonite which meets the American Petroleum Institute (API) Specification 13A, section 4 requirement. Aquagel functions as a viscosifier and filtrate reducer in freshwater drilling fluids.

After the rheological, filtration and swelling tests were conducted on twenty base fluids, fourteen fluids were selected to be blended with various concentrations of Diamino Alkanes (Diamino Butane, Diamino Hexane). Accordingly, various permutations and combinations of the aforementioned chemicals were used in order to create the ultimate inhibitive drilling fluid for the Marcellus shale and other shale formations. 


\section{Problem Review and Justification}

Technical problems instigated by the swelling of shale include formation damage, caving, sloughing, stuck pipe, bit balling, excessive torque \& drag, heaving, suspended drilling activity and lost revenue. Most of these problems, especially formation damage and stuck drill pipe, account for losses of millions of dollars each year in the petroleum industry (Devereux 1998). Given the magnitude of the problems that may be solved through this research, this research is, therefore, tantamount to other vital researches which have been and are currently being carried out theoretically using software and computer programs.

The problem of wellbore instability in shale is one of the largest sources of lost time and trouble cost during drilling. Operational problems that derive from such instabilities range from high solids loading of the mud requiring dilution, to hole cleaning problems due to reduced annular velocities in enlarged hole sections, to full-scale stuck pipe as a result of well caving and collapse. Although borehole stability problems can be problematic in oil-based mud (OBM) and synthetic-based mud, the main problem area lies with water-based mud (WBM) (Ismali et al 2009).

Prudently speaking, OBMs are perhaps a perfect remedy for shale instability, but the high cost of OBMs mean that WBMs would remain the most utilized drilling fluids in the industry (Borgoyne et al 1986). Adverse interactions between water-based muds and troublesome shales have lead to the development of a whole range of additives that are expected to serve as shale inhibitors in water-based muds. Many of these additives are shale specific and others are limited to certain operating conditions. Some inhibitors may be useful for stabilizing cuttings, but may also have no effect, or even an adverse effect, on actual borehole stability. 


\section{Stuck Pipe}

Stuck pipes are one of the most beleaguering problems facing operators and contractors alike. Although there are numerous causes of stuck pipe, this paper exclusively focuses on stuck pipe incidences from a drilling fluid angle or perspective since majority of stuck pipe occurrences are due solely to drilling fluid inadequacy. It is therefore crucial that the reader understands the mechanism of stuck pipe development.

Subsequently, this paper focuses on mechanical stability (Figure 1.2), high drop sloughing, inadequate hole cleaning and chemically active formation as key factors in the causation of stuck pipe.

\section{Inadequate Hole Cleaning:}

Inadequacy in removing cuttings from the well causes the settlement of the cuttings around the drill string, usually the bottomhole assembly (BHA), thereby causing the drill collars to become stuck. Eventually, the cuttings build up and slump in the hole. It is therefore crucial that an optimal drilling fluid which has the appropriate rheological properties or gel strength to elevate cuttings while impeding clay swelling is formulated. Figure 1.1 shows the migration of mud filtrate into the formation, consequently leading to the swelling and dispersion of clay into the wellbore. 


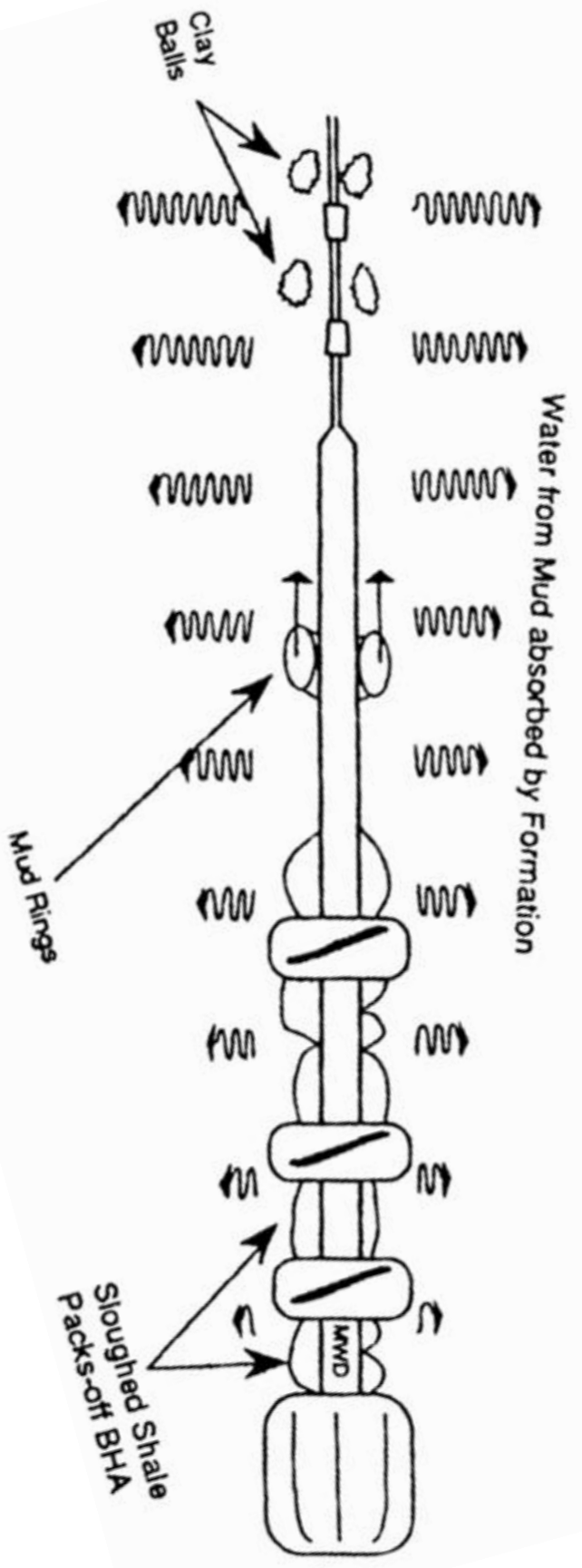

Figure 1.1: Migration of water into the formation, causing the swelled shale to collapse and accumulate around the BHA (Schlumberger, www.slb.com) 
* Chemically Active Formations:

Different formations have different degrees of water absorption. Therefore, it is often important for a mud engineer to understand the characteristics of the formation that will be drilled. The amount of swelling varies from highly reactive "gumbo" to Smectite-containing shale.

When drilling with WBM, water is absorbed into these types of formations (commonly Smectitecontaining shale), propelling them to swell, weaken and disperse. Consequently, chunks of shale break off and fall into the borehole.

As a result, the hydrated shale sticks to the drill string and accumulates in abounding quantities to fill the entire annulus around the BHA, causing it to become stuck.

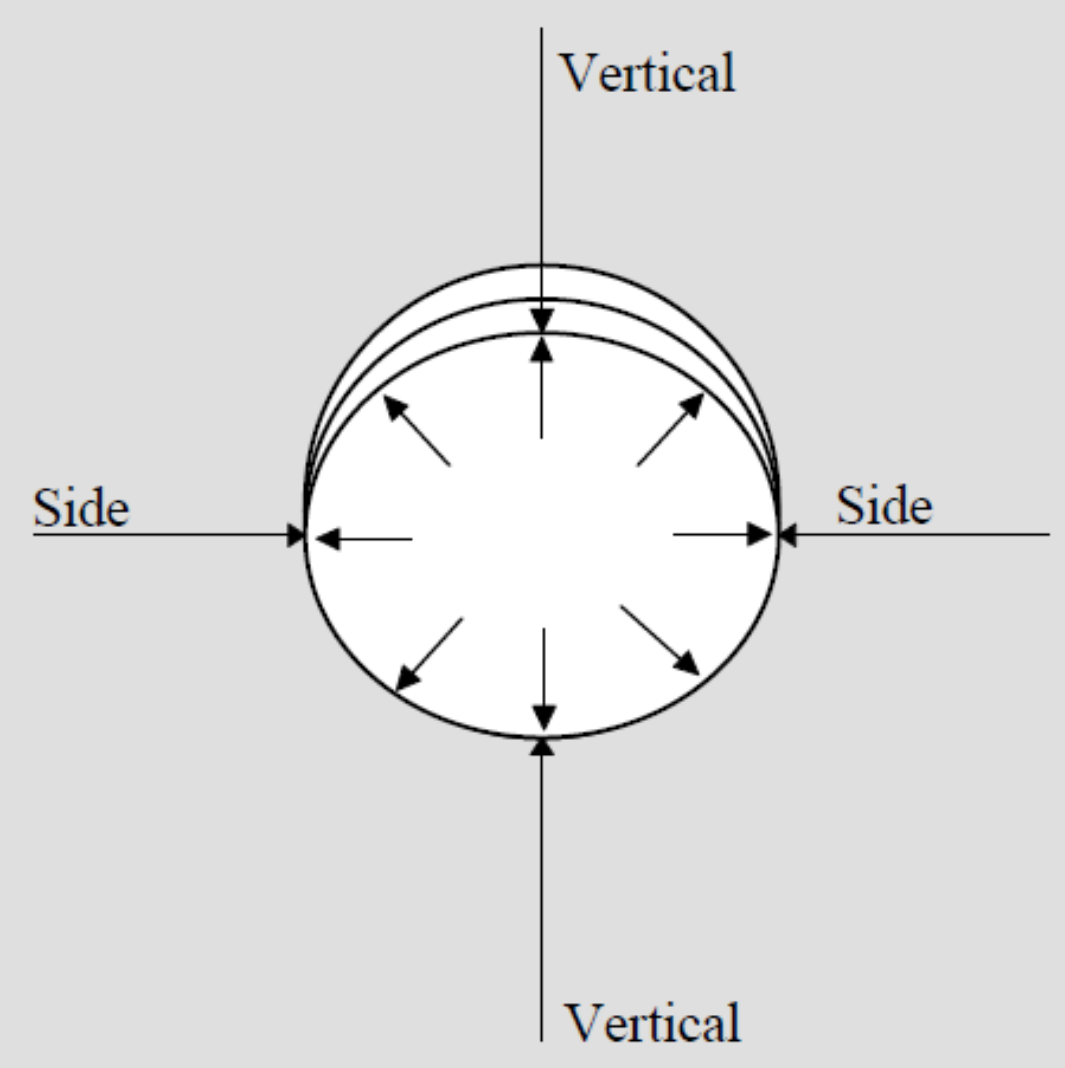

Figure 1.2: Insufficient mud weight to keep the hole from contracting (Schlumberger, www.slb.com) 
Consequences of Chemically Active Formations:

Lost drilling time to free the pipe

Time and cost to fish the pipe

Tool abandonment in the hole due to difficult and expensive fishing operations

* Bit balling:

The term Bit balling refers to the adhesion of sticky unconsolidated material, usually drill cuttings, between the teeth of a drill bit. The aforementioned phenomenon mostly occurs in soft formations with bad bottomhole cleaning. Bit balling is a poorly understood phenomenon that is usually approached on a trial-and-error basis by empirically testing additives for their effect on rate of penetration (ROP). There are many factors involved in bit balling unrelated to the fluid.

Bit balling occurs because of the stress release that occurs in the cutting immediately after the cutting is generated. This stress release means that hydration is triggered, and water is drawn from any available source, including the surface of the drill bit and other nearby cuttings. In drawing water inwards, cuttings may 'vacuum' themselves onto the bit and each other, causing the bit to ball. Bit balling can be avoided by designing the drilling fluid to either increase or lower the water content of the clay.

By increasing the water content, the cuttings might be made to disperse, but this could give rise to an unwanted build-up of fine solids in the mud. The zones in which bit balling may occur depend on the type of shale, its specific clay type and clay content, and therefore its swelling 
pressure, it is difficult to predict in advance whether or not the actual fluid is prone to cause bit balling problems. If bit balling is known to be a problem in specific shale, one solution is to design the drilling fluid so that the cuttings are dehydrated. This can be accomplished by using a mud system that builds membranes and dehydrates the shale by osmosis. Figure 1.3 shows a balled bit.

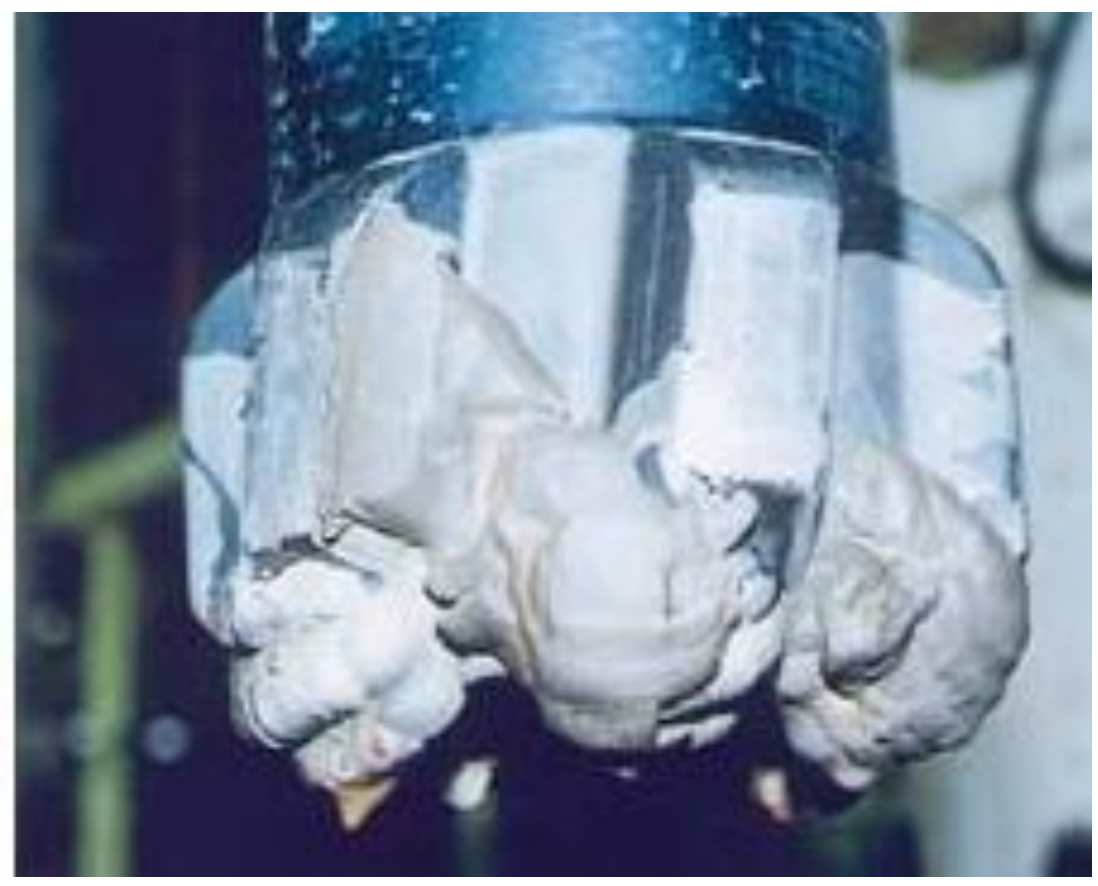

Figure 1.3: Bit balling reduces penetration rate (Oil and Gas Journal, www.ogj.com )

Consequences of Bit balling:

$\square$ Reduced penetration rate

$\square$ Increased cost if the drilling contractor is drilling on a per time basis rather than per foot basis.

Reduction of flushing-fluid flow due to partially blocked nozzles. 
$\square$ Excessive shear and bit-tooth wear due to the halting of individual cone rotation when drilling with roller-cone bits. 


\section{Literature Review}

\section{Comparison of Previous Research to this Research}

Some work has been done on the swelling of clay and rheological properties of drilling fluids. In 1981, Ronald P. Bernard evaluated effects of hydroxides and chlorides of various ions $\left(\mathrm{K}^{+}, \mathrm{Na}^{+}, \mathrm{Ca}^{2+}\right.$ and $\left.\mathrm{Mg}^{2+}\right)$ on the rheological properties of Attapulgite based muds and Sepiolite based muds at high temperature (up to $600^{\circ} \mathrm{F}$ ). With respect to Attapulgite, he discovered that the Attapulgite/ $\mathrm{MgCl}_{2}$ systems exhibited increased yield point, but better fluid loss control with respect to other chlorides and hydroxides at high temperatures.

In addition he discovered that $\mathrm{Ca}(\mathrm{OH})_{2}$ samples remained moderately stable with respect to temperature change. With regards to Sepiolite, Bernard realized that yield point and gel strength increased with temperature in all the Sepiolite/Chloride muds. Additionally, Bernard noted that Sepiolite maintained acceptable rheological properties for use as a high temperature drilling fluid.

In 2009, Kehinde Adesoye performed a research on the characterization of shale, taking into account the effects of various chlorides $\left(\mathrm{KCl}, \mathrm{NaCl}, \mathrm{CaCl}_{2}\right)$ and polymers (PHPA, Xanthan Gum and MEG) on the stability of Norway and Barnett Shale. Subsequently, Adesoye discovered that Smectite clay was responsible for the majority of swelling in shale. Furthermore, he discovered that PHPA/MEG drilling fluids reduced dispersion greatly when compared to PHPA/Salt and Xanthan Gum/Salt drilling fluid systems.

Without a shadow of a doubt, the experiments performed by Bernard and Adesoye are worthy of extolment for their wonderful contribution to a vital topic in the oil industry. However, in this 
study, research experiments go above and beyond those explored by Bernard and Adesoye, incorporating various Alkali metals, Alkali earth metals and Transition metals which were never tested by Bernard and Adesoye. Furthermore, experiments in this study introduce a novel substance $\alpha-\mathrm{w}$ Diamino Aklkane (Diamino Butane and Diamino Hexane) which has never been incorporated into drilling fluids. Wendler and Snethlage showed that the swelling of clays in shale can be reduced by treatment with $\alpha-\omega$ Diamino Alkanes; however, this is yet to be proven in the Oil industry. More so, $\alpha-\mathrm{w}$ Diamino Alkanes are molecules having Amine groups at each end of an Alkane chain. Each Amine group attaches itself to one end of the exchangeable layer which leads to a shrinkage of the Smectite clay, Shale and subsequent elimination of a refuge for water attachment.

Subsequently, experimental studies focused on the formulation of an optimum inhibitive drilling fluid for the Marcellus shale through the comparison of $\alpha-\omega$ Diamino Alkanes (Diamino Butane and Diamino Hexane), while incorporating chlorides and hydroxides of various Alkali metals, Alkaline earth metals and Transition metals. Table 1.1 shows a sample of base drilling fluids which were tested for rheological properties, filtration properties and Smectite inhibition tendencies before the incorporation of Diamino Alkane into selected fluids for further testing on the Marcellus Shale. 


\begin{tabular}{|c|c|}
\hline Base Drilling Fluid Systems & Composition, weight percent \\
\hline Aquagel & $5 \%$ Aquagel \\
\hline \multirow[t]{4}{*}{ Aquagel $+\mathrm{ZnCl}$} & $0.5 \% \mathrm{ZnCl}+5 \%$ Aquagel \\
\hline & $1 \% \mathrm{ZnCl}+5 \%$ Aquagel \\
\hline & $2 \% \mathrm{ZnCl}+5 \%$ Aquagel \\
\hline & $3 \% \mathrm{ZnCl}+5 \%$ Aquagel \\
\hline \multirow[t]{4}{*}{ Aquagel $+\mathrm{CaCl}_{2}$} & $0.5 \% \mathrm{CaCl}_{2}+5 \%$ Aquagel \\
\hline & $1 \% \mathrm{CaCl}_{2}+5 \%$ Aquagel \\
\hline & $2 \% \mathrm{CaCl}_{2}+5 \%$ Aquagel \\
\hline & $3 \% \mathrm{CaCl}_{2}+5 \%$ Aquagel \\
\hline \multirow[t]{4}{*}{ Aquagel+LiCl } & $0.5 \% \mathrm{LiCl}+5 \%$ Aquagel \\
\hline & $1 \% \mathrm{LiCl}+5 \%$ Aquagel \\
\hline & $2 \% \mathrm{LiCl}+5 \%$ Aquagel \\
\hline & $3 \% \mathrm{LiCl}+5 \%$ Aquagel \\
\hline \multirow[t]{4}{*}{ Aquagel $+\mathrm{MgOH}_{2}$} & $0.5 \% \mathrm{MgOH}_{2}+5 \%$ Aquagel \\
\hline & $1 \% \mathrm{MgOH}_{2}+5 \%$ Aquagel \\
\hline & $2 \% \mathrm{MgOH}_{2}+5 \%$ Aquagel \\
\hline & $3 \% \mathrm{MgOH}_{2}+5 \%$ Aquagel \\
\hline \multirow[t]{4}{*}{ Aquagel+LiOH } & $0.5 \% \mathrm{LiOH}+5 \%$ Aquagel \\
\hline & $1 \% \mathrm{LiOH}+5 \%$ Aquagel \\
\hline & $2 \% \mathrm{LiOH}+5 \%$ Aquagel \\
\hline & $3 \% \mathrm{LiOH}+5 \%$ Aquagel \\
\hline \multirow[t]{4}{*}{ Aquagel+KCl } & $0.5 \% \mathrm{KCl}+5 \%$ Aquagel \\
\hline & $1 \% \mathrm{KCl}+5 \%$ Aquagel \\
\hline & $2 \% \mathrm{KCl}+5 \%$ Aquagel \\
\hline & $3 \% \mathrm{KCl}+5 \%$ Aquagel \\
\hline \multirow[t]{4}{*}{ Aquagel $+\mathrm{MgCl}_{2}$} & $0.5 \% \mathrm{MgCl}_{2}+5 \%$ Aquagel \\
\hline & $1 \% \mathrm{MgCl}_{2}+5 \%$ Aquagel \\
\hline & $2 \% \mathrm{MgCl}_{2}+5 \%$ Aquagel \\
\hline & $3 \% \mathrm{MgCl}_{2}+5 \%$ Aquagel \\
\hline \multirow[t]{4}{*}{ Aquagel $+\mathrm{CaOH}_{2}$} & $0.5 \% \mathrm{CaOH}_{2}+5 \%$ Aquagel \\
\hline & $1 \% \mathrm{CaOH}_{2}+5 \%$ Aquagel \\
\hline & $2 \% \mathrm{CaOH}_{2}+5 \%$ Aquagel \\
\hline & $3 \% \mathrm{CaOH}_{2}+5 \%$ Aquagel \\
\hline \multirow[t]{4}{*}{ Aquagel+NaCl } & $0.5 \% \mathrm{NaCl}+5 \%$ Aquagel \\
\hline & $1 \% \mathrm{NaCl}+5 \%$ Aquagel \\
\hline & $2 \% \mathrm{NaCl}+5 \%$ Aquagel \\
\hline & $3 \% \mathrm{NaCl}+5 \%$ Aquagel \\
\hline \multirow[t]{4}{*}{ Others } & $2 \% \mathrm{KCl}+$ DiaminoButane \\
\hline & $2 \% \mathrm{KCl}+$ Diamino Hexane \\
\hline & $2 \% \mathrm{CaCl}_{2}+$ Diamino Butane \\
\hline & $2 \% \mathrm{CaCl}_{2}+$ Diamino Hexane \\
\hline
\end{tabular}

Table 1.1: Base Drilling Fluid Systems and their compositions 


\section{Objectives and Significance of Study}

The main goals of this research are listed as follows:

a.) To formulate an optimum inhibitive drilling fluid for the Marcellus shale and other shale formations.

b.) Evaluate the effect of chlorides and hydroxides of various Alkali earth metals, Alkaline metals and Transition metals on the swelling of the Marcellus Shale, other shale formations.

c.) Evaluate the effect of chlorides and hydroxides of various Alkali earth metals, Alkaline metals and Transition metals on the rheological properties of Aquagel/bentonite Water based fluids.

d.) Evaluate the effect of chlorides and hydroxides of various Alkali earth metals, Alkaline metals and Transition metals on the filtration properties of Aquagel/Bentonite Water based fluids.

e.) Evaluate rheological, filtration and swelling effect of selected fluids with $\alpha-w$ Diamino Alkanes: Diamino Butane and Diamino Hexane. 
The aforementioned objectives were achieved by performing the experiments listed in Table 1.2.

\section{Experiments Performed}

Cation Exchange Capacity Tests

口 X-ray Diffraction Tests

口 Rheological Tests

L Linear Swelling Tests

口 Filtration Tests

Other experiments as required for this research.

\section{Incorporated Chemicals}

\begin{tabular}{|c|c|}
\hline \multicolumn{2}{|c|}{ Major Chemicals Used for this Research } \\
\hline Chemical Name & Chemical Abbreviation \\
\hline Diamino Hexane & DH \\
\hline Diamino Butane & DB \\
\hline Magnesium Hydroxide & $\mathrm{MgOH}_{2}$ \\
\hline Magnesium Chloride & $\mathrm{MgCl}_{2}$ \\
\hline Calcium Hydroxide & $\mathrm{CaOH}_{2}$ \\
\hline Calcium Chloride & $\mathrm{CaCl}_{2}$ \\
\hline Potassium Chloride & KCl \\
\hline Sodium Chloride & $\mathrm{NaCl}$ \\
\hline Zinc Chloride & $\mathrm{ZnCl}_{2}$ \\
\hline Lithium Hydroxide & LiOH \\
\hline Lithium Chloride & LiCl \\
\hline Methylene Blue Indicator & MBI \\
\hline$\alpha-\omega$ Diamino Alkanes & DA \\
\hline
\end{tabular}

Table 1.2: List of chemicals used for this research 


\section{Chapter 2}

\section{Fundamentals of Drilling Fluids, Shale and Shale \& Drilling Fluid Interactions}

\section{Marcellus Shale}

The Marcellus shale refers to group of marine sedimentary rocks found in the North East of the US. Its abundance in the North East is evident in its stretch from the northern tier of New York, northern and western Pennsylvania, eastern Ohio, western Maryland and most of West Virginia. The Marcellus Shale contains large reserves of natural gas and oil which makes it an attractive energy target in conjunction with its close proximity to the huge market in the east coast of the US.

The Marcellus shale is a black shale that occasionally contains pyrite $\left(\mathrm{FeS}_{2}\right)$, Siderite $\left(\mathrm{FeCO}_{3}\right)$ and limestone beds. Shale often tends to split along its bedding plane; a property called fissility. Shallow shale located in the upper portion of the formation is lighter in color and tend to split into smaller thin edged fragments after exposure to air.

Research has shown that 500 trillion cubic feet of natural gas lies within the Marcellus shale formation. Figure 2.1 shows an isopatch map of the Marcellus Shale in the State of West Virginia, Figure 2.2 shows the geographic distribution of the Marcellus Shale in the United States while Figure 2.3 displays a stratigraphic column of the Marcellus Shale. 


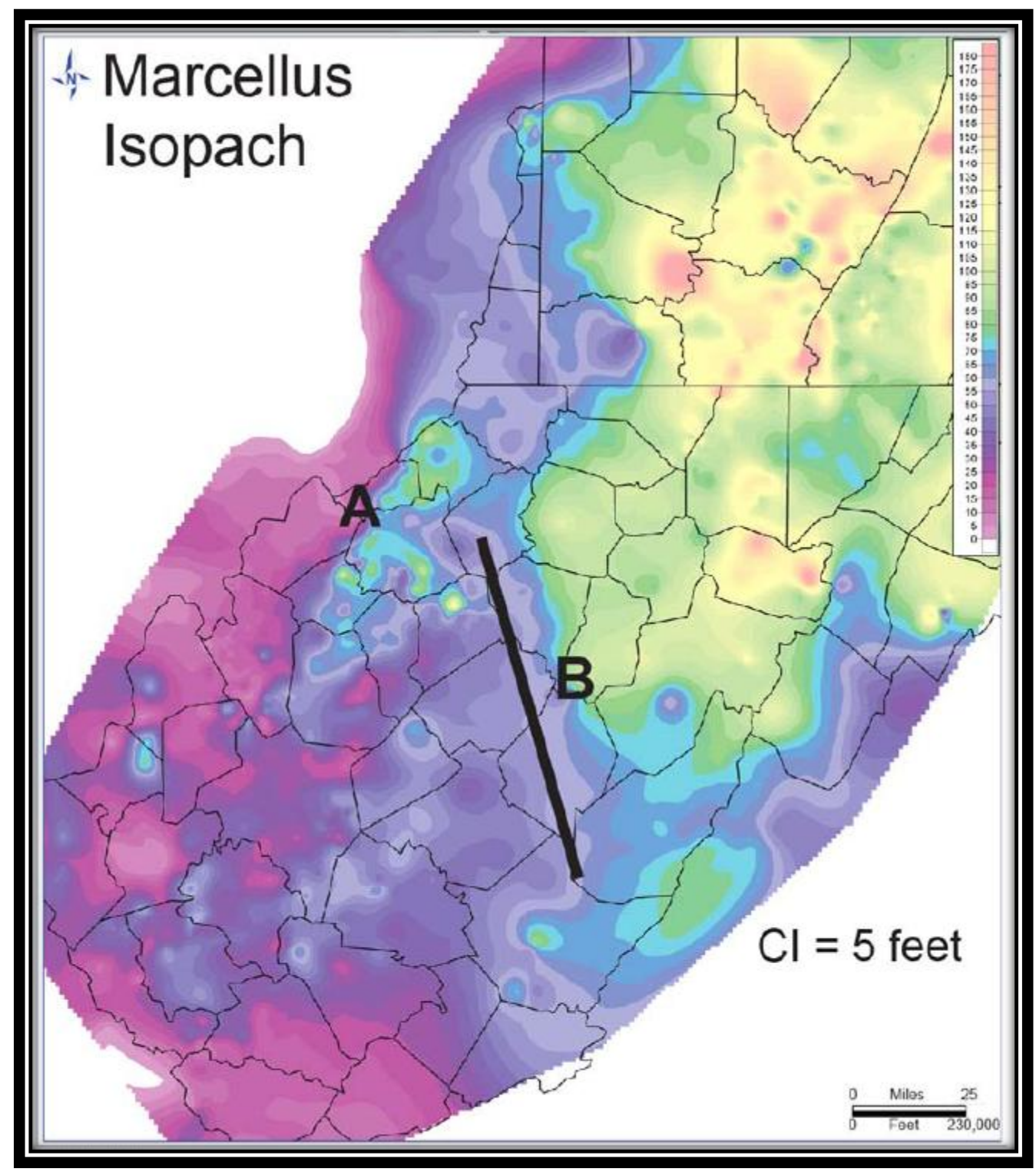

Figure 2.1: Isopach of the Marcellus Shale in West Virginia

(http://www.mapwv.gov/UnconventionalResources/marcellusLithoAndPetroPaper.pdf) 


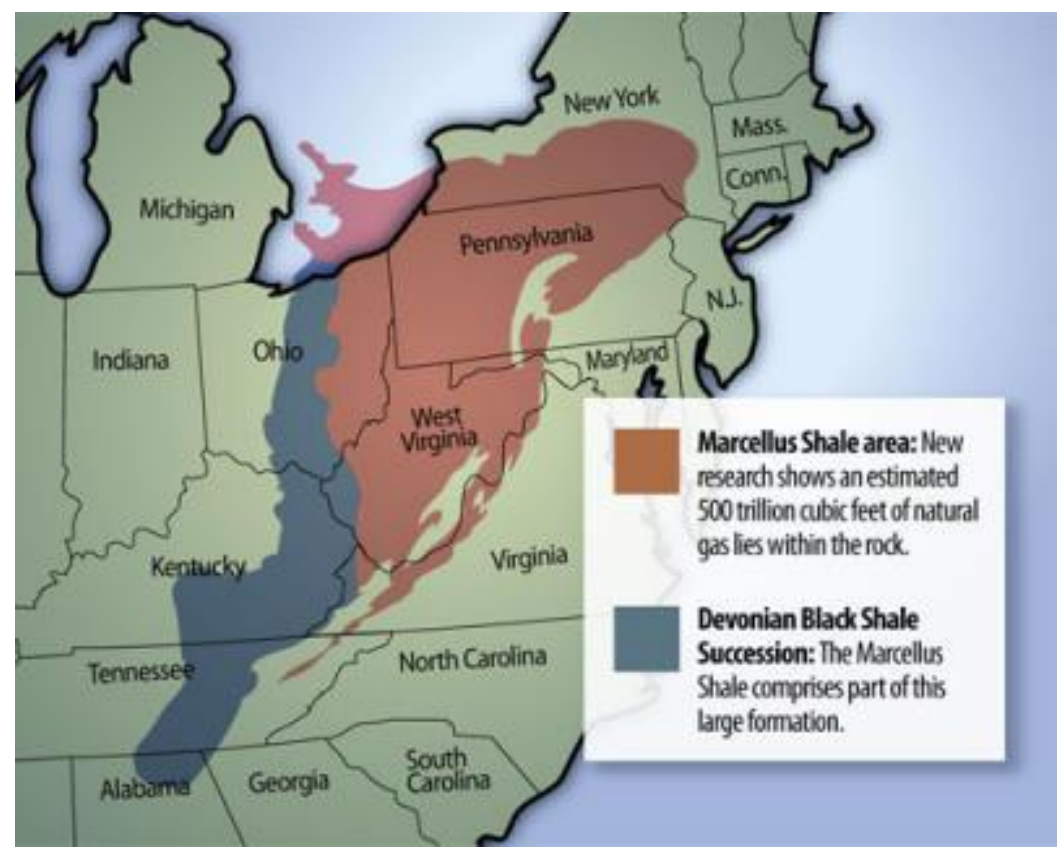

Figure 2.2: Marcellus Shale Map (www.netl.doe.gov).

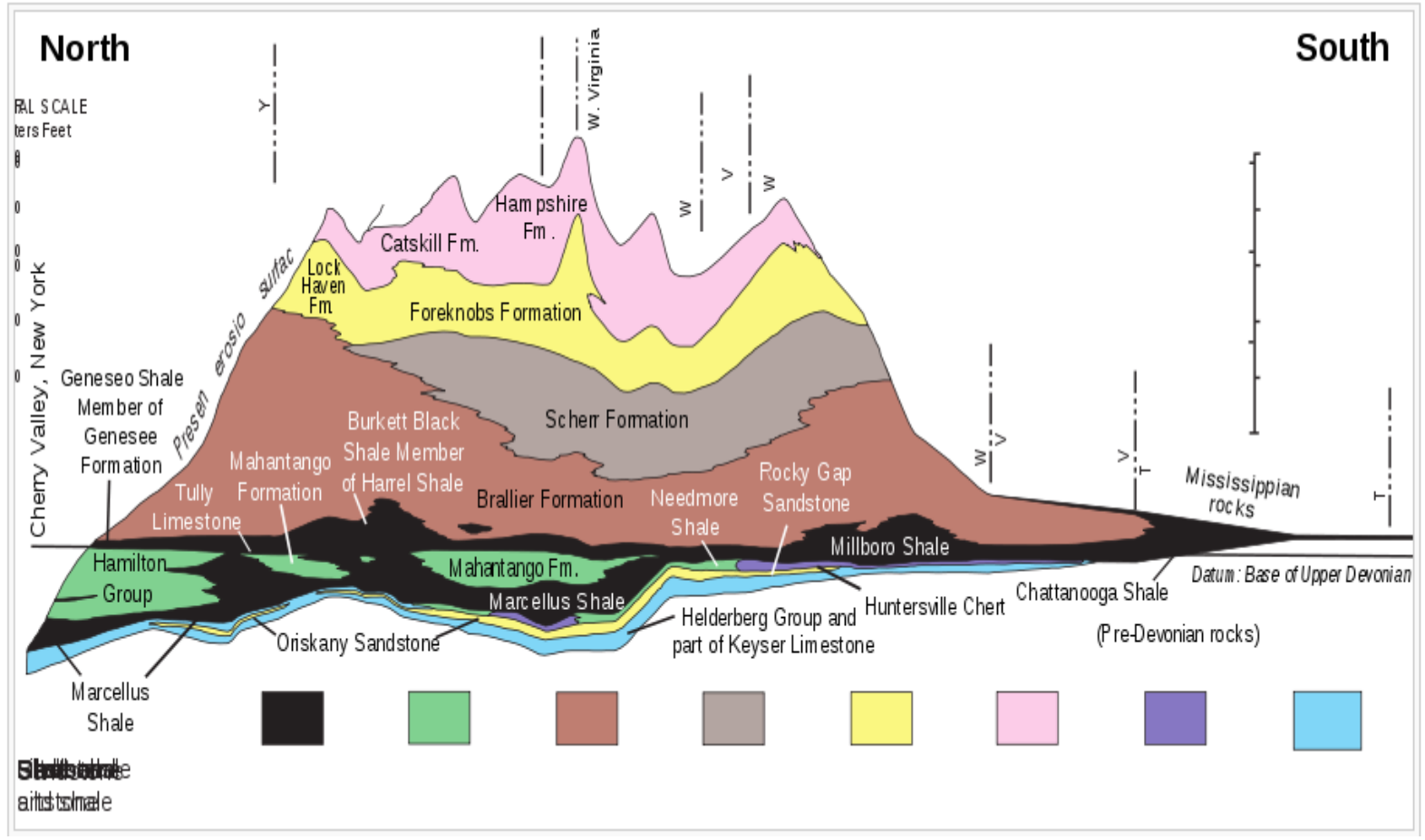

Figure 2.3: Marcellus Shale Stratigraphic Column (www.netl.doe.gov). 


\section{Mineralogy}

Other minerals and clays found in shale include Smectite, Feldspar, Quartz, Carbonates, Anhydrite, Apalite, Gypsum, Illite, Kaolinite, Chlorite, Mixed Clay, etc. However, this research is mostly interested in the Smectite clay mineral since it unsurprisingly constitutes the majority of swelling clays in shale hydrocarbon reservoirs, even though it only represents a few percentage of the shale. This is apparently due to the large surface area and continuity of the Smectite clay throughout the shale reservoir. In layman's terms, the above expression refers to the thin sheet of Smectite clay covering the shale surface like a blanket and its infinite spread throughout the formation.

Smectite Clay can be classified as follows:

Diagenetic: Formed from the process of consolidation and lithification.

Detrital: Formed from weathering and mechanical deposition.

Neogenetic: Formed from the reaction of thermal fluid with reservoir shale to form new Smectite clays during EOR operations. 


\section{Chemistry of Shale Expansion}

Smectite clay is composed of tiny crystalline particles called plates and each plate comprises of layers which can be octahedral or tetrahedral. Each tetrahedral sheet comprises of units called tetrahedrons as shown in Figure 2.4. Furthermore, each tetrahedron is composed of a central silicon ion which is surrounded by or bound to four oxygen atoms. The oxygen atoms are shared among adjacent tetrahedrons. It is this sharing of oxygen atoms among adjacent tetrahedrons that forms tetrahedral sheets.

\section{The Simplest Structure}

\section{- Tetrahedron \\ $\square$ One silicon ion surrounded by four oxygen atoms. \\ - Tetrahedral sheets \\ Tetrahedral sheets are joined by shared oxygen atoms}

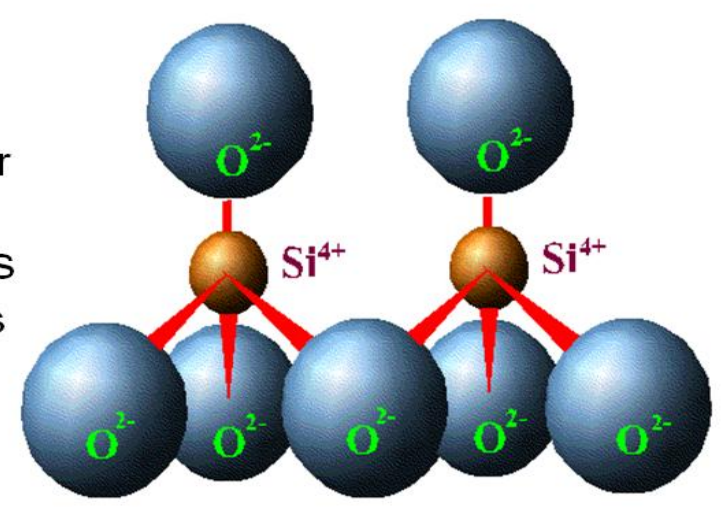

Figure 2.4: Tetrahedron Structure (http://www.soils.umn.edu).

Similarly, each octahedral sheet comprises of units called octahedrons (Figure 2.5). Furthermore, each octahedron is composed of an Aluminum or Magnesium ion which is surrounded by or bound to six oxygen atoms. The oxygen atoms are shared among adjacent tetrahedrons. It is this sharing of oxygen atoms among adjacent octahedrons that forms octahedral sheets (Figure 2.6). 


\section{The Eight-sided Octahedron}

- Octahedron

$\square$ Six oxygen with a central $\mathrm{Al}^{3+}$ atom

- Octahedral sheet

$\square$ Octahedral sheets are linked together by shared oxygen

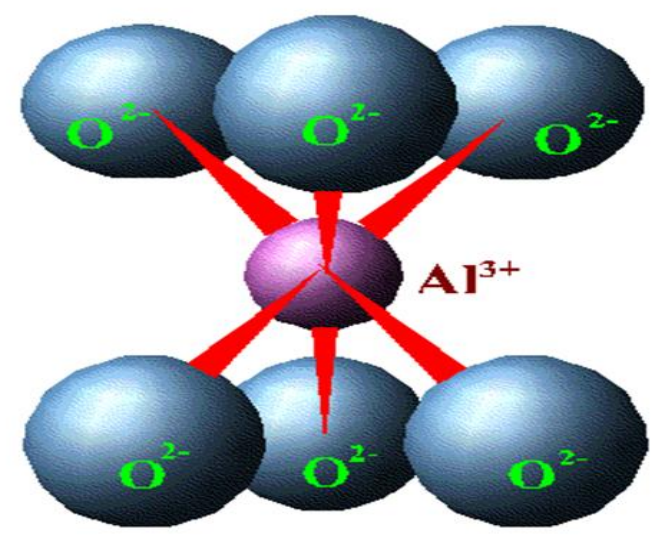

Figure 2.5: Octahedron Structure (http://www.soils.umn.edu $)$.

\section{Octahedral Sheet}

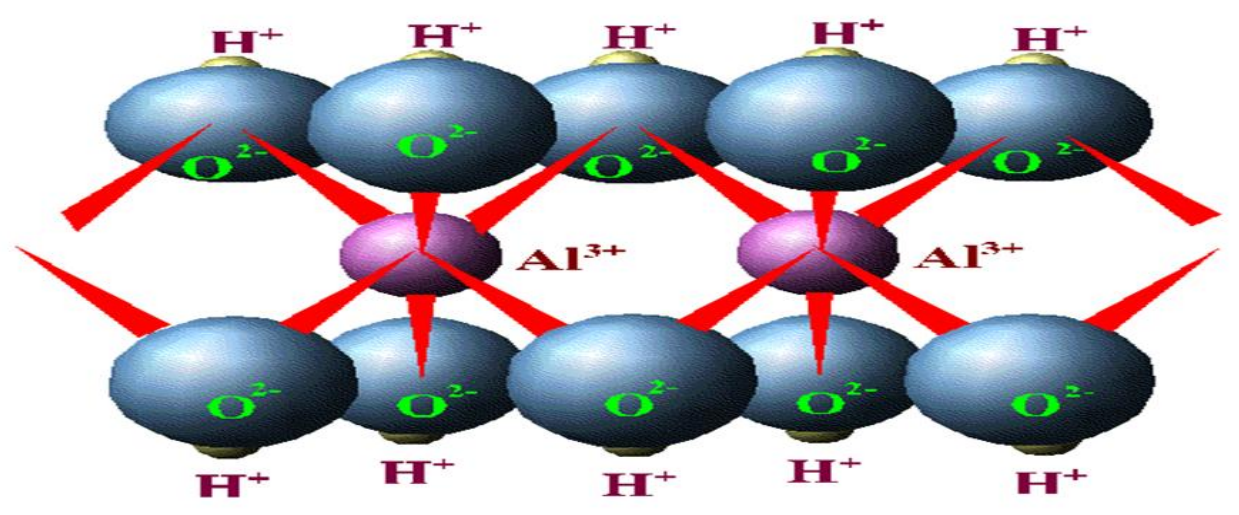

Figure 2.6: Octahedral Structure (http://www.soils.umn.edu).

Two primary ratios exist with regards to the way octahedral sheets bind to tetrahedral sheets.

One of such ratios is the (1:1) which consists of one octahedral sheet attached to one tetrahedral sheet Figure 2.7. Each unit of (1:1) is then separated by an exchangeable layer. An exchangeable layer refers to a layer of separation between each (1:1) unit and this layer is often a refuge or attachment site for water molecules which can cause swelling of clay and shale in other ratio 
systems. However, it should be noted that clays with (1:1) ratios are resistive to swelling due to the strong hydrogen bonds found in the exchangeable layers between units of (1:1) layers.

Again, with regards to expansion, clays with the 1:1 ratio system are resistive to expansion. This is because the molecules are held together by strong hydrogen bonds which resist the occurrence of isomorphous substitution. Isomorphous substitution refers to the replacement of one atom by another atom of similar size in the crystal lattice without disrupting or changing the crystal structure of the mineral (Adesoye 2009). For example, in Tetrahedral Sheets: $\mathrm{Al}^{3+}$ can be substituted for $\mathrm{Si}^{4+}$. Also, in Octahedral Sheets: $\mathrm{Mg}^{2+}$ can be substituted for $\mathrm{Al}^{3+}$. This causes an unbalanced external negative charge in the layers which are compensated by the adsorption of ions on the edges of clay particles.

Also each (1:1) unit is attached to another (1:1) unit through strong hydrogen bonds which shrink the exchangeable layer and makes it difficult for the exchangeable layer to absorb water.

On the contrary, the 2:1 ratio system involves an octahedral sheet sandwiched between two tetrahedral sheets as shown in Figure 2.8. Each (2:1) unit is separated from another by a weak Van Der Waal force which makes it easy for water to penetrate into the exchangeable layers and consequently cause swelling of the clay and shale. Notably, Smectite clay belongs to this category of clays. 


\section{Clay Mineral Structure}

- Clay particles are composed of tetrahedral and octahedral layers stacked on top of each other.

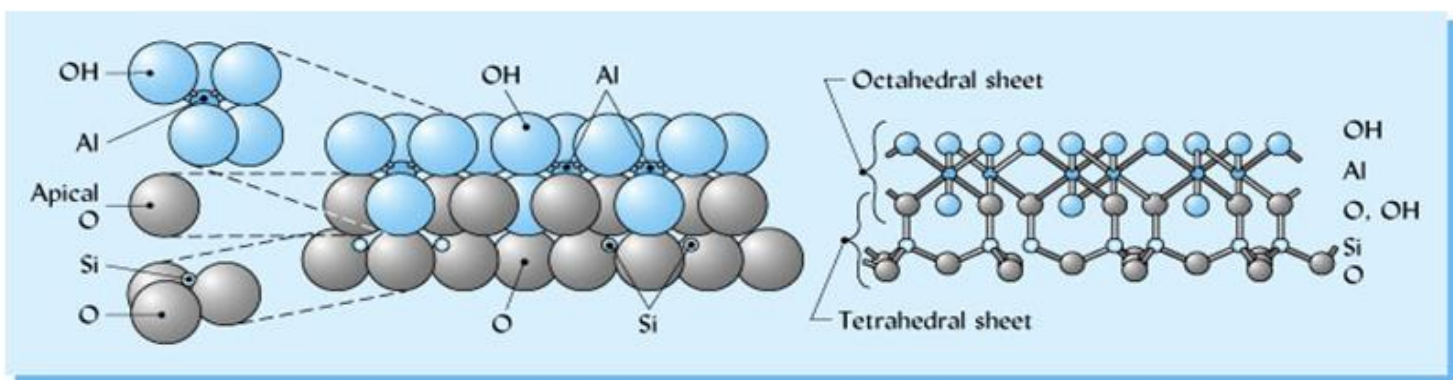

Figure 2.7: Octahedral and Tetrahedral Sheets (1:1) ratio (http://www.soils.umn.edu).

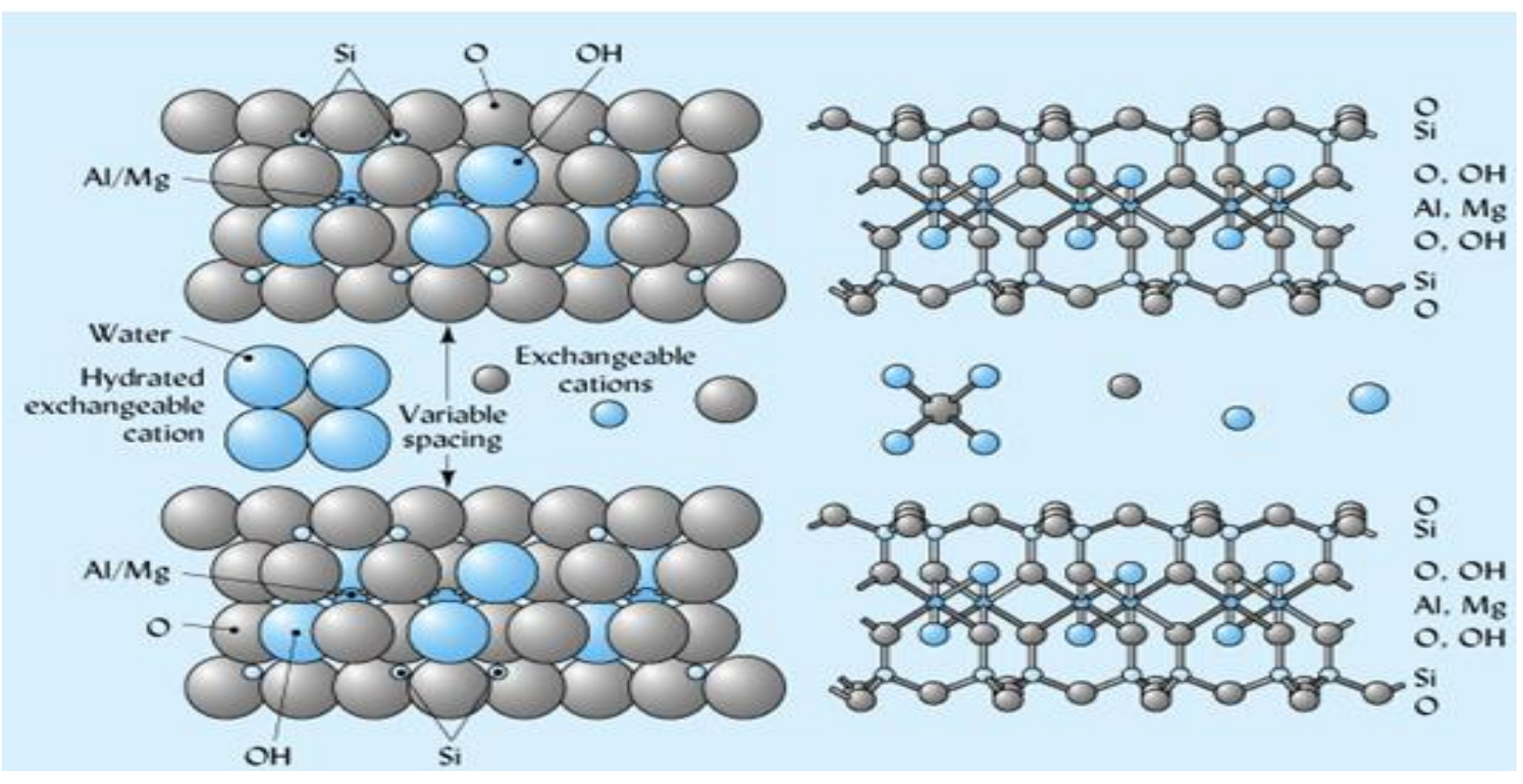

Figure 2.8: Octahedral and Tetrahedral Sheets (2:1) ratio (http://www.soils.umn.edu). 


\section{Cation Exchange Capacity}

As noted earlier, isomorphous substitution refers to the replacement of one atom by another atom of similar size in the crystal lattice without disrupting or changing the crystal structure of the mineral (Adesoye 2009). For example, in Tetrahedral Sheets: $\mathrm{Al}^{3+}$ can be substituted for $\mathrm{Si}^{4+}$. Also, in Octahedral Sheets: $\mathrm{Mg}^{2+}$ can be substituted for $\mathrm{Al}^{3+}$. This causes an unbalanced internal negative charge in the layers (surface location) which are compensated by the adsorption of ions on the edges of clay particles.

However, the ions which are adsorbed for compensation can be replaced by water molecules, causing expansion in the process. The Cation Exchange Capacity (CEC) test measures the ability of a clay mineral to give up these compensation ions in its exchangeable layer for the adsorption of water. Some ions such as $\mathrm{K}^{+}$migrate into the exchangeable layers thereby pulling the layers together and narrowing the refuge for water. Nevertheless, $\mathrm{K}^{+}$can be replaced by other cations which tend to increase the lattice spacing between the layers. The objective of this project is to incorporate Diamino Alkanes into fluids to see if they can hold the layers closely together or compress the exchangeable layers even in the presence of exchangeable-layer-ionic-substitution.

The higher the CEC value in meq/100g (milliequivalent weights of methylene blue/100g of dry clay), the higher is clay's tendency to absorb water and swell. In subsequent chapters, this research paper comprehensively explains the Methylene Blue Method of CEC measurement. The Methylene Blue Method which was introduced by Jones in 1964 for the determination of Bentonite content of drilling fluids and later modified by Chenevert and Ossianya in 1991 for shale samples was used for this research. 
Numerous shale samples were donated by the US Department of Energy for the operation of this research, most samples coming from the Marcellus shale in West Virginia.

CEC experiments were performed on Smectite clay mineral to determine the CEC value of the clay and its consequent effect on shale swelling. Smectite constitutes the majority of swelling clays in shale hydrocarbon reservoirs, even though they only contribute a few percentage of the shale as a result of the large surface area and continuity of the Smectite clay throughout the shale reservoir.

\section{Water Based Drilling Fluids}

Water based fluids refer to drilling fluid in which water or salt water is the major liquid phase as well as the wetting or external phase. Major categories of WBM include freshwater, seawater, lime etc. However, subcategories of these abound.

Drilling fluids are mainly used for removing cuttings from the well through hydraulic power, suspending and releasing cuttings by using gel strength, controlling formation pressure through the application of hydrostatic pressure, sealing permeable formations through the formation of a mud cake, maintaining wellbore stability through the application of hydrostatic pressure, minimizing formation damage by creating a mud cake on the wall of the well, cooling, lubricating and supporting the bit and drill string, transmitting hydraulic energy to downhole tools and bit, ensuring adequate formation evaluation/logging, controlling corrosion and facilitating cementing and completion. 


\section{Plastic Viscosity}

Plastic viscosity is the resistance of the drilling fluid to flow. Plastic viscosity is a parameter of the Bingham plastic model. Plastic viscosity is the slope of the shear stress versus shear rate curve above the yield point. It mainly represents the viscosity of a mud when extrapolated to infinite shear rate on the basis of the mathematics of the Bingham model. Also, yield point is the other parameter of that model. A low plastic viscosity indicates that the mud is capable of drilling rapidly because of the low viscosity of mud exiting at the bit. High plastic viscosity is caused by a viscous base fluid and by excess colloidal solids. In other to lower plastic viscosity, a reduction in solids content can be achieved by dilution of the mud.

An increase in solid content of the drilling fluid normally results in higher plastic viscosity values. In order to lower the plastic viscosity, the solid content has to be reduced. With increasing temperate while drilling deeper, the plastic viscosity of the drilling mud will decrease because the viscosity of the base fluid decreases.

Also, a high plastic viscosity means that the drilling fluid has a high ability of raising cuttings from the bottom of the borehole to the surface. However, an excessively high plastic viscosity could lead to frictional pressure losses which are detrimental to the efficiency of drilling.

Plastic viscosity can be measured by the use of a Rheometer or Viscometer which would be described in the following chapters. 


\section{Apparent Viscosity}

This refers to the viscosity of a fluid measured at the shear rate specified by API. In the Bingham plastic rheological model, apparent viscosity is one-half of the Rheometer dial reading at 600

rpm (1022 $\mathrm{sec}^{-1}$ shear rate) using a direct-indicating, rotational viscometer. For example, if a 600-rpm dial reading is 80 and then the apparent viscosity is $80 / 2$, or $40 \mathrm{cp}$.

\section{Yield Point}

Yield point (YP) is the resistance of initial flow of a drilling fluid or the stress required in order to move the fluid. Also the yield point can be described as the attractive force among colloidal particles in drilling mud. The yield point indicates the ability of the drilling fluid to carry cuttings from the bottom of the borehole to the surface. Additionally, frictional pressure loss is directly related to the yield point. With high YP fluids, high pressure loss occurs while the mud is being circulated.

Yield point is a parameter of the Bingham plastic model. Yield point is the yield stress extrapolated to a shear rate of zero. A Bingham plastic fluid plots as a straight line on a shear stress (y-axis) versus shear rate (x-axis) plot, in which Yield point is the zero-shear-rate intercept. Plastic viscosity is the slope of the line. Yield point is calculated from 300- and 600rpm dial readings of the viscometer and by subtracting plastic viscosity from the 300-rpm dial reading. Yield point is used to evaluate the ability of a mud to lift cuttings out of the annulus. A high yield point implies a non-Newtonian fluid, one that carries cuttings better than a fluid of similar density but with a lower yield point. Yield point is lowered by adding a Deflocculant to clay-based mud and increased by adding freshly dispersed clay or a Flocculant, such as lime, cement or polymers. 


\section{Gel Strength}

The Gel Strength of a drilling fluid measures the ability of the fluid to suspend cuttings when the fluid is standing motionless. It is the shear stress measured at low shear rate after a mud has set quiescently for a period of time (10 seconds and 10 minutes in the standard API procedure, although measurements after 30 minutes or 16 hours may also be made).

More so, it is a measure of thixotropic properties of a drilling fluid under non-flow conditions. Gel strengths can be classified as weak-fragile or as strong-progressive. The former is normally associated with thin mud which initially have a high gel strength which is easily broken. However, the later is associated with a thicker mud and is hard to break in initial rotation. Also, the gel strength of such fluids increases with stagnation time. Gel strength results from flocculation or attractive forces due to opposite charges at the molecular level.

\section{Mud Cake}

This refers to a low permeability filter cake, deposited on the wall of the hole, which consists of consolidated sticky solids from the drilling mud. The main function of the mud cake is to reduce formation damage by preventing the penetration of the mud filtrate into the formation. The filtration property of a drilling fluid measures the ability of the fluid to form a thin, lowpermeability filter cake. Normally, the permeability of the cake is directly proportional to its thickness. Filtrate loss from the fluid is dependent on the permeability of the filter cake or mud cake, permeability of the formation being drilled and pressure at the point of contact between the borehole and the formation. 


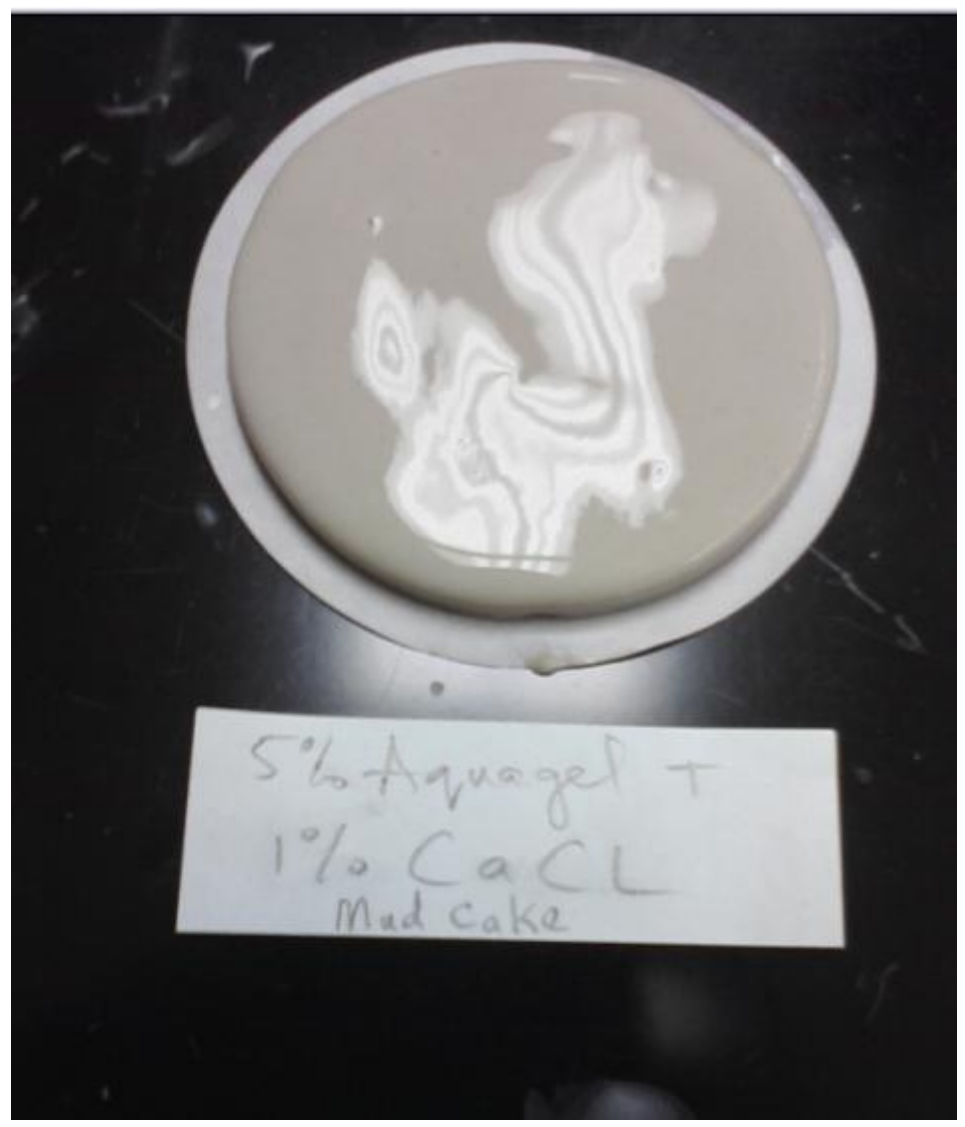

Figure 2.9: Mud Cake Sample

When filtrate loss is low, a thin filter cake is formed and drilling problems are minimized. However, a thick filter cake can reduce the effective size of the borehole causing problems such as an increase in torque on the rotating drill string, excessive drag and adherence of the pipe to the wall of the borehole. Figure 2.9 shows a mud cake of a base drilling fluid consisting of $5 \%$ Aquagel $+1 \% \mathrm{CaCl}_{2}$ by weight.

\section{Filtrate Loss}

This refers to the unwanted migration of the liquid part of the drilling mud or cement slurry into a formation, often minimized or prevented by the blending of additives with the mud or cement. 
For this research, it is the fluid accumulated in a graduated cylinder at the end of a 30 minute filter press operation or filtration measurements.

\section{Other Fluid Types}

Oil Based Mud refers to a mud whose base fluid is a petroleum product such as diesel fuel. The main reasons for the use of OBMs include enhanced shale inhibition, increased lubricity and greater cleaning ability with low viscosity. Also, OBMs can withstand very high temperatures without breaking down. However, the high cost of OBMs as well as sensitive environmental factors still gives WBMs the edge over OBMs.

Emulsion mud refer to a water based drilling fluid that contains dispersed oil or synthetic hydrocarbons as an internal phase. In the past, the emulsion mud employed diesel or crude oil dispersed into alkaline water based mud. However, synthetic liquids are now being substituted for an oil in emulsion mud. The advantage of synthetic liquids over oil is that they are environmentally safe. 


\section{Chapter 3}

\section{Experimental Procedure Mineralogy Analysis by X-ray diffraction}

The objective of this experiment was to determine the mineral and clay compositions available in the shale samples as well as their percentage distribution. Such minerals and clay components may include Feldspar, Quartz, Carbonates, Anhydrite, Apalite, Gypsum, Illite, Smectite, Kaolinite, Chlorite and mixed clays among others. The aim was to select shale samples with high Smectite content in order to see clearly, the swelling effects of various drilling fluids since Smectite clay is responsible for the majority of shale swelling However, upon extensive literature review and research, it was realized that the Marcellus Shale in Northern West Virginia had very little Smectite content as shown in Figure 3.1 by the XRD results. Due to limited resources, shale XRD results from nearby shale wells were used for the analysis of this experiment. Hence, the effect of other clays such as Kaolinite, Calcite, Illite including very little Smectite, on shale swelling were studied. 


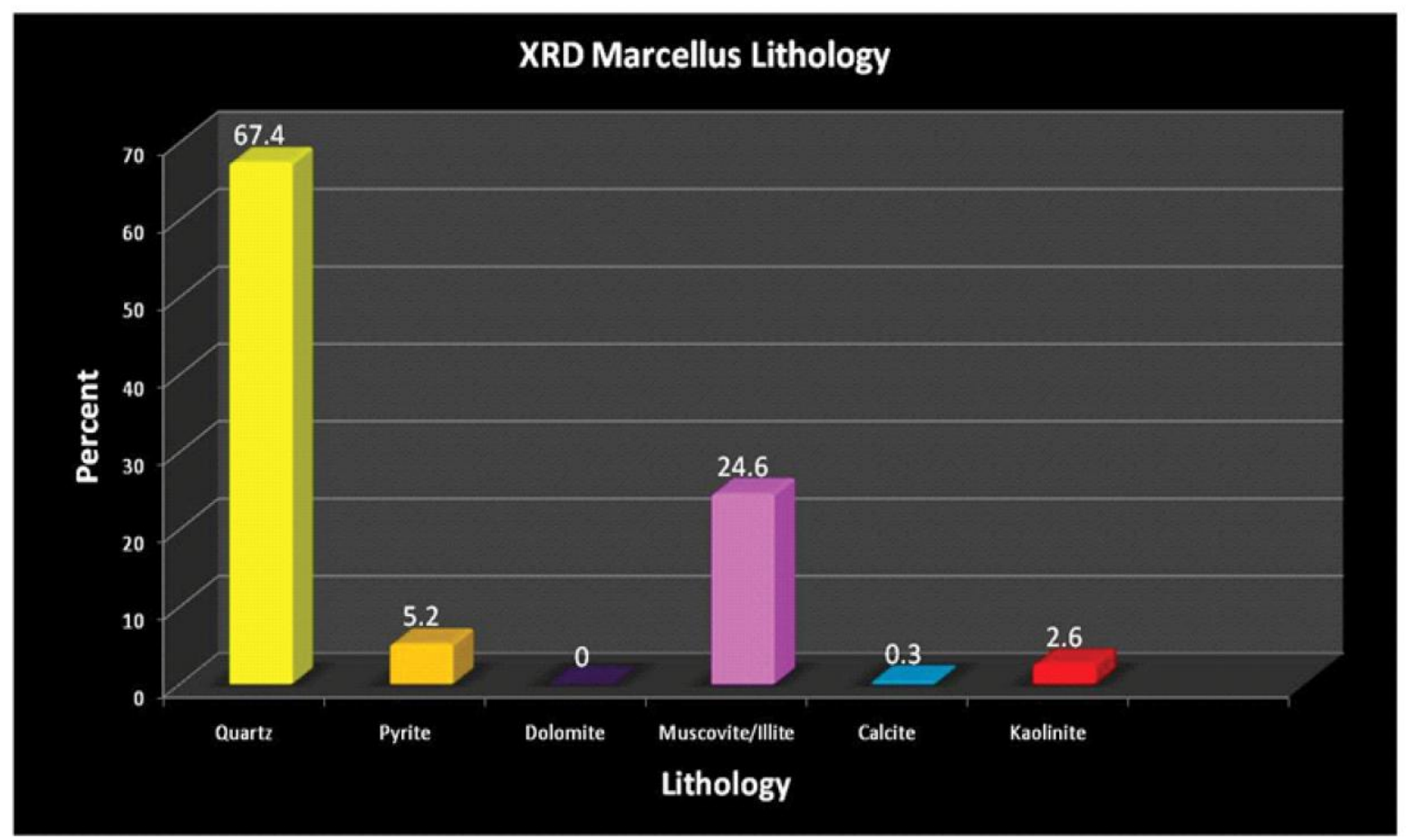

Figure 3.1: Approximation of X-ray diffraction results for the Marcellus Shale in West Virginia (http://www.mapwv.gov/UnconventionalResources/marcellusLithoAndPetroPaper.pdf)

Figure 3.1 shows an example of X-Ray Diffraction (XRD) results for a similar single core sample from the Marcellus in the study area. This sample has a high amount of quartz (67\%) and fairly low amount of clay (24\%), which is characteristic of the 36 Marcellus Shale core samples examined throughout the study area. Also it is important to identify the significant amount of pyrite. This sample has about 5\% but the samples can range from 5-10\% pyrite. Figure 3.2 compares XRD results obtained at WVU to those obtained elsewhere for a given Marcellus Shale sample. 


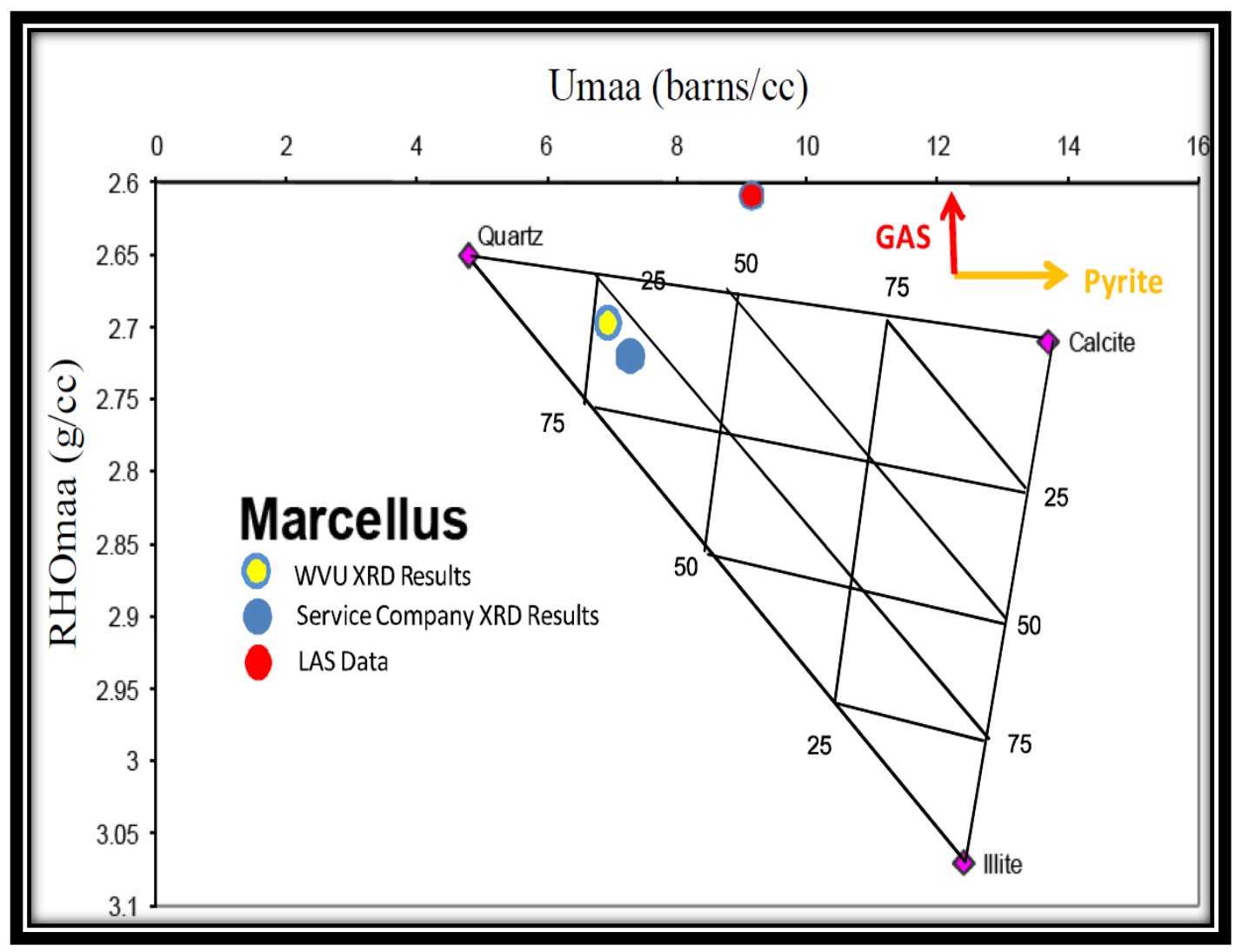

Figure 3.2: Rhomaa Umaa Plot compared with XRD results from single shale sample of the Marcellus Shale in West Virginia

(http://www.mapwv.gov/UnconventionalResources/marcellusLithoAndPetroPaper.pdf) 


\section{Cation Exchange Capacity Test}

\section{(Methylene Blue Method)}

This experiment involved the titration of Smectite clay suspensions using Methylene blue dye. Titration normally involves a titrating fluid whose volume and concentration is known in addition to a titrand whose volume is known, but whose concentration is not known. Titration is said to be complete when the endpoint is reached and this is often indicated by an indicator. More so, at the end of a titration, the volume of titrating fluid used is often measured for analysis. In acid-base titration, the endpoint is the point at which $\mathrm{ph}=7.0$ or when the number of moles of the titrant equals the number of moles of the titrand. The titration experiment that was used in this research was vital in determining the CEC of Smectite samples in question.

The Methylene blue method was used to determine the CEC of the Smectite commonly found in shale formations. This method involved the titration of clay suspensions using Methylene blue dye. The method was first employed by Jones 1964 to determine Bentonite content of drilling fluids; however, the method has since been modified by Chenevert and Osisanya 1991 for shale samples. Furthermore, Methylene blue is an organic dye that readily displaces exchangeable cations present in clay minerals in shale.

Experimental Procedure:

The clay samples were obtained. Then, $20 \mathrm{~g}$ of shale was added to $700 \mathrm{ml}$ of deionized water. The mixture was then mixed for 10 minutes, using a multimixer or blender. Next, $4 \mathrm{ml}$ of the mixture was transferred into a $500 \mathrm{ml}$ flask, using a syringe followed by an addition of $20 \mathrm{ml}$ of 
deionized water. The resulting mixture was treated with $30 \mathrm{ml}$ of $3 \%$ hydrogen peroxide and $0.1 \mathrm{ml}$ of $5 \mathrm{~N}$ Sulfuric acid. The main objective was for the swelling clay present in the formation shale to absorb as much Methylene blue as possible; however, organic matters in the shale also absorb Methylene blue. Therefore, in order to obtain an accurate result from the experiment, hydrogen peroxide was added to oxidize any organic matter present.

Next, the solution was boiled gently for 12 minutes and then diluted with $100 \mathrm{ml}$ of deionized water. Figure 3.3 illustrates a titration apparatus.

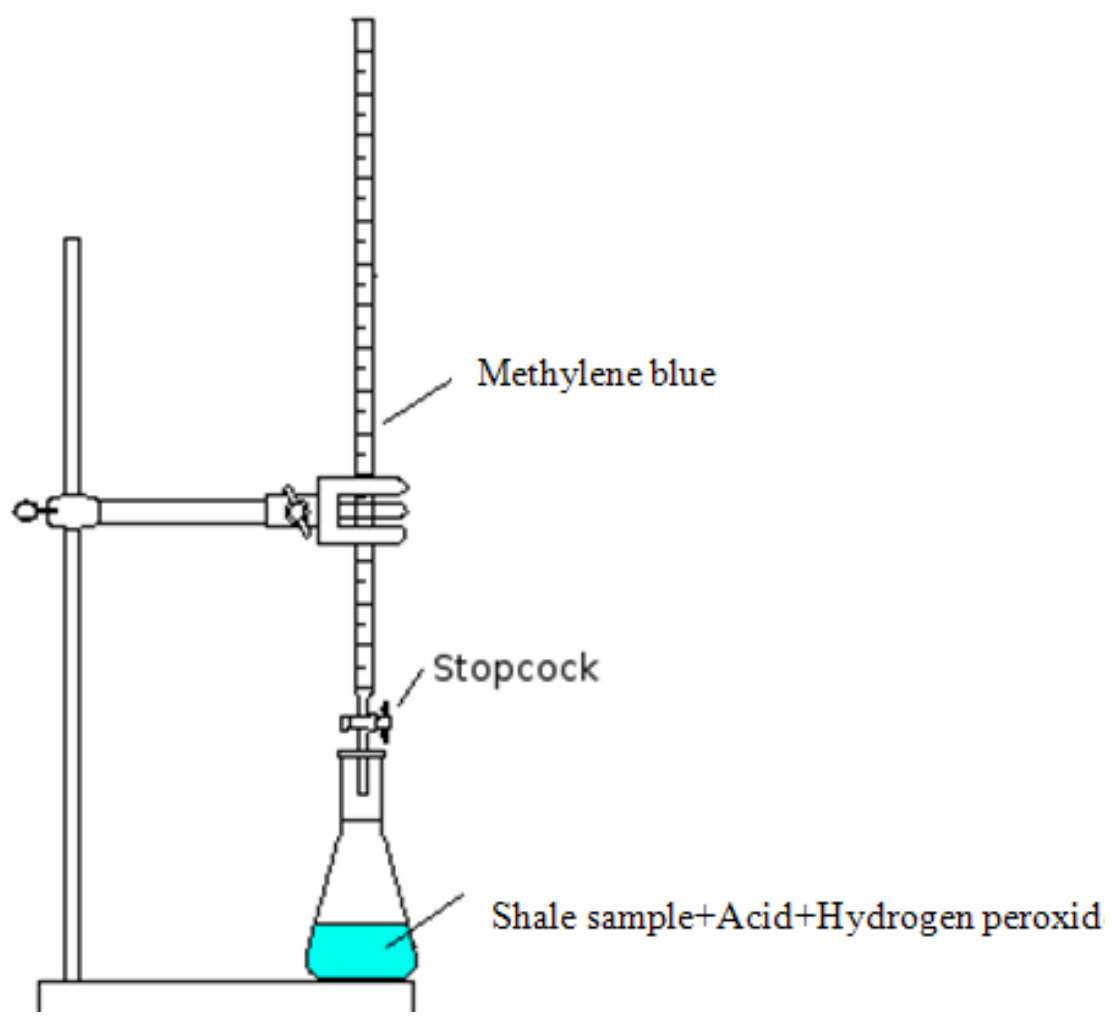

Figure 3.3: Titration Assembly 


\section{Spot-test for Endpoint determination of Methylene blue titration}

The mixture was titrated using $0.02 \mathrm{M}$ Methylene blue solution. The Methylene blue was added in increments of $0.5 \mathrm{ml}$ and drops of the mixture were placed on a filter paper until a purple halo was noticed around the solid region as shown in Figure 3.4. This halo signifies the complete adsorption of Methylene blue on all the available exchangeable sites possessed by the shale. This was the endpoint of the titration.

$$
C E C=\frac{\mathrm{C}_{\mathrm{d}} * \mathrm{~V}_{\mathrm{mb}} * \mathrm{C}_{\mathrm{MB}}}{\mathrm{v}_{\mathrm{df} * \mathrm{M}_{\mathrm{s}}}}
$$

Where,

$\mathrm{CEC}=$ Cation exchange capacity, Meq/100g of solid

$\mathrm{C}_{\mathrm{d}}=$ volume constant (Equal to one)

$\mathrm{V}_{\mathrm{mb}}=$ Volume of Methylene blue titrated, $\mathrm{ml}$

$\mathrm{C}_{\mathrm{mb}}=$ Concentration of Methylene blue solution, $\mathrm{M}$

$\mathrm{V}_{\mathrm{df}}=$ Volume of dispersed fluid, $\mathrm{ml}$

$M_{s}=$ Mass of shale dispersed, $g$ 


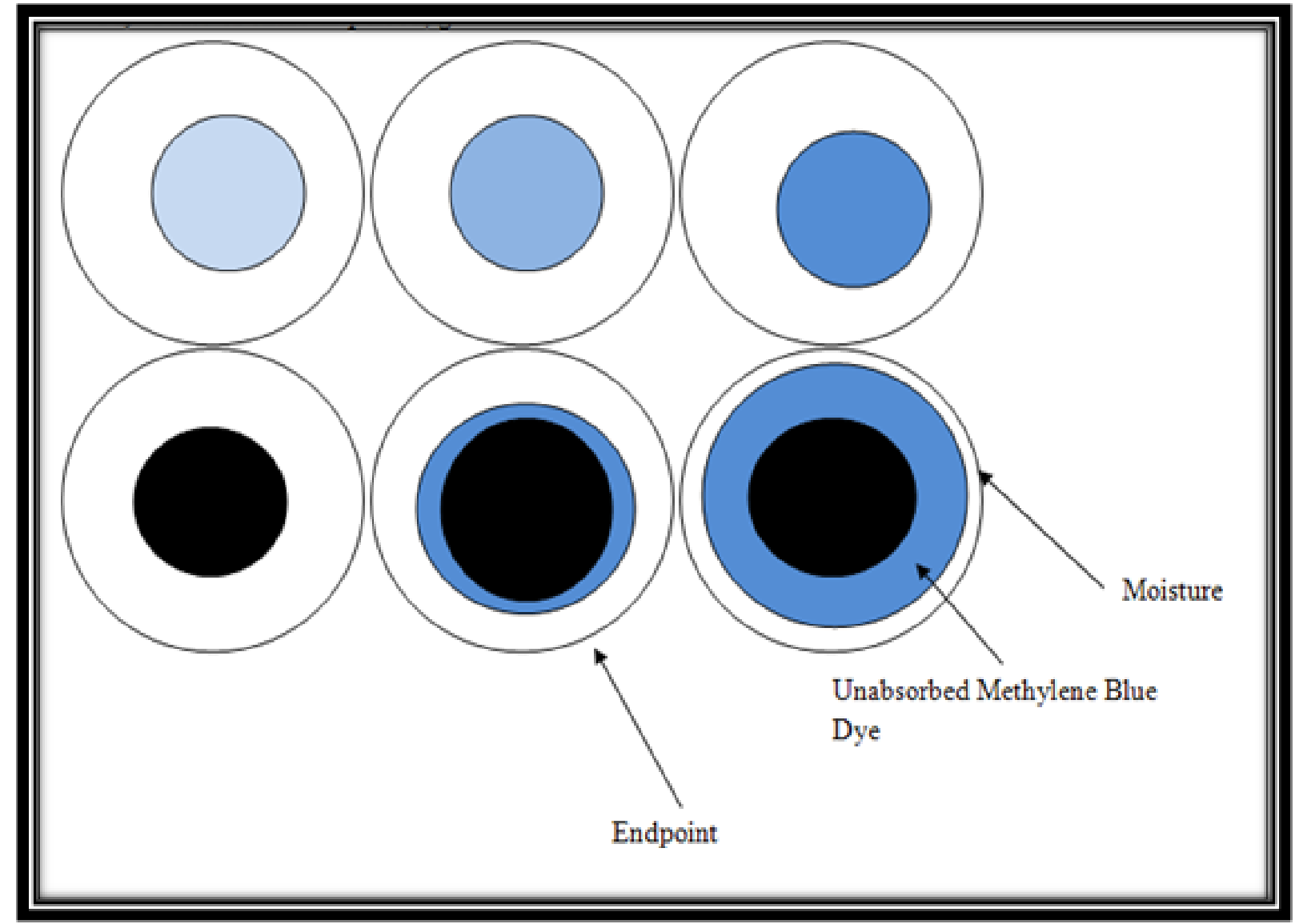

Figure 3.4: CEC testing

\begin{tabular}{|c|c|}
\hline \multicolumn{2}{|c|}{ CEC Exchange Capacity } \\
Result \\
\hline Clay & CEC \\
\hline Smectite & 142 \\
\hline
\end{tabular}

Table 3.1: CEC Result for Smectite Clay 


\section{Rheological Measurements}

\section{Preparation of Drilling Fluid Samples}

Numerous drilling fluid samples were prepared for rheological analysis. Base fluids which were tested before the incorporation of $\alpha$-w Diamino Alkanes (Diamino Butand and Diamino Hexane) consisted of $5 \%$ Aquagel by weight and $0.5 \%, 1 \%$ or $3 \%$ by weight of a Chloride or Hydroxide of an Alkali metal, Alkaline earth metal or Transition metal. $450 \mathrm{ml}$ of water was measured and poured into a blender cup, the cup was placed in a multi-mixer (Figure 3.6) and the multi-mixer blender was turned on. $22 \mathrm{~g}$ of Aquagel was measured (Figure 3.5) and poured into the water as the mixture was blending. Next, $0.5 \%, 1 \%$ or $3 \%$ by weight of Chloride or Hydroxide of an Alkali metal, Alkaline earth metal or Transition metal was added to the mixture while it was blending. The mixtures were allowed to blend for 17 minutes until a homogenous solution was

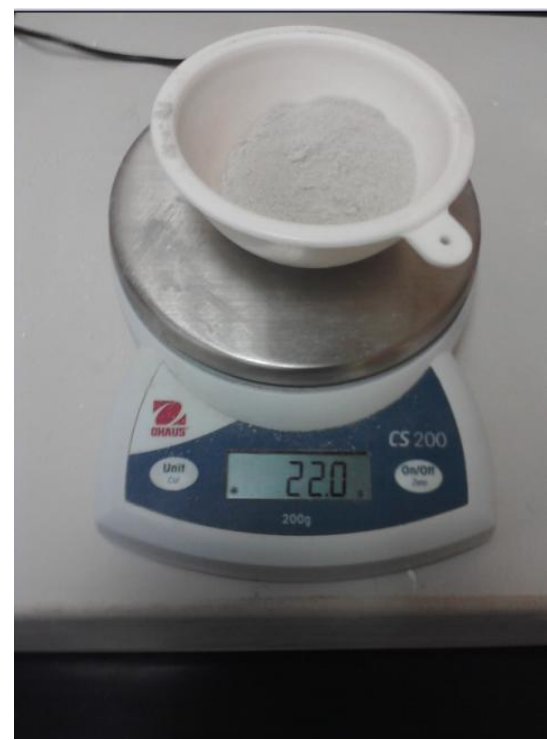

Figure 3.5: Weighing Scale

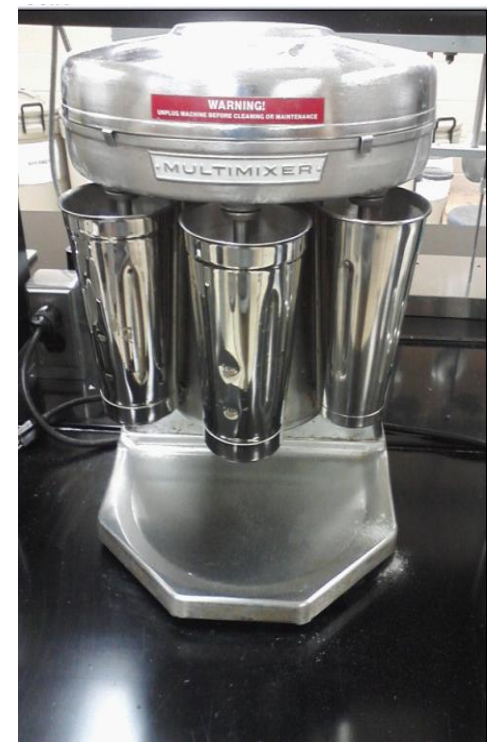

Figure 3.6: Drilling Fluid Blender 


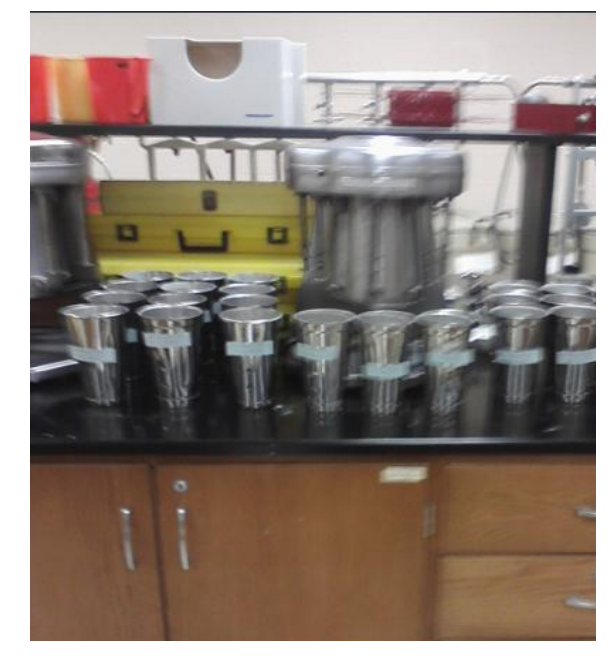

Figure 3.7: Various Formulated Drilling Fluids ready for testing

\section{Mud Weight Measurement}

The mud weight or density can be obtained by weighing a precise volume of mud and then dividing the weight by the volume. However, by using a mud balance, the volume is fixed and the weight is conveniently read from the scale on the balance arm. The mud weight of drilling fluid samples, for this research, was measured by setting the balance in a level spot after which a clean dry cup was filled with mud from the steel blender container. Next, a lid was firmly sat on the cup with a twisting motion, making sure that a small amount of mud escaped out of the hole on top. Subsequently, the hole was covered with a finger and excess mud was carefully wiped off. Next, the balance arm was set on the fulcrum and the weight was slid until the cup and the arm were balanced. Once balance was achieved, the mud weight was recorded from the left side of the sliding weight. The mud weight was read to the nearest $0.1 \mathrm{lb} / \mathrm{gal}$. 


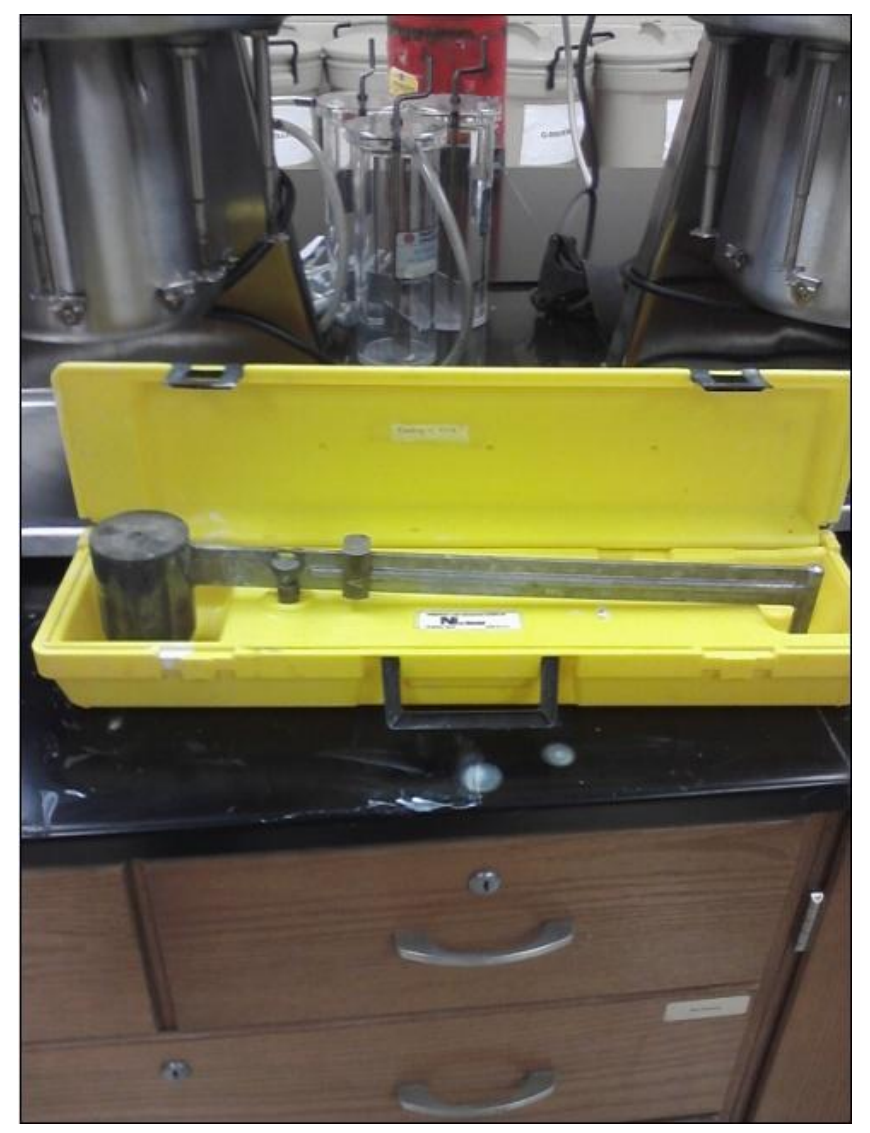

Figure 3.8: Mud Balance

Figure 3.7 shows a sample of base drilling fluids used in this research while Figure 3.8 shows a mud balance used in measuring density of the base drilling fluids. 


\section{Plastic Viscosity Measurement}

Plastic viscosity of various mud systems were measured by the use of the Baroid 286 Model Rheometer available at the West Virginia University (WVU) Mud Lab (Figure 3.9). Two dial readings were taking at $600 \mathrm{RPM}$ and $300 \mathrm{RPM}$ after which there difference was taken to obtain the plastic viscosity of the fluid. Figure 3.9 shows how PV is measured.

Plastic viscosity,

$\mu_{\mathrm{p}}=\theta_{600}-\theta_{300}$

Where:

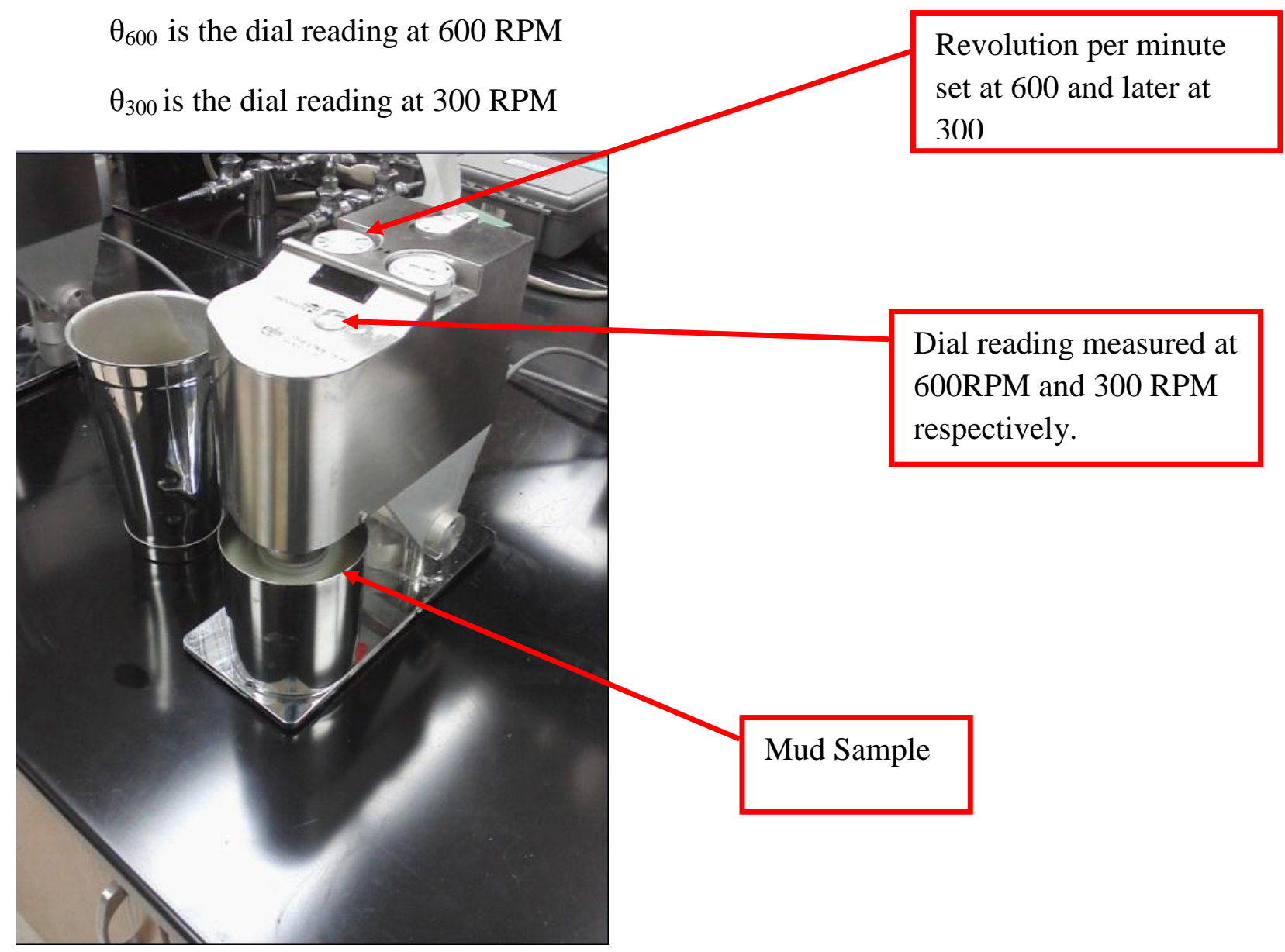

Figure 3.9: Rheometer for PV measurement demonstration 


\section{Apparent Viscosity Measurement}

The Apparent viscosity of all mud systems were also measured using the Baroid 286 Model Rheometer available at the WVU Mud lab. A dial reading was recorded at 600 RPM for each mud system after which the dial reading was divided by 2 to obtain the apparent viscosity. Figure 3.10 shows how $\mathrm{AV}$ is measured.

Apparent viscosity,

$\mu_{\mathrm{a}}=\theta_{600} / 2$.

Where:

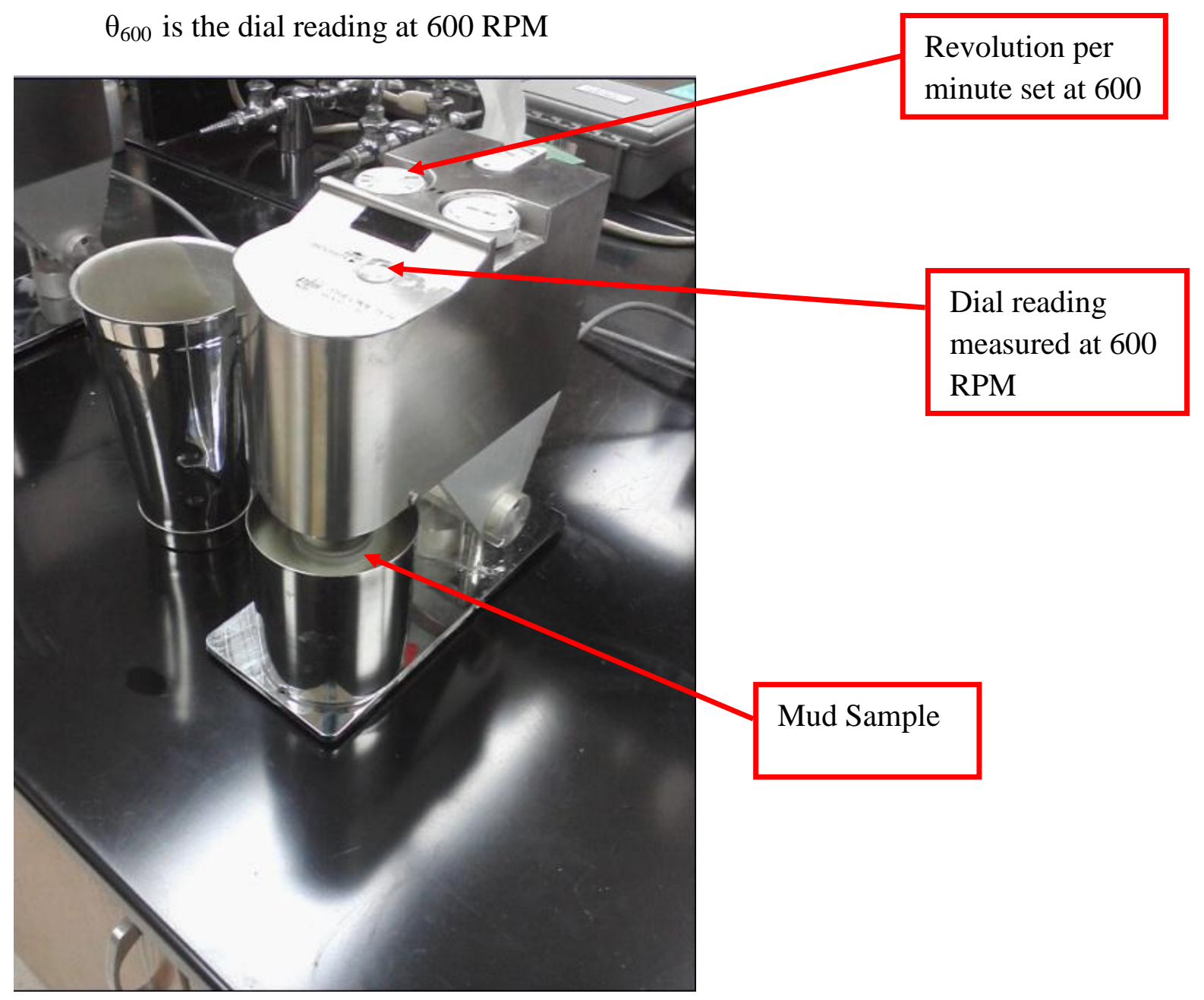

Figure 3.10: Rheometer for AV measurement demonstration 


\section{Yield Point Measurement}

The yield point of various mud systems were measured by the use of the Baroid 286 Model Rheometer available at the WVU Mud Lab. Dial readings were taking at 600 RPM and 300 RPM after which there difference was taken to obtain the plastic viscosity of the fluid. Next, the plastic viscosities were subtracted from the 300 RPM dial readings to obtain the yield points of the various fluids. Figure 3.11 shows how YP is measured.

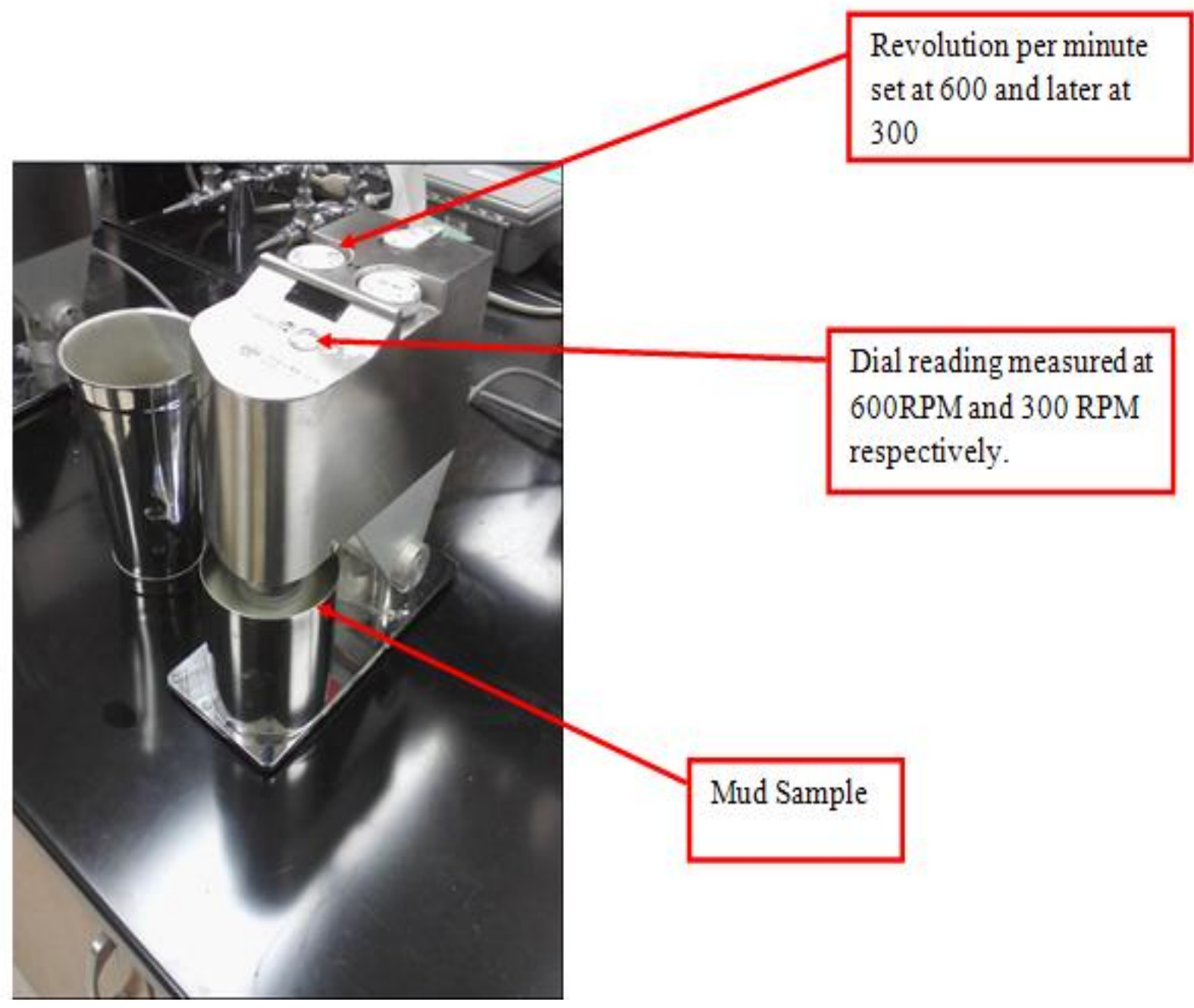

Figure 3.11: Rheometer for YP measurement demonstration 
Yield Point,

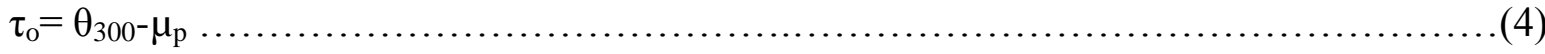

Where:

$\theta_{300}$ is the dial reading at $300 \mathrm{RPM}$

$\mu_{\mathrm{p}}$ is Plastic Viscosity

$\tau_{\mathrm{o}}$ is Yield Point 


\section{Gel Strength}

The gel strength of all mud systems were also measured using the Baroid 286 Model Rheometer available at the WVU Mud lab. A dial reading was recorded at Gel for each mud system to obtain the gel strength. Figure 3.12 shows how Gel Strength is measured. Dial Reading measured at Gel or $3 \mathrm{RPM}=$ Gel Strength

Revolution per minute set at Gel or 3 RPM
Dial reading measured at $\mathrm{Gel}$ or $3 \mathrm{RPM}=\mathrm{Gel}$ Strenght

Mud Sample

Figure 3.12: Rheometer for GS measurement demonstration 


\section{Swelling Test}

Eventually, 14 drilling fluids were selected, among the lengthy list of drilling fluid formulations, to evaluate the effect of various chemicals on the inhibition of Smectite clay. The initial linear length of the clay or shale sample was measured while placed in a calibrated container. The drilling fluid candidate of interest was introduced into the flask. The apparatus (Figure 3.15) was then left to stand for a total of 120 minutes after which the percentage linear swelling of the clay or shale samples was measured. A linear swell meter obtained from the Civil Engineering Department at West Virginia University (Figure 3.15 and 3.16) was used to measure the inhibitive capability of the drilling fluids on Marcellus Shale samples (Figure 3.13) from Well \# 6 in West Virginia. The linear swell meter consisted of a flask, piston, clamp, sensitive meter capable of measuring to $1000^{\text {th }}$ of an inch and other components.

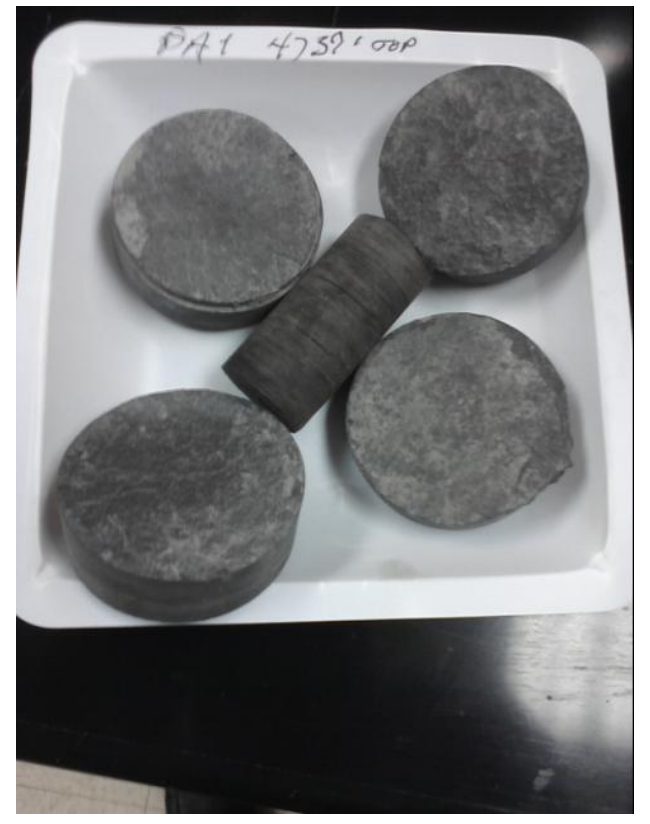

Figure 3.13: Uncrushed Marcellus Shale samples from WV\#6 well in West Virginia. $4737 \mathrm{ft}$ (Courtesy of US DOE)

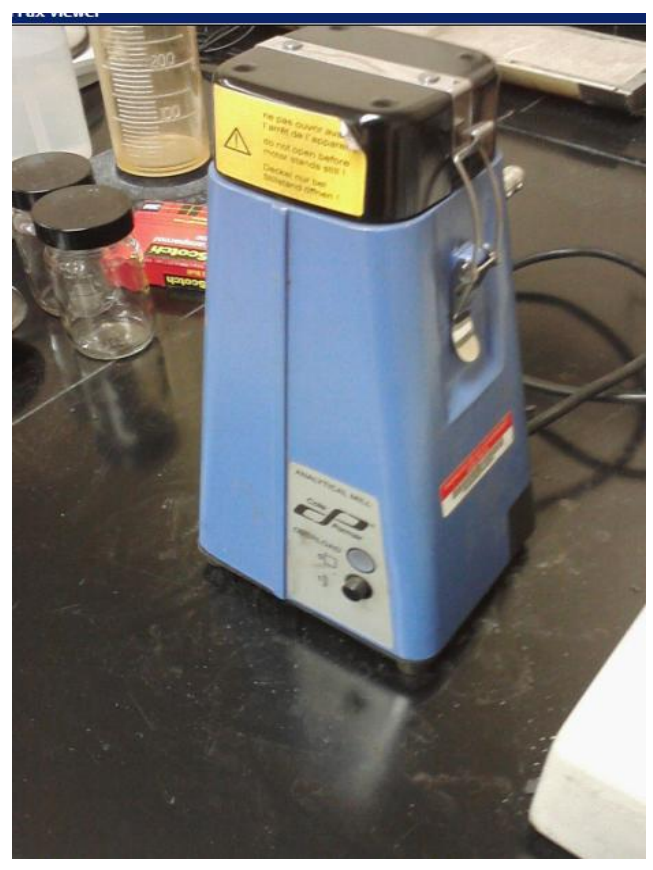

Figure 3.14: Shale Grinder 
The grinder in Figure 3.14 was used to ground shale samples for XRD analysis.

The $\%$ linear swelling results were calculated using the equation below:

$\varepsilon=\Delta \mathrm{L} / \mathrm{L} * 100 \%$

Where,

$\varepsilon$ is the percentage linear swelling

$\Delta \mathrm{L}$ is the change in shale length, inches

Highly Sensitive Meter: $1000^{\text {th }}$ of an inch

$\mathrm{L}$ is the original length of the shale, inches

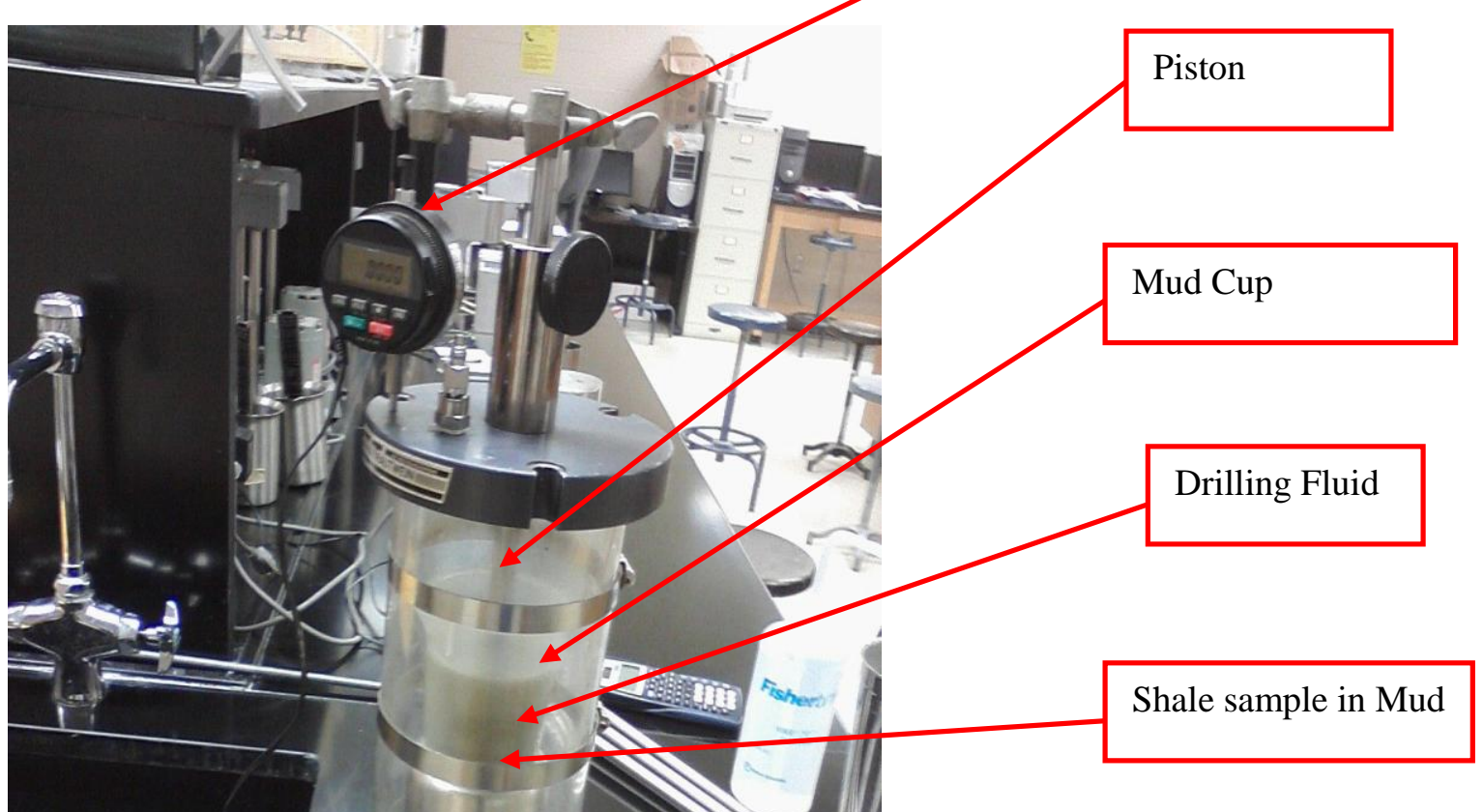

Figure 3.15: Linear Swell Meter 


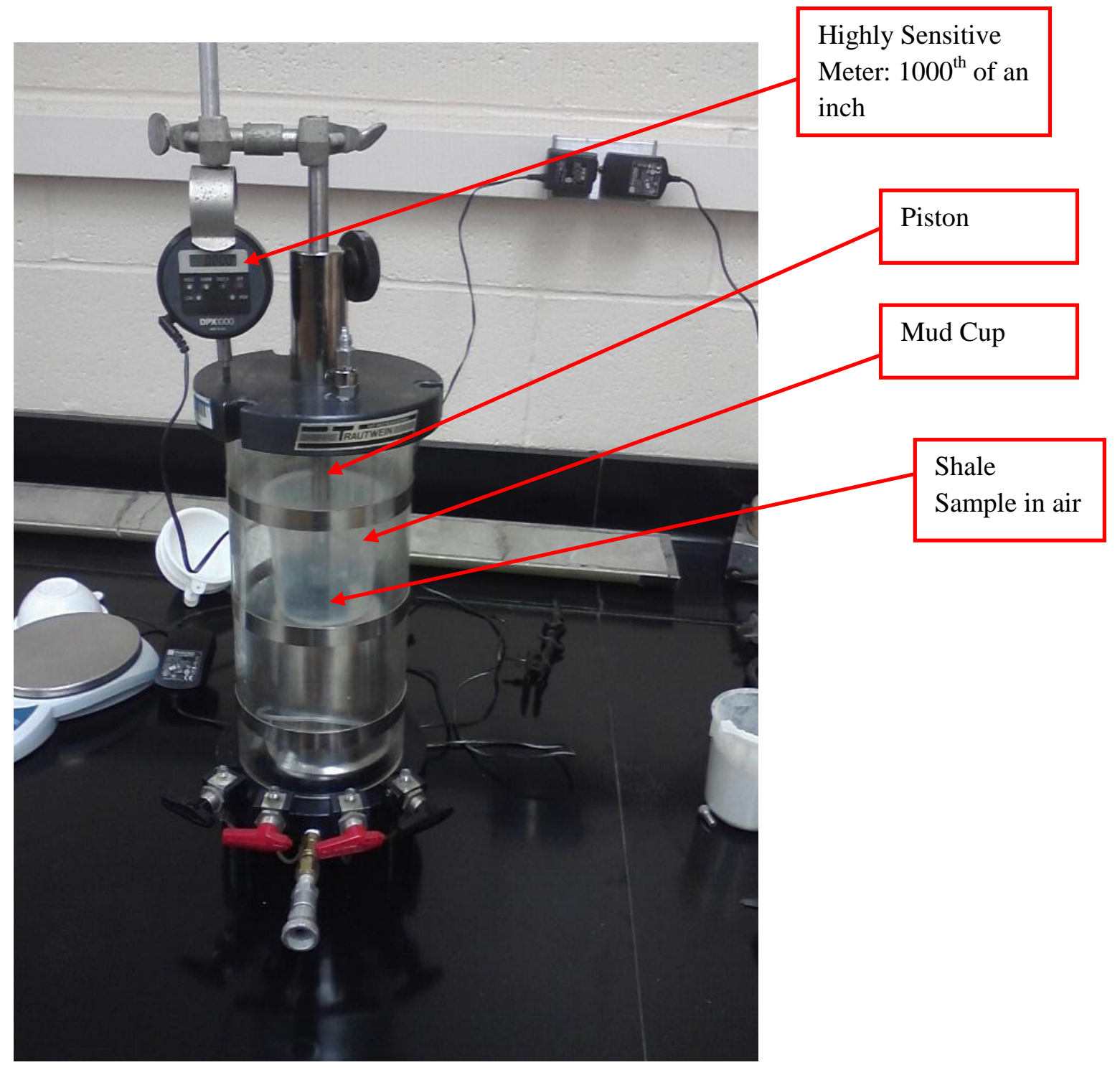

Figure 3.16: Linear Swell Meter without drilling fluid 


\section{Filtration Analysis}

\section{Filtrate Loss Measurement}

The filtration and wall-building characteristics of the mud samples were measured using the Baroid filter press (Figure 3.17). Basically, this apparatus consists of a cylinder 2.5" high and 3" in diameter and a rubber boot which holds the fluid inside the steel container as shown in

Figure 3.17. Pressure was applied on the fluid to force the water component to filter through a piece of filter paper, collecting in a graduated cylinder. This water loss collected is called filtrate loss. A high filtrate loss is a poor and unwanted mud property. A cake is built on the filter paper during this process.

The measuring apparatus was set up by assembling the following components in this order: base cap, a rubber gasket, a screen, a sheet of filter paper, a rubber gasket, and cell. Next the cell was secured to the base cap. Next, the cup was filled to within $1 / 8^{\prime \prime}$ of the top with mud after which a rubber gasket was placed on top of the cell and the top cap secured. Furthermore, the press was placed into its stand and the pressure equipment was hooked up. A dry graduated cylinder was placed under the press. Also, 100 psi was applied to the sample immediately when the experiment started. The test was run for 30 minutes which is the standard API time duration for filter press measurements. During the 30 minute time interval, filtrate loss was measured at every 1 minute interval for each mud as shown in Table A.2. 


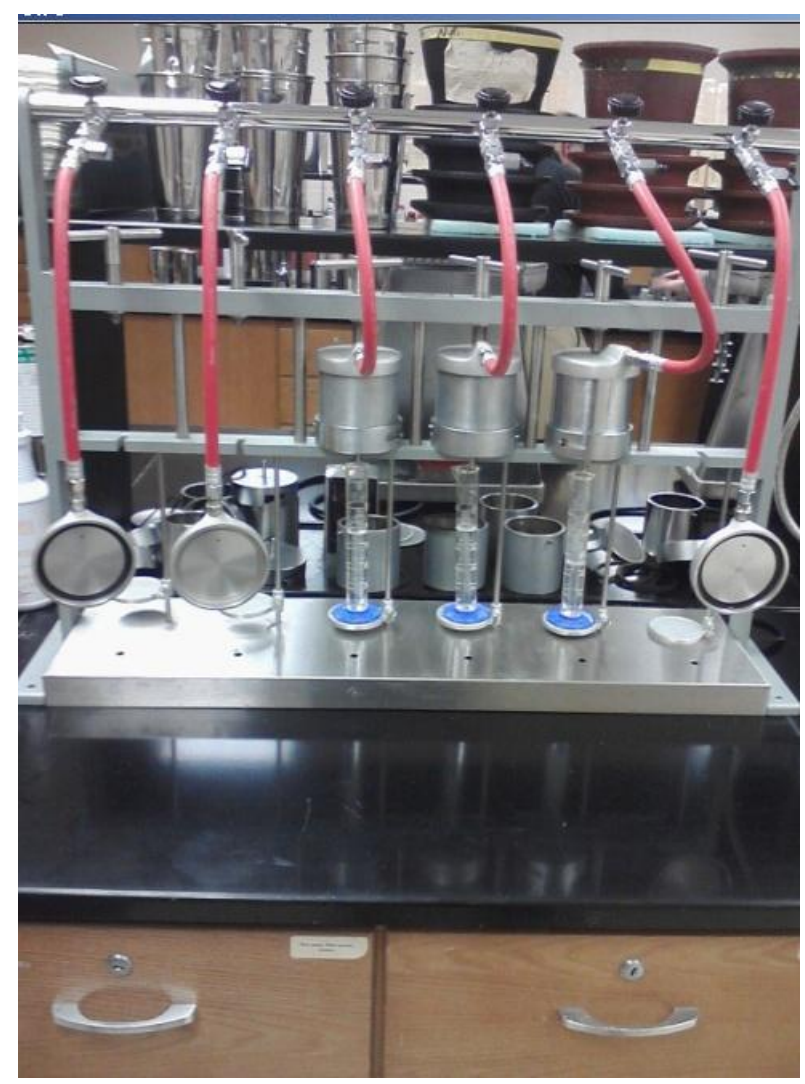

Figure 3.17: Filter Press 


\section{Mud Cake Measurement}

After the filter press had been run for 30 minutes and the resulting filtrate volume had been recorded, the filter press assembly comprising of a filter paper, screen, rubber gaskets and cylinder was disassembled. Next, the filter paper was taken off and the filter cake thickness was measured and reported to the nearest 1/32". The thickness of the mud cake was measured using a unit caliper as shown in Figure 3.18 below.
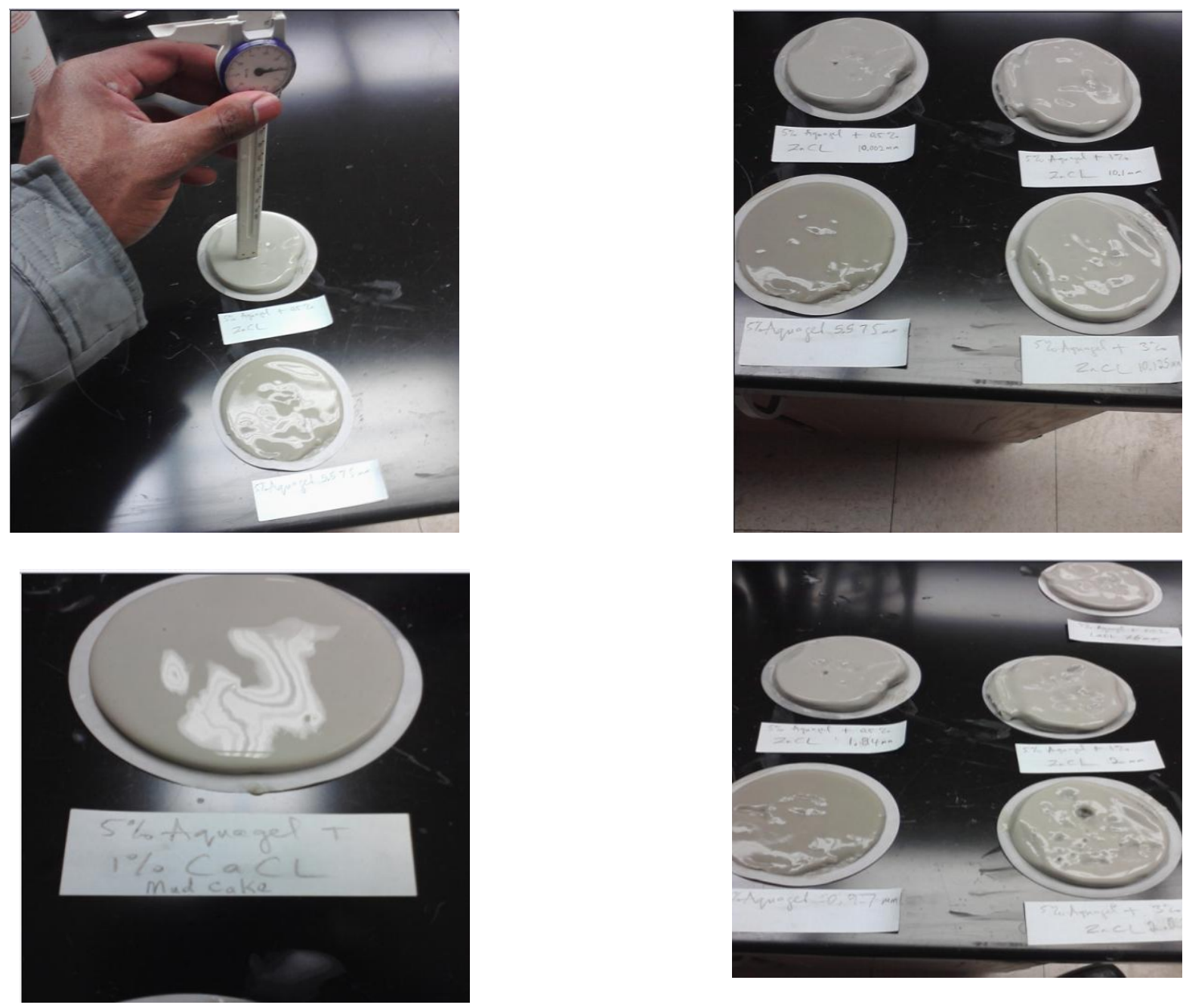

Figure 3.18: Mud Cake measurements 


\section{Chapter 4}

In this chapter, evaluations and analysis of the results obtained from the experimental procedures that were elaborated upon in the trailing chapters are explained. Additionally, based on the results from rheological and filtration experiments, some fluids were selected for further testing with $\alpha$-w Diamino Alkanes (Diamino Butane and Diamino Hexane).

\section{Experimental Results and Data Analysis}

\section{Rheological Analysis of Base Fluids}

With regards to plastic viscosity (PV), most base fluids experienced an increase in plastic viscosity within the concentration range of $0.5-1 \%$ of a Chloride or Hydroxide of a respective metal after which their plastic viscosities began to decline. Fluids which fell under this category

included $\mathrm{KCl}$-Aquagel, $\mathrm{CaOH}_{2}$-Aquagel, $\mathrm{MgOH}_{2}$-Aquagel, $\mathrm{MgCl}_{2}$-Aquagel and $\mathrm{LiOH}$-Aquagel fluids. However, $\mathrm{CaCl}_{2}$-Aquagel and $\mathrm{LiCl}$-Aquagel systems showed slight increase between $0.5 \%-1 \%$ weight concentrations after which their plastic viscosities appeared to level off. Regardless of the declining trend of the plastic viscosities of these fluids after the $1 \%$ mark, the $\mathrm{KCl}$-Aquagel fluid had a much higher plastic viscosity than the rest as shown in Figure 4.1. Another chemical which proved to increase plastic viscosity of Aquagel based fluid was LiOH, a surprise candidate given its attenuated use in the industry.

Nevertheless, there were three exceptions to the aforementioned trend. The PV of the $\mathrm{ZnCl}-$ Aquagel fluid tended to increase sharply from $0.5 \%$ to $1 \%$ concentration after which its PV continued to increase but at a decreased rate as shown in Figure 4.1. The NaCl-Aquagel system 
showed a steady decline as the concentration of the $\mathrm{NaCl}$ increased. This, perhaps, is not a surprise as the drilling engineers are familiar with the effect of $\mathrm{NaCl}$ on water based drilling fluids.

Special attention was given to the $\mathrm{LiOH}$-Aquagel system due to its novelty in the industry and it showed a fascinating trend with respect to PV. Its PV decreased between $0.5-1 \%$ concentrations after which it showed a steep increase in PV, perhaps too steep to cause unwanted pressure losses during mud circulation while drilling. The rate of PV increase for the LiOH-Aquagel system was exceptionally high after the $1 \%$ mark.

Overall, $2 \% \mathrm{LiOH}, 1 \% \mathrm{KCl}$ and $0.5 \% \mathrm{NaCl}$ appeared to have improved or acceptable PVs when compared to the PV of the initial Aquagel-only system shown in Table A.1. 


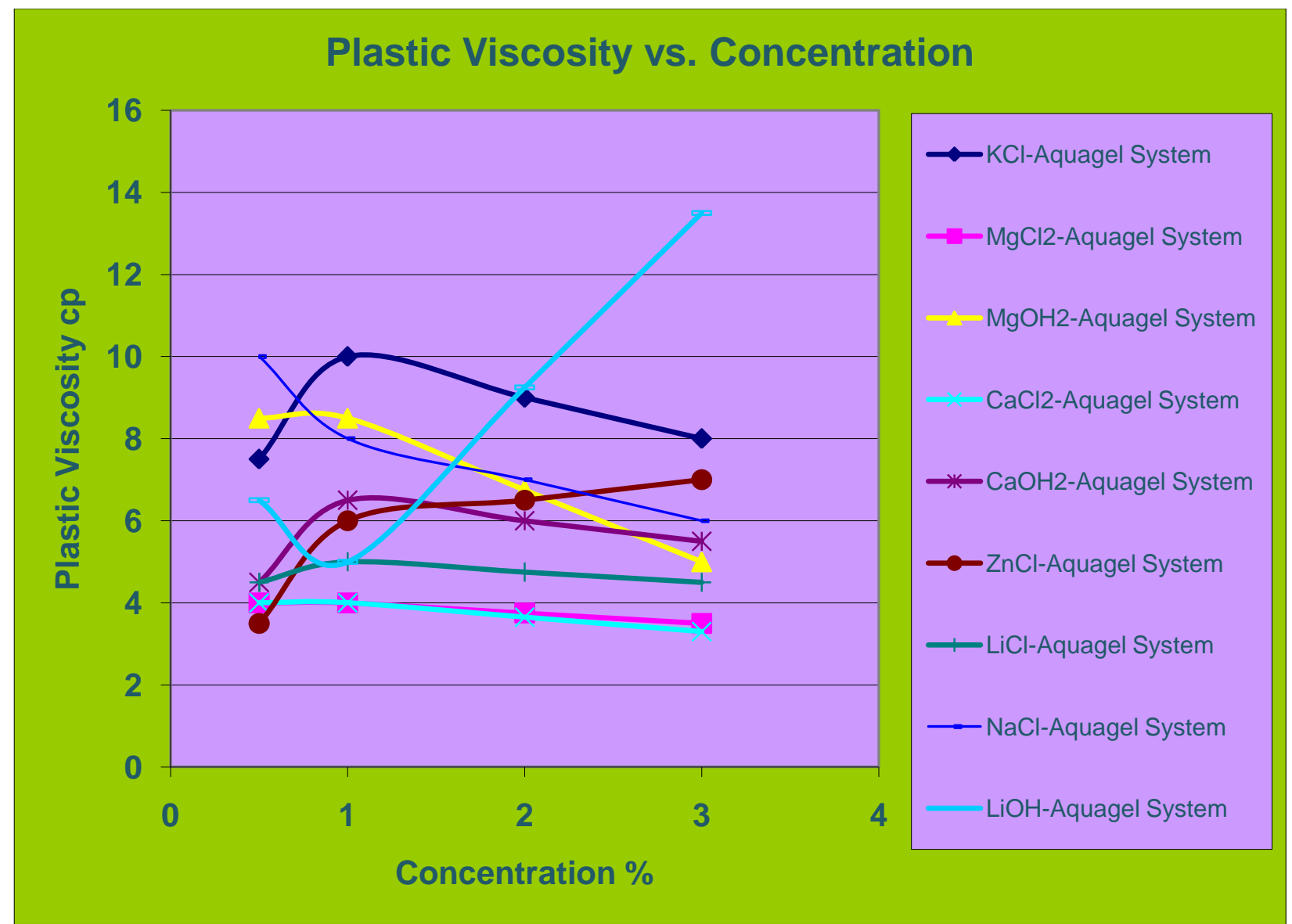

\section{Figure 4.1: Variation of Plastic Viscosity of Base Fluids with Hydroxide and Chloride} concentrations.

In the evaluation of the apparent viscosity (AV) of various base mud systems, the LiOH-Aquagel system appeared to have an AV which was insurmountably greater than the rest. A difference of about $23 \mathrm{cp}$ was observed between the AV of $\mathrm{LiOH}$-Aquagel system at $3 \%$ concentration and the second highest $\mathrm{AV}$ at $3 \%$ concentration, that of the $\mathrm{KCl}$-Aquagel system. The rest of the system curves at $3 \%$ concentration had an average separation or gap of about $2.2 \mathrm{cp}$.

The AV (Figure 4.2) of the LiOH-Aquagel system was so high that it was nearly eliminated for the second phase of this research which involved the blending of the base fluids with various concentrations of DiaminoAlkanes (DiaminoButane, DiaminoHexane) and various permutations 
and combinations of the aforementioned chemicals in order to create the ultimate inhibitive drilling fluid for the Marcellus shale and other shale formations.

Five systems (LiOH-Aquagel, $\mathrm{ZnCl}$-Aquagel, $\mathrm{KCl}$-Aquagel, $\mathrm{CaOH}_{2}$-Aquagel and $\mathrm{MgOH}_{2}$ Aquagel) showed an increase in $\mathrm{AV}$ as concentration increased. However, NaCl-Aquagel and LiCl-Aquagel systems showed a decrease in AV with increase in concentration while $\mathrm{MgCL}_{2}$ Aquagel and $\mathrm{CaCl}_{2}$-Aquagel systems leveled off as concentration increased.

Systems that showed acceptable AVs included $2 \%$ and $3 \% \mathrm{KCl}$-Aquagel systems, $0.5 \%$ to $3 \%$ $\mathrm{ZnCl}$-Aquagel systems, 1 to $3 \% \mathrm{CaOH}_{2}$-Aquagel systems and $0.5 \%-3 \% \mathrm{MgOH}_{2}$-Aquagel systems. 


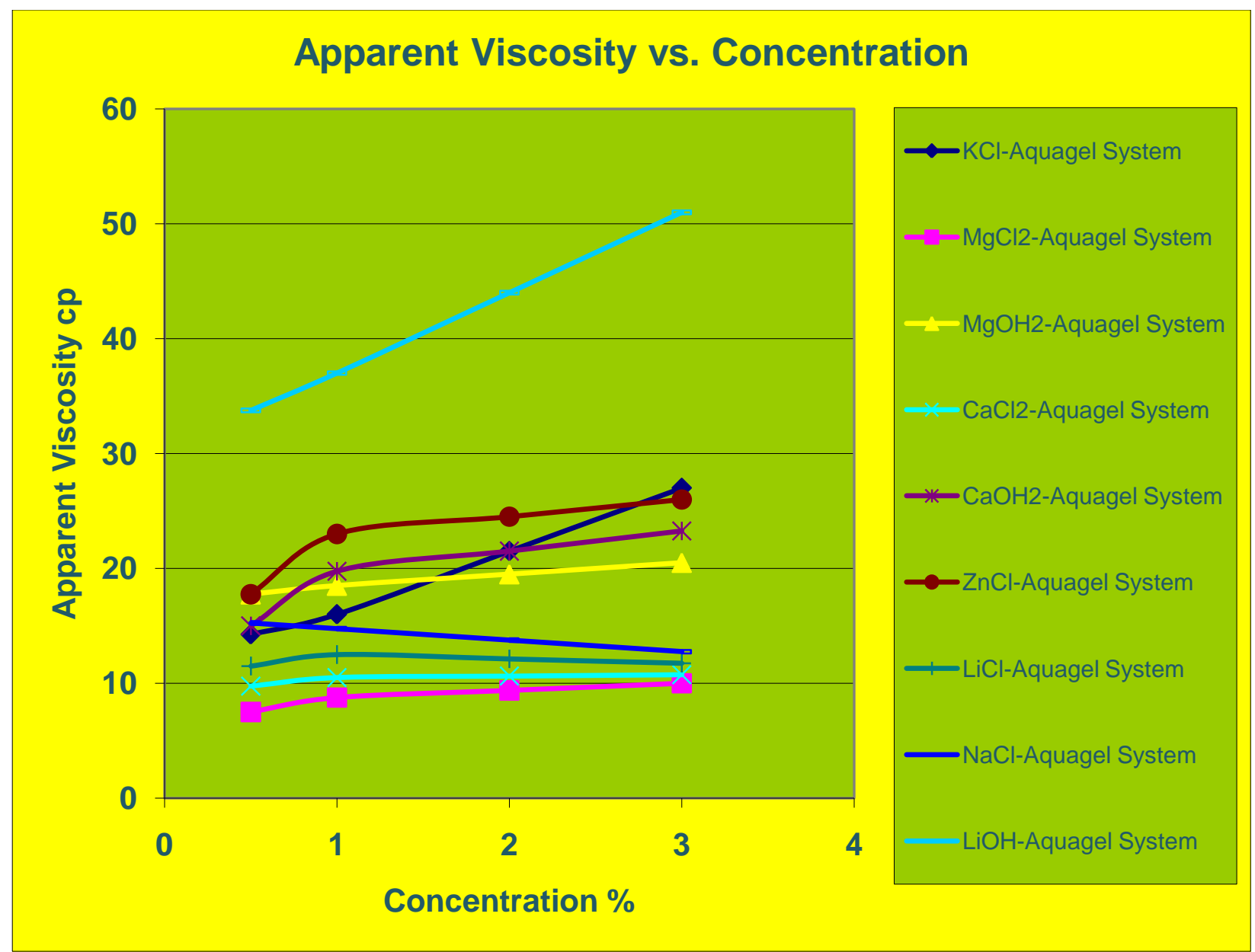

Figure 4.2: Variation of Apparent Viscosity of Base Fluids with Hydroxide and Chloride concentrations.

Gel strength is an important property of drilling fluids as it measures the ability of the drilling fluid to suspend cuttings when motionless. However, there is a trade off. Too high a gel strength which is related to yield point could result in high pressure losses when circulating the mud while drilling.

$\mathrm{LiOH}-A q u a g e l$ systems possessed the highest gel strength followed by $\mathrm{MgOH}_{2}$-Aquagel and $\mathrm{KCl}$-Aquagel systems just trailing behind as shown in Figure 4.3. Out of all the systems, four systems ( $\mathrm{LiOH}$-Aquagel, $\mathrm{MgOH}_{2}$-Aquagel, $\mathrm{KCl}$-Aquagel and $\mathrm{CaOH}_{2}$-Aquagel) showed a 
decrease in gel strength as concentration increased. LiCl-Aquagel system showed a slight increase while $\mathrm{CaCl}_{2}$-Aquagel and $\mathrm{MgCl}_{2}$-Aquagel systems leveled off.

Overall, $0.5 \%-3 \%$ KCl-Aquagel, $0.5 \% \mathrm{NaCl}$-Aquagel, $0.5 \%-3 \% \mathrm{MgOH}_{2}$-Aquagel, $0.5 \%-3 \%$ LiOH-Aquagel showed improved gel strength.

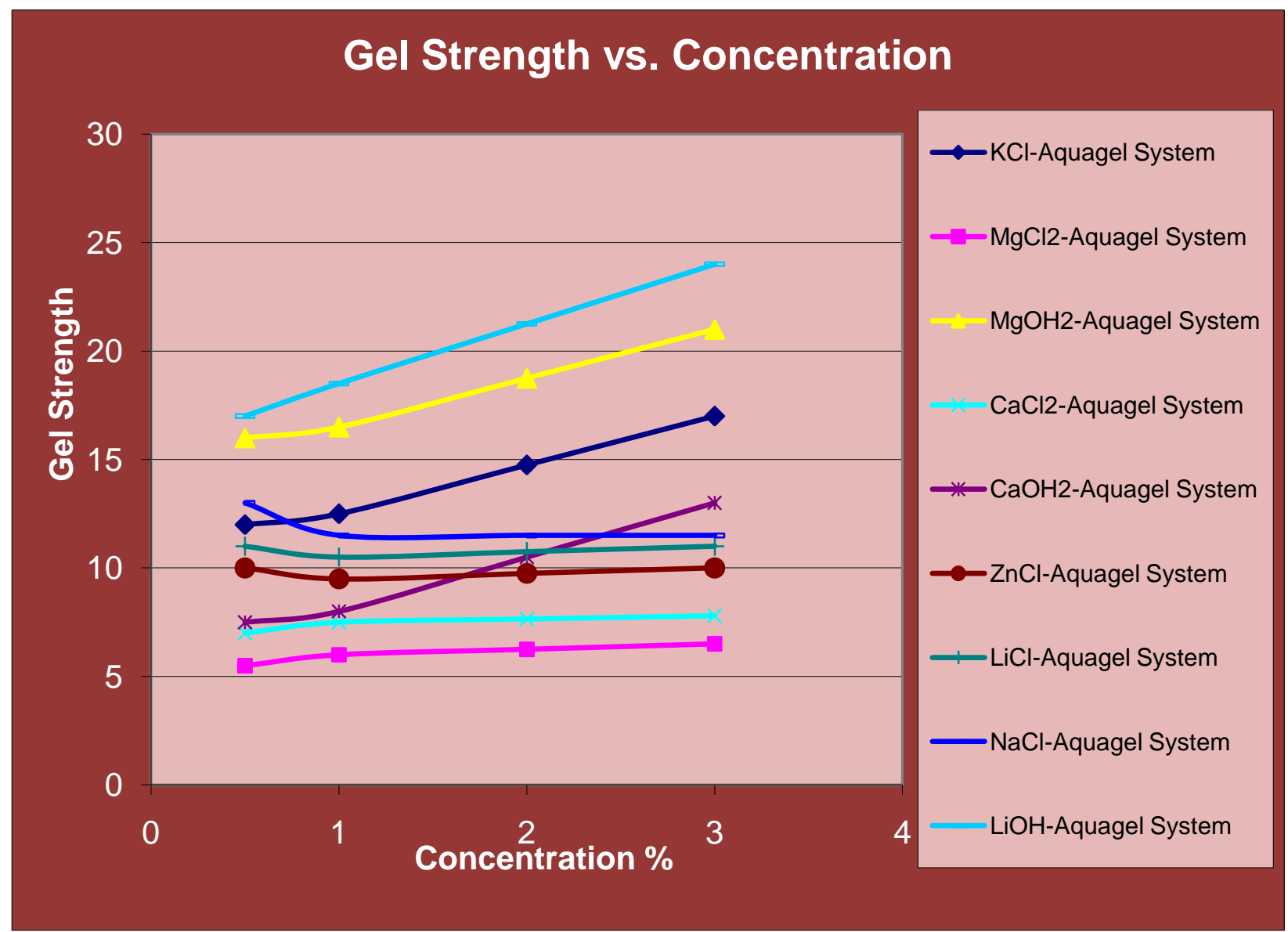

Figure 4.3 Variation of Gel Strength of Base Fluids with Hydroxide and Chloride concentrations.

As expected, due to the close relationship between YP and gel strength, LiOH-Aquagel system which possessed the highest gel strength also possessed the highest YP which was extremely higher than the rest as shown in Figure 4.4. 


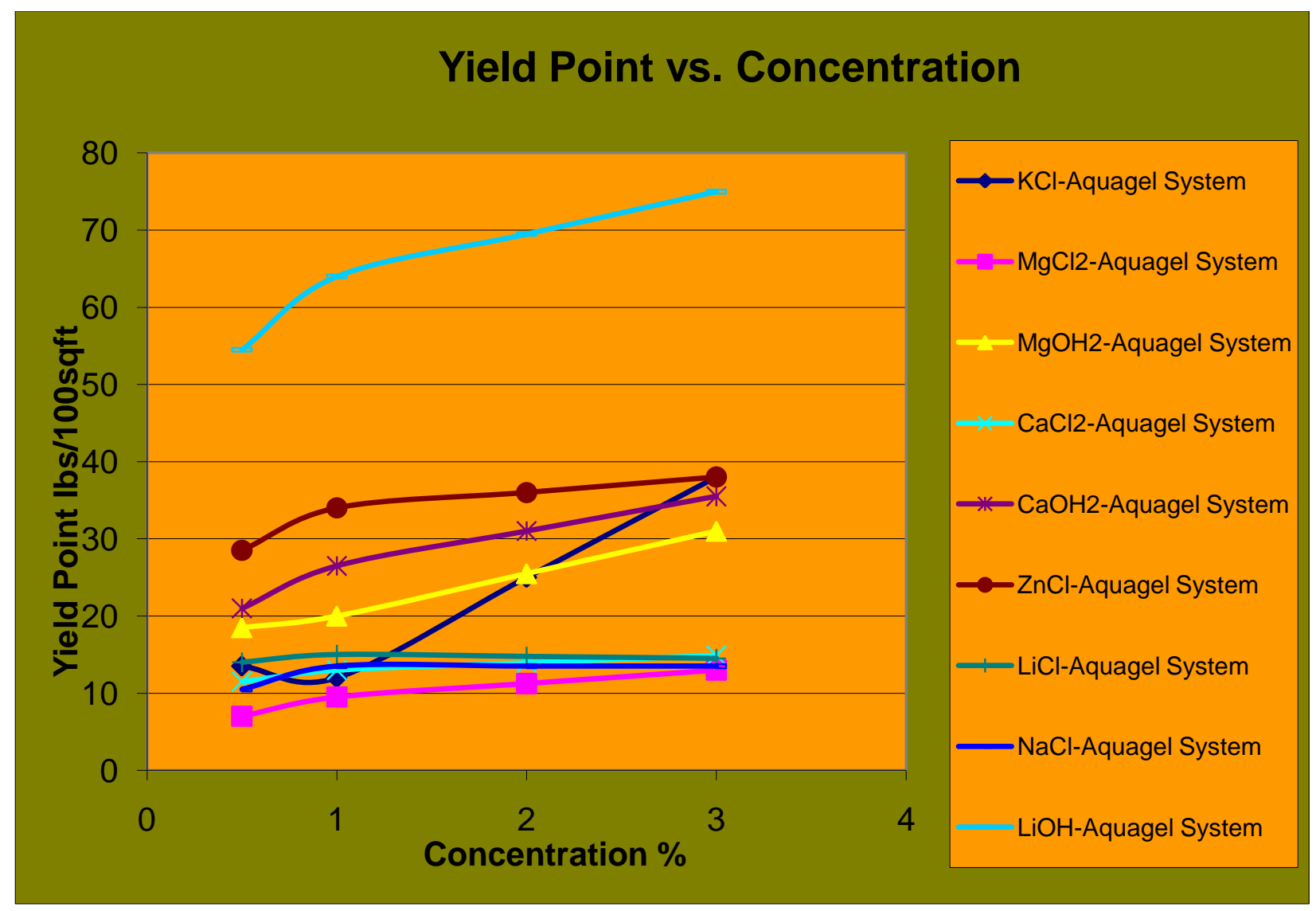

Figure 4.4 Variation of Yield Point of Base Fluids with Hydroxide and Chloride concentrations.

Mud systems with improved YP included 0.5\%-3\% $\mathrm{MgCl}_{2}$-Aquagel, 0.5\%-1\% KCl-Aquagel, 0.5\%-3\% $\mathrm{CaCl}_{2}$-Aquagel and 0.5\%-3\% LiCl-Aquagel systems. The rest had excessive yield points which were greater than those of the 5\% Aquagel base system shown in Table A.1. Mud systems with low YP were of interest here since they possessed little or no increase of frictional pressure loss during circulation. Pressure is required in raising cuttings effectively from downhole to the surface, through the annulus of the hole. However, frictional pressure loss is detrimental to this cause.

Of the hydroxide systems, there was an increase in yield point in the following order $\mathrm{MgOH}_{2}-$ Aquagel, $\mathrm{CaOH}_{2}$-Aquagel and $\mathrm{LiOH}-$ Aquagel systems, with $0.5 \% \mathrm{MgOH}_{2}$-Aquagel system having the most acceptable YP of all the hydroxide systems examined as shown in Figure B.1. 
Most of the hydroxide systems experienced improved gel strength except for $0.5 \%-1 \%$ concentration $\mathrm{CaOH}_{2}$-Aquagel systems. The overall gel strength of the hydroxide system increased in the following order: $\mathrm{CaOH}_{2}$-Aquagel, $\mathrm{MgOH}_{2}$-Aquagel and $\mathrm{LiOH}$-Aquagel system as shown in Figure B.2.

Hydroxide systems that showed improved AV included $1 \%-3 \% \mathrm{MgOH}_{2}$-Aquagel, $1 \%-3 \%$ $\mathrm{CaOH}_{2}$ and $1 \%-3 \%$ LiOH-Aquagel systems. The $0.5 \% \mathrm{CaOH}_{2}$-Aquagel system showed a degradation in AV when compared to the 5\% Aquagel base fluid. Overall, the AV increased in the following order: $\mathrm{MgOH}_{2}$-Aquagel, $\mathrm{CaOH}_{2}$-Aquagel and $\mathrm{LiOH}$-Aquagel system as shown in Figure B.3.

However, only $0.5-1 \% \quad \mathrm{MgOH}_{2}$-Aquagel and 3\% LiOH-Aquagel systems showed an improvement in PV when compared to the 5\% Aquagel base system as shown in Figure B.4.

As for the Chloride systems, $0.5-3 \% \mathrm{ZnCl}$-Aquagel and 3\% $\mathrm{KCl}$-Aquagel systems showed unacceptable YPs that far exceeded those of the 5\% Aquagel base system as shown in Figure B.5. However, $0.5-3 \%$ LiCl-Aquagel, $0.5-3 \%$ NaCl-Aquagel and 0.5-3\% $\mathrm{MgCl}_{2}$-Aquagel systems showed remarkable low yield points, lower than that of the 5\% Aquagel base system. $\mathrm{MgCl}_{2}$-Aquagel system exhibited the lowest $\mathrm{YP}$ of the chloride systems with $\mathrm{ZnCl}$-Aquagel exhibiting the highest in the Chloride system as shown in Figure B.5.

Furthermore, of all the Chloride systems, only $1 \%-3 \% \mathrm{KCl}$ showed improved gel strength while $0.5 \% \mathrm{NaCl}$ showed an acceptable gel strength when both systems where compared to the 5\% Aquagel base system as can be seen in Figure B.6. Gel strength tended to increase in the following order: $\mathrm{MgCl}_{2}$-Aquagel, $\mathrm{CaCl}_{2}$-Aquagel, $\mathrm{ZnCl}$-Aquagel, LiCl-Aquagel, $\mathrm{NaCl}$-Aquagel and $\mathrm{KCl}$-Aquagel system. 
More so, of the various Chloride systems, only 3\% ZnCl-Aquagel and 3\% $\mathrm{KCl}$-Aquagel systems showed improved AVs. AV increased in the following order: $\mathrm{MgCl}_{2}$-Aquagel, $\mathrm{CaCl}_{2}$-Aquagel, LiCl-Aquagel, NaCl-Aquagel, ZnCl-Aquagel and $\mathrm{KCl}$-Aquagel system as shown in Figure B.7. With regards to PV of the Cloride systems, only $1 \% \mathrm{KCl}$-Aquagel system showed improved PV with $0.5 \% \mathrm{NaCl}$-Aquagel system showing an acceptable PV when compared to the 5\% Aquagel base system as shown in Figure B.8. 


\section{Filtration Analysis of Base Fluids}

A 30 minute filtrate loss analysis was conducted on the base fluids which consisted of a $5 \%$ Aquagel system or $5 \%$ Aquagel $+(0.5 \%-3 \%)$ of a Chloride or Hydroxide system; with the Chloride and Hydroxide term referring to those of Alkali metals, Alkaline earth metals and Transition metals. The goal of the experiment was to see which base system had an improved filtrate loss and mud cake when compared to the 5\% Aquagel base system. The tabular results of the filtration analysis can be seen on Table A.2.

After the filtration analysis was conducted, fluids where classified into three categories namely:

Extreme high loss systems (250-310 ml filtrate loss), High loss systems $(80-110 \mathrm{ml})$ and Low loss systems (15-45 ml) as shown in Figure 4.5. 


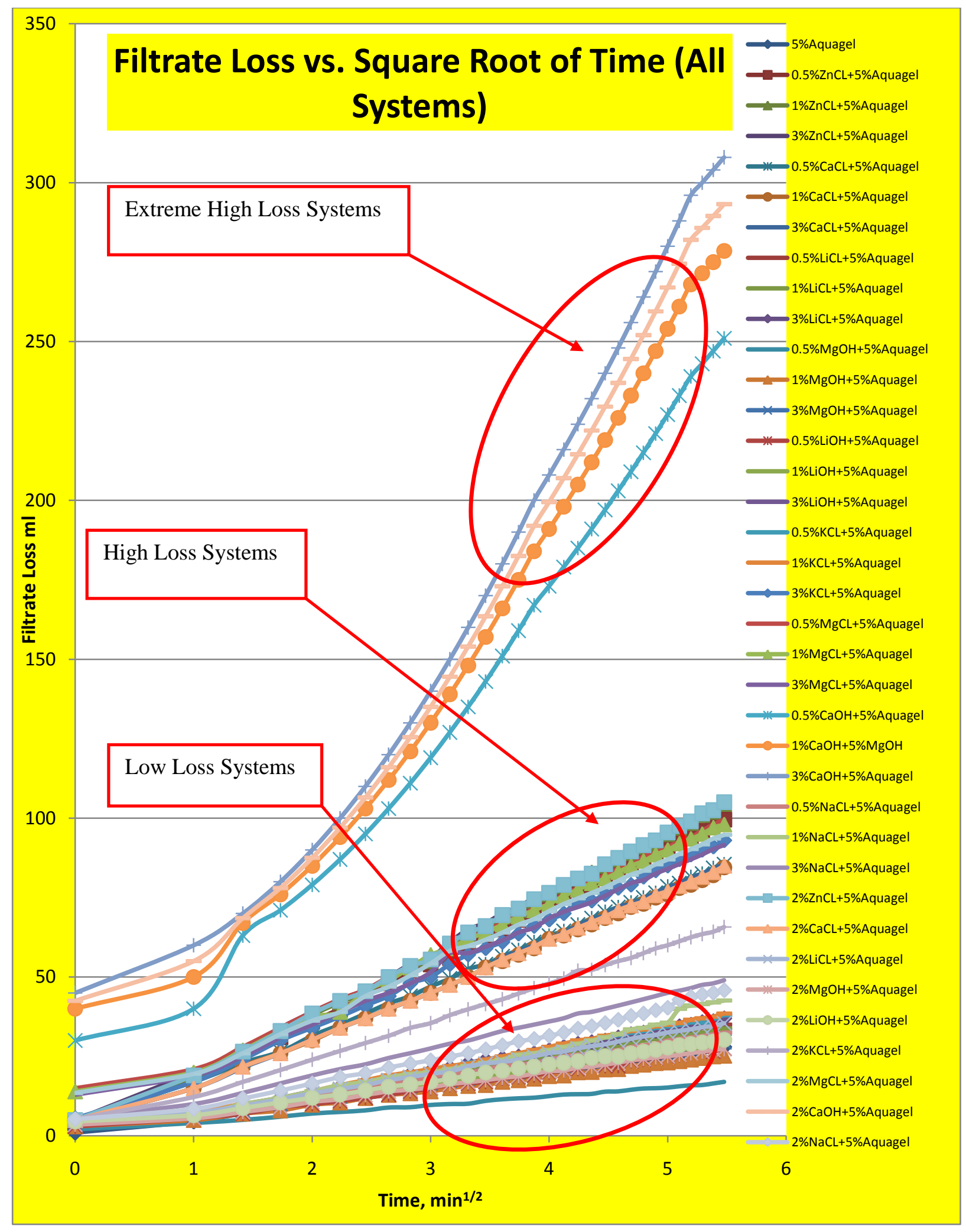

Figure 4.5: Filtrate Loss Classification of Base Drilling Fluids. 
Overall, $0.5 \% \mathrm{MgCl}_{2}$-Aquagel system appeared to have the lowest filtrate loss at $17 \mathrm{ml}$, while 3\% CaOH-Aquagel system had the highest at $308 \mathrm{ml}$ as shown in Table A.2.

The extreme high loss category consisted only of the $\mathrm{CaOH}_{2}$-Aquagel systems, with filtrate losses drastically increasing as the concentration of $\mathrm{CaOH}_{2}$ increased from $0.5 \%$ to $3 \%$ as shown in Figure B.13. With respect to the high loss category, $1 \% \mathrm{CaCl}_{2}$-Aquagel system had the lowest filtrate loss at $85 \mathrm{ml}$ while $3 \% \mathrm{ZnCl}$-Aquagel system had the highest at $106 \mathrm{ml}$, with the other members of this category falling between the two aforementioned systems as shown in Figure B.16. However, in the Low loss category, (Figure 4.6 and Figure 4.10 ), $0.5 \% \mathrm{MgCl}_{2}$-Aquagel system showed a remarkable improvement in filtrate loss when compared to the filtrate loss of the 5\% Aquagel base system. A surprising $10 \mathrm{ml}$ drop in filtrate loss was noticed between the 5\% Aquagel system and the $0.5 \% \mathrm{MgCl}$-Aquagel system as shown in Table A.2 and Figure 4.6.

For the Low loss category, filtrate loss decreased in the following fashion: 1\%NaCL-Aquagel, $1 \% \mathrm{KCl}$-Aquagel, $0.5 \% \mathrm{KCl}$-Aquagel, $3 \% \mathrm{LiCl}$-Aquagel, 2\%LiCl-Aquagel, $0.5 \% \mathrm{LiCl}$-Aquagel, $1 \% \mathrm{LiCl}$-Aquagel, $\quad 0.5 \% \mathrm{NaCl}$-Aquagel, $3 \% \mathrm{LiOH}$-Aquagel, $3 \% \mathrm{MgOH}_{2}$-Aquagel, $2 \% \mathrm{LiOH}-$ Aquagel, $1 \% \mathrm{LiOH}$-Aquagel, $0.5 \% \mathrm{LiCl}$-Aquagel, $2 \% \mathrm{MgOH}_{2}$-Aquagel, $1 \% \mathrm{MgOH}$-Aquagel and $0.5 \% \mathrm{MgOH}_{2}$-Aquagel system as shown in Table 4.1 . 


\begin{tabular}{|c|c|}
\hline Low Loss Systems & 30 minute Filtrate loss, ml \\
\hline $1 \%$ NaCl-5\%Aquagel System & 42.60 \\
\hline $1 \%$ KCl-5\%Aquagel System & 38.50 \\
\hline $0.5 \%$ KCl-5\%Aquagel System & 38.00 \\
\hline $3 \%$ LiCl-5\%Aquagel System & 37.00 \\
\hline $0.5 \%$ LiCl-5\%Aquagel System & 35.00 \\
\hline $1 \%$ LiCl-5\%Aquagel System & 33.80 \\
\hline $0.5 \%$ NaCl-5\%Aquagel System & 32.50 \\
\hline $3 \%$ LiOH-5\%Aquagel System & 32.00 \\
\hline $3 \% \mathrm{MgOH}_{2}$-Aquagel System & 29.50 \\
\hline $1 \% \mathrm{LiH}_{-} \%$ Aquagel System & 28.50 \\
\hline $5 \%$ Aquagel System & 28.00 \\
\hline $0.5 \% \mathrm{LiOH}_{-} \%$ Aquagel System & 27.50 \\
\hline $1 \% \mathrm{MgOH}_{2}-5 \%$ Aquagel System & 25.20 \\
\hline $0.5 \% \mathrm{MgOH}_{2}-5 \%$ Aquagel System & 17.00 \\
\hline $2 \% \mathrm{LiCl}_{-} \%$ Aquagel System & 35.00 \\
\hline $2 \% \mathrm{MgOH}_{2}-5 \%$ Aquagel System & 27.00 \\
\hline $2 \% \mathrm{LiOH}_{-}$\% Aquagel System & 35.00 \\
\hline
\end{tabular}

Table 4.1: 30 minute filtrate loss for Low loss systems.

From Table 4.1, the following systems showed an improved filtrate loss in comparison to the 5\% Aquagel base drilling fluid: $0.5 \% \mathrm{LiOH}-5 \%$ Aquagel System, $1 \% \mathrm{MgOH}_{2}-5 \%$ Aquagel System, $2 \% \mathrm{MgOH}_{2}-5 \%$ Aquagel System and $0.5 \% \mathrm{MgOH}_{2}-5 \%$ Aquagel System.

Figure B15 shows the high loss systems, Figure B14 shows the high and low loss systems while Figure B13 shows the extreme high loss systems. 


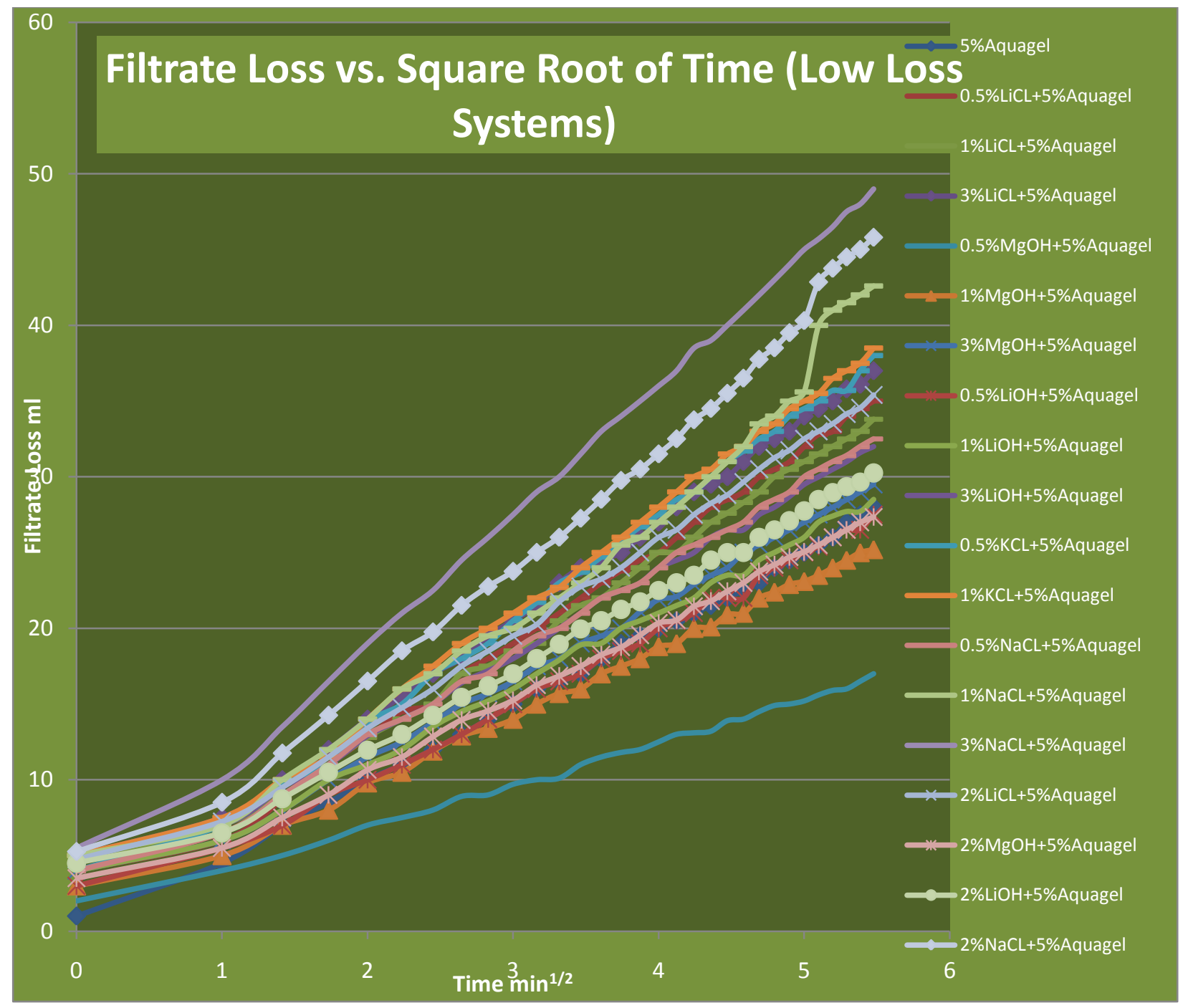

Figure 4.6:Variation of Filtrate loss with square root of time for Low Loss Systems.

Individual analysis of each system showed that the filtrate loss of the LiCl-Aquagel systems appeared to increase as the concentration of $\mathrm{LiCl}$ increased as shown in Figure B.11. Systems which had a similar trend, in which their filtrate loss was directly proportional to concentration of the salts or hydroxides of their perspective metals, included $\mathrm{MgOH}_{2}$-Aquagel, $\mathrm{LiOH}$-Aquagel, ZnCl-Aquagel, $\mathrm{KCl}$-Aquagel, $\mathrm{CaOH}_{2}$-Aquagel and $\mathrm{NaCl}$-Aquagel systems as shown in Figure B9, Figure B10, Figure B11, Figure B12, Figure B16, Figure B17, Figure B18, Figure B19. $\mathrm{MgCl}_{2}$ system is illustrated in Figure B20. 
However, systems such as the $\mathrm{CaCl}_{2}$-Aquagel system showed no clear trend with regards to the trend in filtrate loss with respect to the concentration of $\mathrm{CaCl}_{2}$. Nevertheless, the $\mathrm{MgCl}_{2}$-Aquagel system showed a fascinating trend which is rarely seen among salts. The filtrate loss of the $\mathrm{MgCl}_{2}$-Aquagel system actually decreased as the concentration of $\mathrm{MgCl}_{2}$ increased as shown in Figure 4.7 .

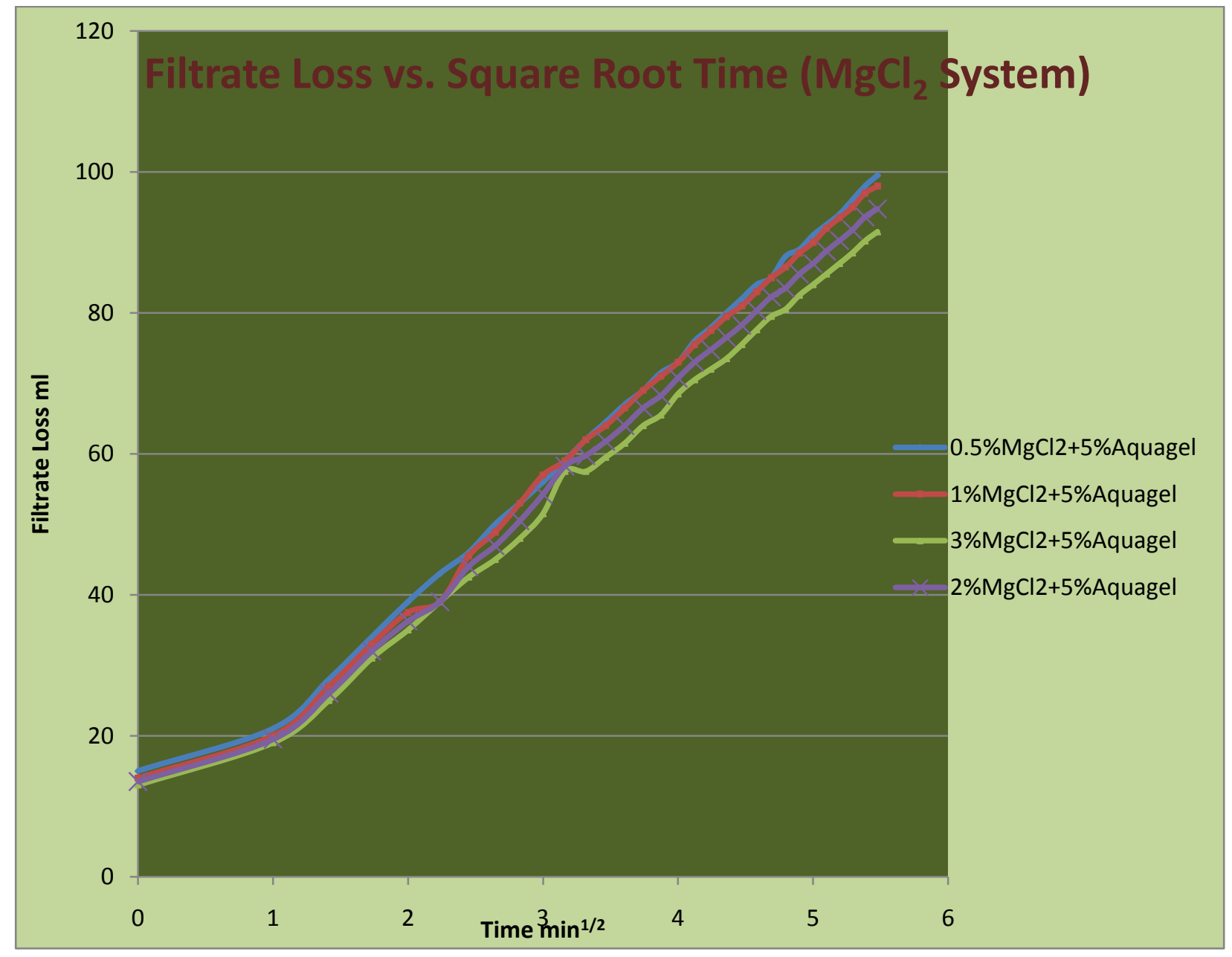

Figure 4.7: Variation of Filtrate loss with square root of time for $\mathrm{MgCl}_{2}$-Aquagel systems.

In order to ascertain that the rare trend of the $\mathrm{MgCl}_{2}$-Aquagel system was actually occurring, a Fann Resistivity Meter Model 88C (Figure 4.8) was used to measure the resistivity of the filtrates collected from the filtration analysis of $0.5 \%, 1 \%$ and $3 \% \mathrm{MgCl}_{2}$-Aquagel systems. As expected, 
the resistivity of the $3 \% \mathrm{MgCl}_{2}$-Aquagel system was lower than the resistivity of the $1 \% \mathrm{MgCl}_{2}$ Aquagel system which in turn was lower than that of the $0.5 \% \mathrm{MgCl}_{2}$-Aquagel system. Resistivity decreased as the concentration of the $\mathrm{Mg}+$ ions increased. This is simply because there are more ions available to conduct current, thereby reducing resistivity. This measurement of resistivity reassured that the results in Figure 4.7 were indeed what they were and that no erroneous misplacement of the various systems had occurred.

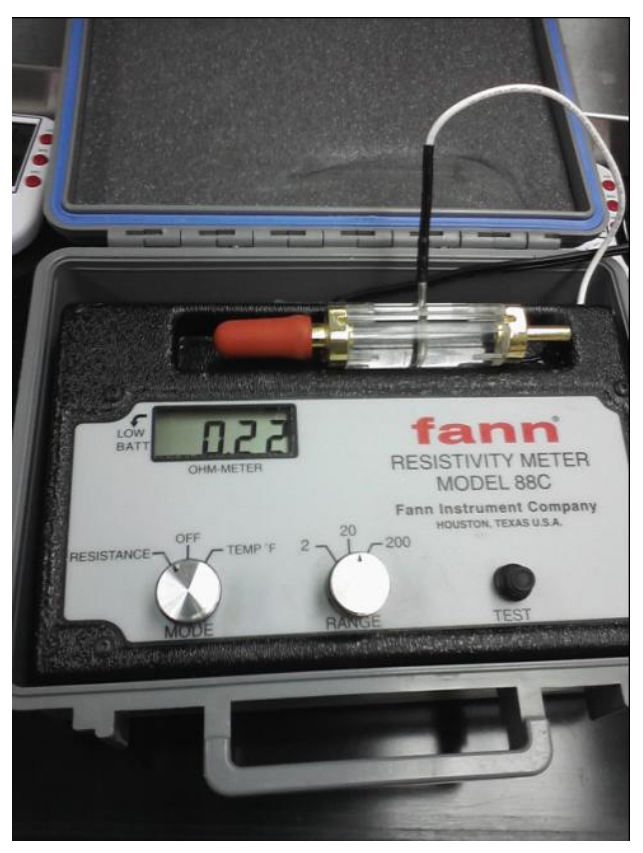

\section{Figure 4.8: The Fann Resistivity Meter Model 88C.}

Filtrate loss versus time graphs for other base drilling fluid systems can be found in Appendix B.

When a thin filter cake is formed and drilling predicaments are minimized as a result of low filtrate loss. However, a thick filter cake can reduce the effective size of the borehole causing problems such as an increase in torque on the rotating drill string, excessive drag and adherence of the pipe to the wall of the borehole. 
Therefore, a good mud cake was judged based on how adequate its thickness was. The term "adequacy" means that the mud is thin enough to avoid the aforementioned problems listed above, but also thick enough to prevent formation invasion and damage. The $0.5 \%-1 \% \mathrm{MgOH}_{2}$ Aquagel system had the most adequate mud cake thickness followed by the $3 \%$ LiCl-Aquagel system and then the $3 \% \mathrm{MgOH}_{2}$-Aquagel system. However, $1 \%-3 \% \mathrm{CaOH}_{2}$ system had the highest mud cake thickness as shown in Figure 4.9 below.

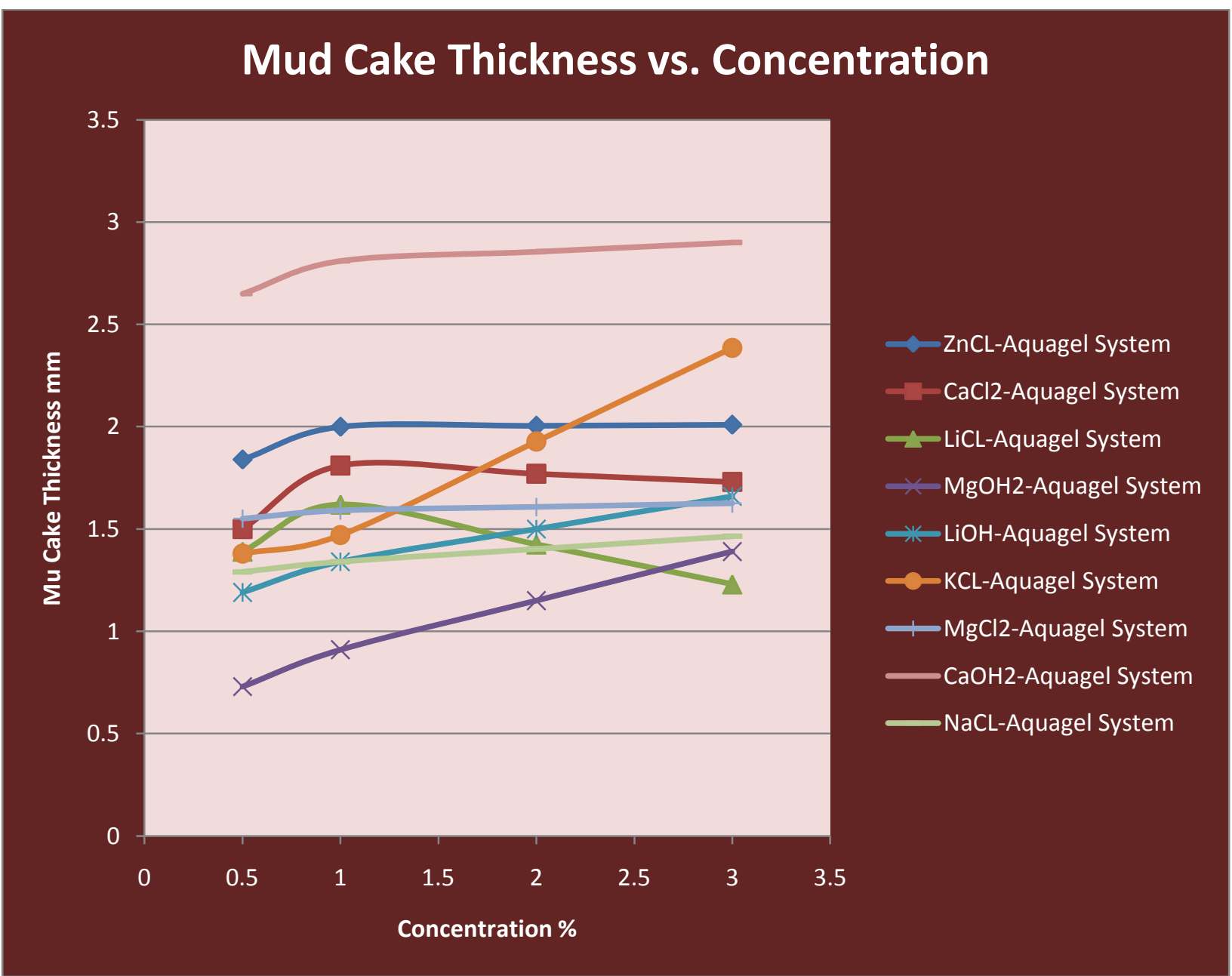

Figure 4.9: Variation of mud cake thickness with concentration for Base Drilling Fluids. 


\section{Quadratic Filtrate Loss Correlations}

The Quadratic Filtrate Loss Correlations (Table 4.2) was developed during the course of this research work. It provides a convenient and efficient way to calculate filtrate loss $(\mathrm{ml})$ of Bentonite based fluids, which have been mixed with Chlorides and Hydroxides of various Alkali metals, Alkaline Earth Metals and Transition Metals, in real time (min). The constants a, b and c in Table 4.2 can be interpolated or extrapolated to evaluate the filtrate loss for lower or higher concentrations of the aforementioned chemicals above $3 \%$. The equations have been rigorously tested and turned out to be $92.33 \%$ accurate, using various grams of Aquagel for a given concentration of the aforementioned chemicals. In reality, drilling companies, service companies and operators often use concentrations of salts between $1 \%$ to $2.5 \%$ and rarely $3 \%$. 


\begin{tabular}{|c|c|}
\hline \multicolumn{2}{|c|}{ Quadratic Filtrate Loss Correlations } \\
\hline Base Drilling Fluid Systems & Filtrate Loss Equations \\
\hline & $\mathrm{V}=\mathbf{a t} \mathbf{t}^{2}+\mathbf{b t}+\mathbf{c}$ \\
\hline $3 \% \mathrm{CaOH}_{2}+$ Aquagel & $V=-0.0844 t^{2}+11.423 t+45.716$ \\
\hline $2 \% \mathrm{CaOH}_{2}+$ Aquagel & $V=-0.0879 t^{2}+11.073 t+43.903$ \\
\hline $1 \% \mathrm{CaOH}_{2}+$ Aquagel & $\mathrm{V}=-0.0915 \mathrm{t}^{2}+10.724 \mathrm{t}+42.09$ \\
\hline $0.5 \% \mathrm{CaOH}_{2}+$ Aquagel & $\mathrm{V}=-0.0968 \mathrm{t}^{2}+10.022 \mathrm{t}+37.03$ \\
\hline $3 \% \mathrm{LiOH}+$ Aquagel & $\mathrm{V}=-0.0192 \mathrm{t}^{2}+1.3927 \mathrm{t}+6.7341$ \\
\hline $2 \% \mathrm{LiOH}+$ Aquagel & $\mathrm{V}=-0.0183 \mathrm{t}^{2}+1.3252 \mathrm{t}+6.262$ \\
\hline $1 \% \mathrm{LiOH}+$ Aquagel & $\mathrm{V}=-0.0174 \mathrm{t}^{2}+1.2576 \mathrm{t}+5.7179$ \\
\hline $0.5 \% \mathrm{LiOH}+$ Aquagel & $\mathrm{V}=-0.0162 \mathrm{t}^{2}+1.214 \mathrm{t}+4.8144$ \\
\hline $3 \% \mathrm{MgOH}_{2}+$ Aquagel & $V=-0.0177 t^{2}+1.2993 t+5.7569$ \\
\hline $2 \% \mathrm{MgOH}_{2}+$ Aquagel & $\mathrm{V}=-0.017 \mathrm{t}^{2}+1.2266 \mathrm{t}+5.2078$ \\
\hline $1 \% \mathrm{MgOH}_{2}+$ Aquagel & $V=-0.0163 t^{2}+1.1539 t+4.6588$ \\
\hline $0.5 \% \mathrm{MgOH}_{2}+$ Aquagel & $\mathrm{V}=-0.0101 \mathrm{t}^{2}+0.7276 \mathrm{t}+3.5891$ \\
\hline $3 \% \mathrm{LiCl}+$ Aquagel & $\mathrm{V}=-0.0224 \mathrm{t}^{2}+1.6418 \mathrm{t}+6.9591$ \\
\hline $2 \% \mathrm{LiCl}+$ Aquagel & $\mathrm{V}=-0.021 \mathrm{t}^{2}+1.5614 \mathrm{t}+6.6365$ \\
\hline $1 \% \mathrm{LiCl}+$ Aquagel & $\mathrm{V}=-0.0197 \mathrm{t}^{2}+1.4811 \mathrm{t}+6.6365$ \\
\hline $0.5 \% \mathrm{LiCl}+$ Aquagel & $V=-0.0213 t^{2}+1.5822 t+5.8739$ \\
\hline $3 \% \mathrm{NaCl}+$ Aquagel & $\mathrm{V}=-0.031 \mathrm{t}^{2}+2.2104 \mathrm{t}+9.2193$ \\
\hline $2 \% \mathrm{NaCl}+$ Aquagel & $\mathrm{V}=-0.0186 \mathrm{t}^{2}+1.7737 \mathrm{t}+8.4653$ \\
\hline $1 \% \mathrm{NaCl}+$ Aquagel & $V=-0.0061 t 2+1.3369 t+7.7114$ \\
\hline $0.5 \% \mathrm{NaCl}+$ Aquagel & $\mathrm{V}=-0.0204 \mathrm{t}^{2}+1.4582 \mathrm{t}+6.2668$ \\
\hline $3 \% \mathrm{KCl}+$ Aquagel & $\mathrm{V}=-0.0639 \mathrm{t}^{2}+4.449 \mathrm{t}+14.37$ \\
\hline $2 \% \mathrm{KCl}+$ Aquagel & $V=-0.0435 t^{2}+3.0804 t+10.602$ \\
\hline $1 \% \mathrm{KCl}+$ Aquagel & $\mathrm{V}=-0.023 \mathrm{t}^{2}+1.7118 \mathrm{t}+6.8337$ \\
\hline $0.5 \% \mathrm{KCl}+$ Aquagel & $V=-0.0243 t^{2}+1.7483 t+6.1534$ \\
\hline $3 \% \mathrm{ZnCl}+$ Aquagel & $\mathrm{V}=-0.0718 \mathrm{t}^{2}+5.0077 \mathrm{t}+16.367$ \\
\hline $2 \% \mathrm{ZnCl}+$ Aquagel & $\mathrm{V}=-0.0721 \mathrm{t}^{2}+5.021 \mathrm{t}+15.77$ \\
\hline $1 \% \mathrm{ZnCl}+$ Aquagel & $\mathrm{V}=-0.0725 \mathrm{t}^{2}+5.0345 \mathrm{t}+15.188$ \\
\hline $0.5 \% \mathrm{ZnCl}+$ Aquagel & $V=-0.0691 t^{2}+4.7989 t+14.785$ \\
\hline $3 \% \mathrm{MgCl}_{2}+$ Aquagel & $V=-0.0595 t^{2}+4.1696 t+17.587$ \\
\hline $2 \% \mathrm{MgCl}_{2}+$ Aquagel & $\mathrm{V}=-0.0623 \mathrm{t}^{2}+4.3458 \mathrm{t}+18.061$ \\
\hline $1 \% \mathrm{MgCl}_{2}+$ Aquagel & $\mathrm{V}=0.0651 \mathrm{t}^{2}+4.522 \mathrm{t}+18.536$ \\
\hline $0.5 \% \mathrm{MgCl}_{2}+$ Aquagel & $\mathrm{V}=-0.0604 \mathrm{t}^{2}+4.374 \mathrm{t}+20.049$ \\
\hline $3 \% \mathrm{CaCl}_{2}+$ Aquagel & $\mathrm{V}=-0.0558 \mathrm{t}^{2}+4.0337 \mathrm{t}+12.542$ \\
\hline $2 \% \mathrm{CaCl}_{2}+$ Aquagel & $\mathrm{V}=-0.0561 \mathrm{t}^{2}+4.0037 \mathrm{t}+12.685$ \\
\hline $1 \% \mathrm{CaCl}_{2}+$ Aquagel & $V=-0.0563 t^{2}+3.9736 t+12.827$ \\
\hline $0.5 \% \mathrm{CaCl}_{2}+$ Aquagel & $V=-0.0582 t^{2}+4.0598 t+13.725$ \\
\hline
\end{tabular}

Table 4.2: Quadratic Filtrate Loss Correlations. 


\section{Linear Filtrate Loss Correlations}

Possessing a higher degree of accuracy and functionality, the Linear Filtrate Loss Correlations (Table 4.3) which was developed during the course of this research work provides a means of measuring filtrate loss (ml) of Bentonite based fluids, which have been mixed with Chlorides and Hydroxides of various Alkali metals, Alkaline Earth Metals and Transition Metals, in real time (min). The constants $g$ and $f$ in Table 4.3 can be interpolated or extrapolated to evaluate the filtrate loss for lower or higher concentrations of the aforementioned chemicals. The aforementioned correlations have been rigorously tested and have been proven to be $95.86 \%$ accurate. 


\begin{tabular}{|c|c|}
\hline \multicolumn{2}{|c|}{ Linear Filtrate Loss Correlations } \\
\hline Base Drilling Fluid Systems & Filtrate Loss Equations \\
\hline & $V=g t^{1 / 2}+f$ \\
\hline $3 \% \mathrm{CaOH}_{2}+$ Aquagel & $\mathrm{V}=56.424 \mathrm{t}^{1 / 2}-12.684$ \\
\hline $2 \% \mathrm{CaOH}_{2}+$ Aquagel & $V=53.642 t^{1 / 2}-10.768$ \\
\hline $1 \% \mathrm{CaOH}_{2}+$ Aquagel & $\mathrm{V}=50.859 \mathrm{t}^{1 / 2}-8.851$ \\
\hline $0.5 \% \mathrm{CaOH}_{2}+$ Aquagel & $V=45.672 t^{1 / 2}-7.2913$ \\
\hline $3 \% \mathrm{LiOH}+$ Aquagel & $\mathrm{V}=5.3551 \mathrm{t}^{1 / 2}+2.406$ \\
\hline $2 \% \mathrm{LiOH}+$ Aquagel & $V=5.0898 t^{1 / 2}+2.1152$ \\
\hline $1 \% \mathrm{LiOH}+$ Aquagel & $\mathrm{V}=4.8245 \mathrm{t}^{1 / 2}+1.8244$ \\
\hline $0.5 \% \mathrm{LiOH}+$ Aquagel & $\mathrm{V}=4.7719 \mathrm{t}^{1 / 2}+0.8403$ \\
\hline $3 \% \mathrm{MgOH}_{2}+$ Aquagel & $\mathrm{V}=5.0324 \mathrm{t}^{1 / 2}+1.6436$ \\
\hline $2 \% \mathrm{MgOH}_{2}+$ Aquagel & $\mathrm{V}=4.7043 \mathrm{t}^{1 / 2}+1.4122$ \\
\hline $1 \% \mathrm{MgOH}_{2}+$ Aquagel & $\mathrm{V}=4.3762 \mathrm{t}^{1 / 2}+1.1808$ \\
\hline $0.5 \% \mathrm{MgOH}_{2}+$ Aquagel & $\mathrm{V}=2.7921 \mathrm{t}^{1 / 2}+1.3179$ \\
\hline $3 \% \mathrm{LiCl}+$ Aquagel & $\mathrm{V}=6.3524 \mathrm{t}^{1 / 2}+1.7872$ \\
\hline $2 \% \mathrm{LiCl}+$ Aquagel & $\mathrm{V}=6.0883 \mathrm{t}^{1 / 2}+1.6309$ \\
\hline $1 \% \mathrm{LiCl}+$ Aquagel & $\mathrm{V}=5.8242 \mathrm{t}^{1 / 2}+1.4746$ \\
\hline $0.5 \% \mathrm{LiCl}+$ Aquagel & $\mathrm{V}=6.1783 \mathrm{t}^{1 / 2}+0.778$ \\
\hline $3 \% \mathrm{NaCl}+$ Aquagel & $\mathrm{V}=8.427 \mathrm{t}^{1 / 2}+2.4573$ \\
\hline $2 \% \mathrm{NaCl}+$ Aquagel & $\mathrm{V}=7.8885 \mathrm{t}^{1 / 2}+0.8883$ \\
\hline $1 \% \mathrm{NaCl}+$ Aquagel & $\mathrm{V}=7.3499 \mathrm{t}^{1 / 2}-0.6807$ \\
\hline $0.5 \% \mathrm{NaCl}+$ Aquagel & $\mathrm{V}=5.564 \mathrm{t}^{1 / 2}+1.7989$ \\
\hline $3 \% \mathrm{KCl}+$ Aquagel & $V=16.702 t^{1 / 2}+1.2295$ \\
\hline $2 \% \mathrm{KCl}+$ Aquagel & $\mathrm{V}=11.69 \mathrm{t}^{1 / 2}+1.2876$ \\
\hline $1 \% \mathrm{KCl}+$ Aquagel & $\mathrm{V}=6.678 \mathrm{t}^{1 / 2}+1.3456$ \\
\hline $0.5 \% \mathrm{KCl}+$ Aquagel & $\mathrm{V}=6.678 \mathrm{t}^{1 / 2}+0.8127$ \\
\hline $3 \% \mathrm{ZnCl}+$ Aquagel & $\mathrm{V}=18.855 \mathrm{t}^{1 / 2}+1.4234$ \\
\hline $2 \% \mathrm{ZnCl}+$ Aquagel & $\mathrm{V}=18.865 \mathrm{t}^{1 / 2}+0.8872$ \\
\hline $1 \% \mathrm{ZnCl}+$ Aquagel & $\mathrm{V}=18.875 \mathrm{t}^{1 / 2}+0.3511$ \\
\hline $0.5 \% \mathrm{ZnCl}+$ Aquagel & $\mathrm{V}=18.009 \mathrm{t}^{1 / 2}+1.7989$ \\
\hline $3 \% \mathrm{MgCl}_{2}+$ Aquagel & $\mathrm{V}=15.66 \mathrm{t}^{1 / 2}+5.359$ \\
\hline $2 \% \mathrm{MgCl}_{2}+$ Aquagel & $\mathrm{V}=16.265 \mathrm{t}^{1 / 2}+5.4314$ \\
\hline $1 \% \mathrm{MgCl}_{2}+$ Aquagel & $\mathrm{V}=16.87 \mathrm{t}^{1 / 2}+5.5038$ \\
\hline $0.5 \% \mathrm{MgCl}_{2}+$ Aquagel & $\mathrm{V}=16.786 \mathrm{t}^{1 / 2}+6.5308$ \\
\hline $3 \% \mathrm{CaCl}_{2}+$ Aquagel & $\mathrm{V}=15.505 \mathrm{t}^{1 / 2}+1.6681$ \\
\hline $2 \% \mathrm{CaCl}_{2}+$ Aquagel & $\mathrm{V}=15.278 \mathrm{t}^{1 / 2}+0.4023$ \\
\hline $1 \% \mathrm{CaCl}_{2}+$ Aquagel & $\mathrm{V}=15.052 \mathrm{t}^{1 / 2}+0.8379$ \\
\hline $0.5 \% \mathrm{CaCl}_{2}+$ Aquagel & $V=15.268 t^{1 / 2}+1.6681$ \\
\hline
\end{tabular}

Table 4.3: Linear Filtrate Loss Correlations. 


\section{Filtrate Loss for Low Loss Systems}

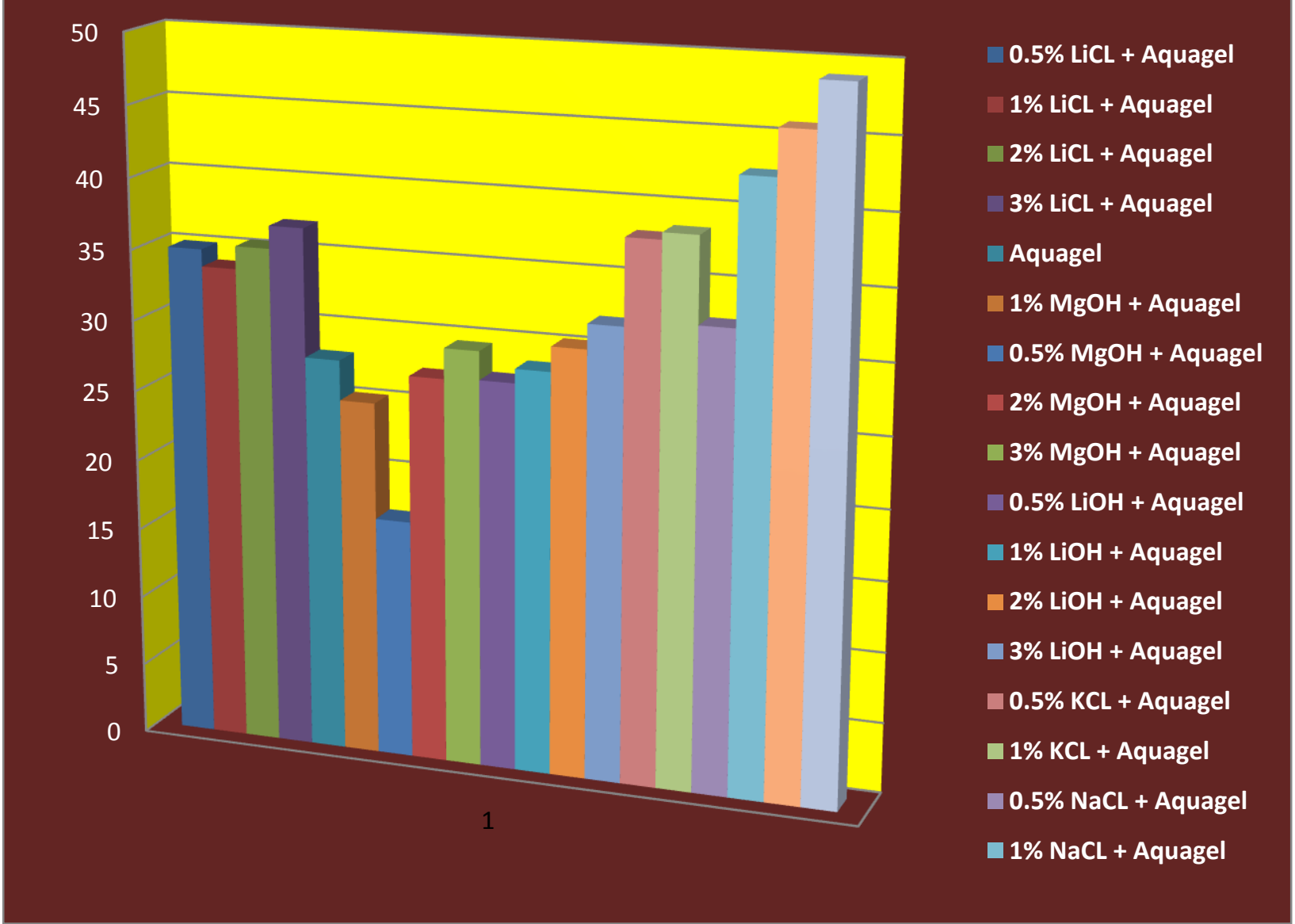

Figure 4.10: Filtrate Loss for Low Loss Systems. 


\section{Swelling Test Experiment}

\section{Smectite Swelling Experiment}

The inhibition testing experiments proceeded with the measurement and recording of the effects of $\mathrm{KCl}, \mathrm{CaCl}_{2}, \mathrm{CaOH}_{2}, \mathrm{MgOH}_{2}, \mathrm{NaCl}, \mathrm{ZnCl}, \mathrm{LiOH}, \mathrm{LiCl}, \mathrm{MgCl}_{2}$ and Diamino Alkanes (Diamino Butane and Diamino Hexane) on the swelling of Smectite or Montmorillonite clay. The aforementioned experiment was later proceeded by the measurement of linear swelling of Shale samples during contact with several drilling fluid candidates.

The Figure 4.11 below displays shale samples from different depths 6300-7743 ft which had been grounded and used in the inhibition test.

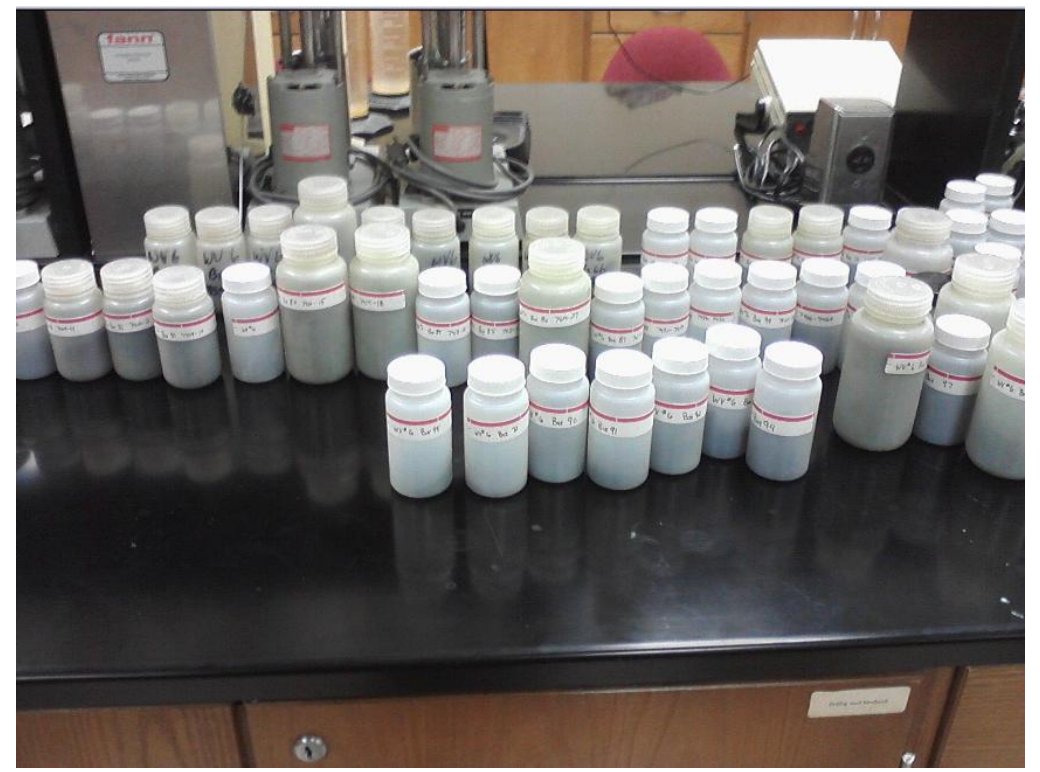

Figure 4.11: Shale Samples.

Ten base drilling fluids were first tested on raw Smectite clay in order to comprehensively understand how theses fluids affected Smectite swelling before the fluids were tested on shale. By performing the inhibition experiment on Smectite, we could clearly see the swelling of the clay and their percentage linear swelling were recorded as shown in Table 4.3 and Figure 4.12. 
Out of the ten base fluids, $\mathrm{KCl}$ caused the least swelling (23\%), followed by $\mathrm{CaCl}_{2}$ which caused a linear swelling increase of $25 \%$. The rest of the fluids failed to produce acceptable inhibitive properties.

As mentioned earlier, $\mathrm{KCl}$ and $\mathrm{CaCl}_{2}$ were found to cause less swelling than the other chemicals. Further incorporation of Diamino Alkanes further reduced the swelling of clay when in contact with the $\mathrm{KCl}$ mud system. However, Diamino Hexane+KCl caused more swelling inhibition (12\% linear swelling) than the Diamino Butane+ $\mathrm{KCl}$ system which, although caused greater inhibition, was just lagging behind Diamino Hexane with a percentage linear swelling of $16.3 \%$.

Although $\mathrm{KCl}$ had caused more inhibited Smectite swelling $23 \%$ than $\mathrm{CaCl}_{2} 25 \%$, it was realized that $\mathrm{CaCl}_{2}$ succeeded in providing better inhibition than $\mathrm{KCl}$ upon the introduction of Diamino Alkanes into both $\mathrm{KCl}$ and $\mathrm{CaCl}_{2}$ systems. Nevertheless, the trend of Diamino Hexane producing more inhibition than Diamino Butane continued to occur. The clays exposed to the four inhibitive fluids were later exposed to a brine solution of $\mathrm{NaCl}$ after which their fortitude to remain resistive to swelling was tested by measuring their linear swelling upon contact with $\mathrm{NaCl}$.

It is well known that cations in Smectite can easily be replaced by other cations (cations are exchangeable). This means that although $\mathrm{KCl}$ caused less swelling in the clay once it inserted itself between the clay layers, it $\left(\mathrm{K}^{+}\right)$could be easily replaced by another cation such as $\mathrm{Na}+$ which may reignite the swelling of the clay. This scenario was tested by exposing the clay which had come into contact with Diamino Butane+KCl, Diamino Hexane+KCl, Diamino 
Butane $+\mathrm{CaCl}_{2}$ and Diamino Hexane+CaCl 2 to a Brine solution containing $\mathrm{NaCl}$. Upon reaction, the clay which had come into contact with Diamino Alkane-KCl system appeared to swell less than the clay which had come into contact with $\mathrm{CaCl}_{2}$-Diamino Alkane systems, with Diamino Hexane just edging out Diamino Butane in the inhibition of Smectite for both $\mathrm{KCl}$ and $\mathrm{CaCl}_{2}$ systems as shown in Table 4.4 and Figure 4.13.

The reason why Diamino Alkanes may serve as potent inhibitors is because they are Alkane chains attached to two Amine groups. These Amine groups attach themselves to two adjacent Smectite layers, thereby pulling them close to each other. Therefore, when $\mathrm{K}^{+}$is replaced by $\mathrm{Na}^{+}$which may lead to swelling in Smectite, Diamino Alkane which are organic molecules tend to hold the layers intact and compact. 


\begin{tabular}{|c|c|}
\hline Drilling Fluid & Percentage Linear Swelling \\
\hline $\mathrm{H}_{2} \mathrm{O}+5 \%$ Aquagel & 62 \\
\hline $1 \% \mathrm{Ca}(\mathrm{OH})_{2}+5 \%$ Aquagel & 34 \\
\hline $1 \% \mathrm{KCl}+5 \%$ Aquagel & 23 \\
\hline $1 \% \mathrm{LiOH}+5 \%$ Aquagel & 50 \\
\hline $1 \% \mathrm{CaCl}_{2}+5 \%$ Aquagel & 25 \\
\hline $1 \% \mathrm{MgCl}_{2}+5 \%$ Aquagel & 35 \\
\hline $1 \% \mathrm{Mg}(\mathrm{OH})_{2}+5 \%$ Aquagel & 44 \\
\hline $1 \% \mathrm{LiCl}+5 \%$ Aquagel & 43 \\
\hline $1 \% \mathrm{NaCl}+5 \%$ Aquagel & 42 \\
\hline $1 \% \mathrm{ZnCl}+5 \%$ Aquagel & 60 \\
\hline $1 \% \mathrm{KCl}+5 \%$ Aquagel+1\%Diamino Butane & 16 \\
\hline $1 \% \mathrm{KCl}+5 \%$ Aquagel+1\%Diamino Hexane & 12 \\
\hline $1 \% \mathrm{Ca}(\mathrm{OH})_{2}+5 \%$ Aquagel+1\%Diamino Butane & 13 \\
\hline $1 \% \mathrm{Ca}(\mathrm{OH})_{2}+5 \%$ Aquagel+1\%Diamino Hexane & 8 \\
\hline \multicolumn{2}{|c|}{ Inhibition Stability Evaluation During Brine Contact } \\
\hline $1 \% \mathrm{KCl}+5 \%$ Aquagel+1\%Diamino Butane & 19 \\
\hline $1 \% \mathrm{KCl}+5 \%$ Aquagel+1\%Diamino Hexane & 15 \\
\hline $1 \% \mathrm{Ca}(\mathrm{OH})_{2}+5 \%$ Aquagel+1\%Diamino Butane & 24 \\
\hline $1 \% \mathrm{Ca}(\mathrm{OH})_{2}+5 \%$ Aquagel+1\%Diamino Hexane & 20 \\
\hline
\end{tabular}

Table 4.4: Results of Inhibition Test on Smectite Montmorillonite Clays. 


\section{Percentage Linear Swelling of Smectite Caused by Fluid Candidates}
$\mathrm{H} 2 \mathrm{O}$
$\mathrm{CaOH} 2$
$\square \mathrm{KCL}$
$\square \mathrm{LiOH}$
$\square \mathrm{CaCL} 2$
$\square \mathrm{MgCL} 2$
$\square \mathrm{MgOH} 2$
$\square \mathrm{LiCL}$
$\mathrm{NaCL}$
$\mathrm{ZnCL}$
- KCL+Diamino Butane
C KCL+Diamino Hexane
- CaCL2+Diamino Butane $\quad$ CaCL2+Diamino Hexane

62

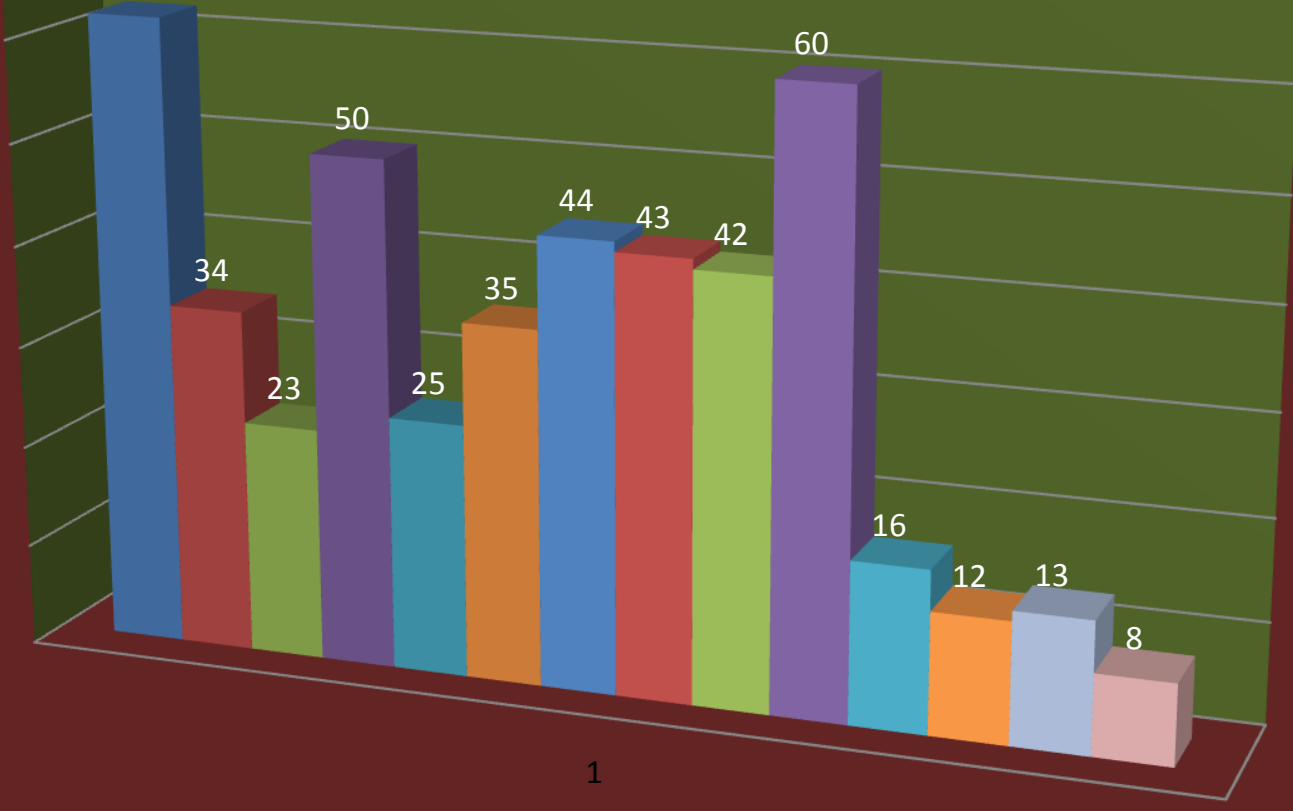

Figure 4.12: \%Linear Swelling of Smectite Caused by Several Fluid Candidates (1\% of Chloride or Hydroxide and $0.5 \%$ of $\mathrm{DB}$ or $\mathrm{DH}$ ). 


\section{Percentage Linear Swelling of Fluid-contacted Smectite after Exposure to $\mathrm{NaCL}$}

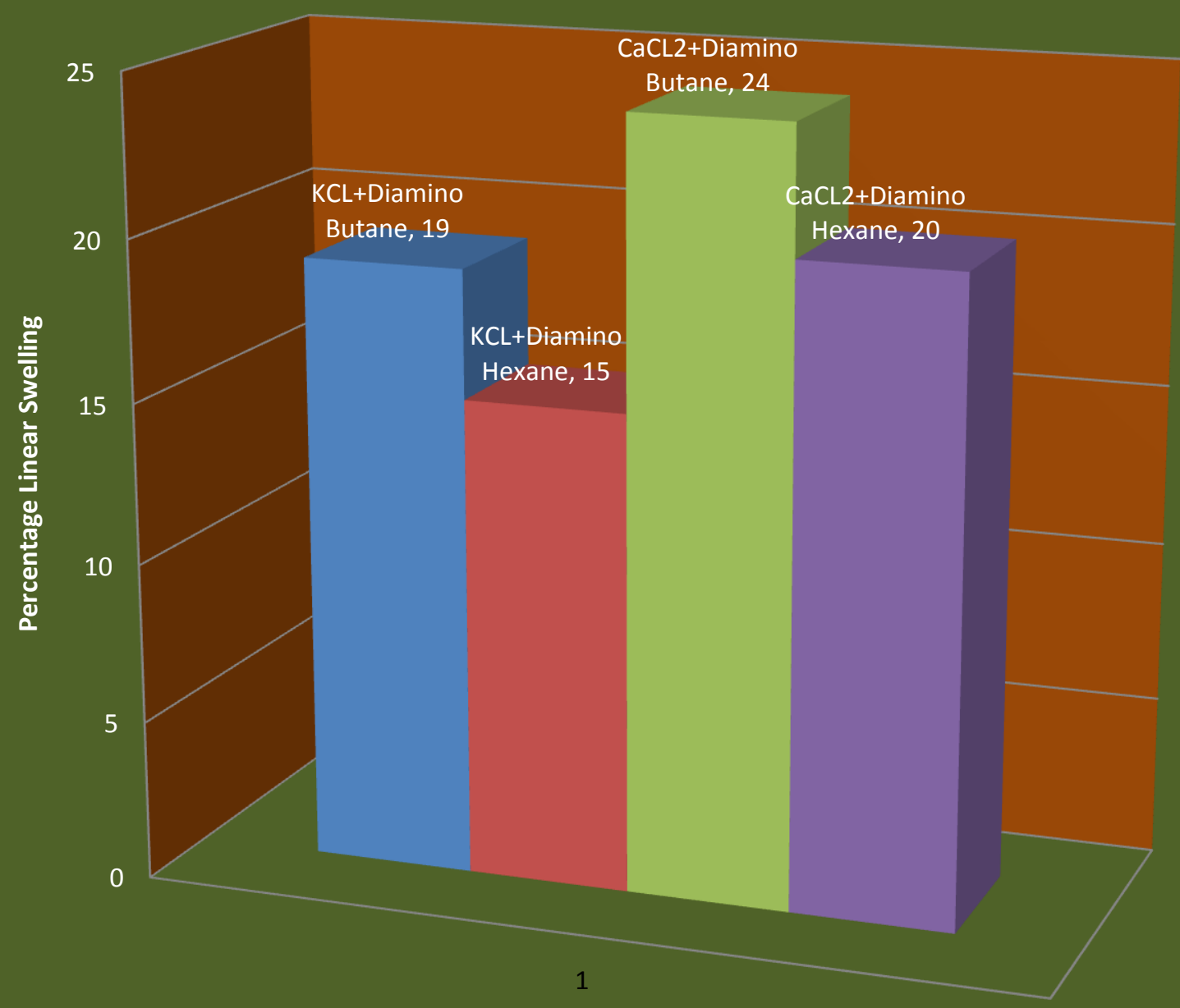

Figure 4.13: \%Linear Swelling of Fluid-contacted Smectite after Exposure to NaCL (1\% of Chloride or Hydroxide and $0.5 \%$ of $\mathrm{DB}$ or $\mathrm{DH}$. 


\section{Marcellus Shale Swelling Experiment}

Based on the rheological, filtration and Smectite swelling experiments, five drilling fluids were selected for further testing on shale inhibition. The fluids which were selected are

$1 \% \mathrm{LiCl}+0.5 \%$ Diamino Hexane+Aquagel, $1 \% \mathrm{MgOH}_{2}+0.5 \%$ Diamino Hexane+Aquagel, $1 \% \mathrm{KCl}+0.5 \%$ Diamino Hexane+Aquagel, $1 \% \mathrm{NaCl}+0.5 \%$ Diamino Hexane+Aquagel and $1 \% \mathrm{CaCl}_{2}+0.5 \%$ Diamino Hexane+Aquagel.

As was noted earlier, Diamino Hexane systems appeared to cause the least swelling among the Diamino Alkane systems. Also, Diamino Hexane systems appeared to cause the most inhibition of Smectite and shale when compared to non-Diamino Hexane systems. It was evident that inhibition is directly proportional to the number of carbon atoms within the Diamino Alkane compounds. Therefore, Diamino Hexane having more carbon atoms than Diamino Butane, tended to cause the least swelling of Smectite and shale alike.

The $1 \% \mathrm{MgOH}_{2}+0.5 \%$ Diamino Hexane+Aquagel system was chosen due to its low yield point, low filtrate loss, acceptable plastic viscosity, low/acceptable gel strength and acceptable mud cake. The plastic viscosity of this system was attractive due to the trends shown be the PV plot with respect to concentration of $\mathrm{MgCl}_{2}$. In addition to showing low $\mathrm{PV}$, the PV plot of this system tended to increase gently, as opposed to rapidly, making the fluid a perfect candidate.

Also, its gel strength showed a gentle increase as well as its yield point. A combination of low YP, low PV, and low gel strength means that frictional pressure loss is reduced during drilling fluid circulation through the drill pipe and annulus. As such, we can drill more efficiently. 
The $1 \% \mathrm{CaCl}_{2}+0.5 \%$ Diamino Hexane+Aquagel system is indeed a special system. It possessed a stable YP with respect to increasing concentration of $\mathrm{CaCl} 2$, high filtrate loss which is unacceptable, decreasing PV with concentration of $\mathrm{CaCl}_{2}$ and gently increasing gel strength. In compensation for unacceptable filtrate losses, the $1 \% \mathrm{CaCl}_{2}+$ Diamino Hexane+Aquagel system makes a good smectite inhibition agent. It is hence recommended that $1 \% \mathrm{CaCl}_{2}+$ Diamino Hexane+Aquagel system be used in conjunction with a filtrate loss agent.

The $1 \% \mathrm{NaCl}+0.5 \%$ Diamino Hexane+Aquagel system was chosen for further testing due to its low YP and the gentle slope of its YP plot with respect to concentration of $\mathrm{NaCl}$. Also, the system possessed a low filtrate loss and low gel strength. Also, its effect on Smectite inhibition was equally intriguing.

The $1 \% \mathrm{KCl}+0.5 \%$ Diamino Hexane+Aquagel system possessed all the fine attributes required of a perfect drilling fluid. The combination of $\mathrm{KCl}$-Aquagel system with Diamino Hexane improved inhibitive properties of the $\mathrm{KCl}$-Aquagel system even better making The $1 \%$ $\mathrm{KCl}+0.5 \%$ Diamino Hexane+Aquagel system a competitive candidate for an optimum fluid. Low and gentle PV trends, low filtrate loss, acceptable gel strength and low YP makes 1\% $\mathrm{KCl}+$ Diamino Hexane+Aquagel system an even more optimum candidate.

As shown in Figure 3.1, the Smectite content of the Marcellus Shale formation in West Virginia is fairly low and minute shale swelling was recorded using a very sensitive linear swell meter. The linear swell meter was capable of measuring up to $1000^{\text {th }}$ of an inch; however, very little swelling was measured when the Marcellus Shale samples came into contact with the drilling fluid finalists, proving the fact that Smectite is indeed responsible for the swelling of shale. 
However, the true mineral composition of the shale samples used in this research were unknown and it is indeed possible that the shale samples may have contained some Smectite clay within, leading to the minute, but insignificant swelling of the shale which was noticed. This research therefore recommends the performance of the experiments contained herein on Shale formations with high Smectite content.

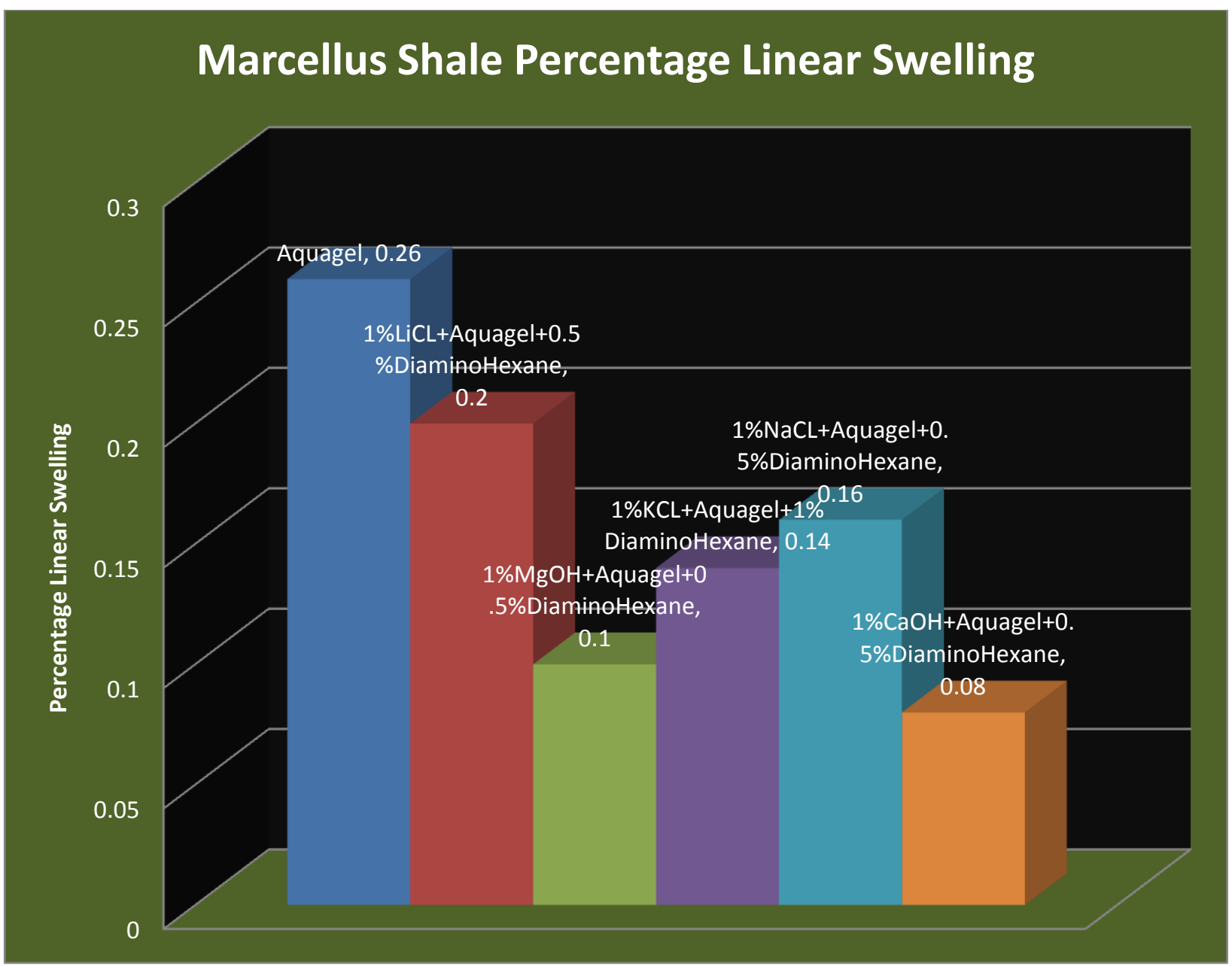

Figure 4.14: Bar Chart for Percentage Linear Swelling of Fluid-contacted Shale 


\section{Chapter 5}

\section{Summary}

This research endeavoured to study the shale inhibitive effect of various novel chemicals such as Diamino Butane, Diamino Hexane in conjunction with Chlorides and Hydroxides of various Alkali metals, Alkali earth metals and Transition metals. More so, this research also evaluated the effect of the aforementioned chemicals on the rheology of Aquagel/Bentonite based drilling fluids.

Aquagel based drilling fluids, upon reacting with the aforementioned chemicals, showed changes in physical, chemical and rheological properties such as plastic viscosity, filtrate loss, gel strength, mud cake and yield point. Of these changes in properties, some were beneficial while others were detrimental and led to the elimination of the drilling fluid from further testing.

Upon the selection of fluids for further testing, based on rheological and filtration performance, the drilling fluids were tested on Smectite clay to evaluate their effect on the inhibition of Smectite. Smectite is the mostly responsible component for the swelling of shale.

Unsurprisingly, Smectite clay mineral constitutes the majority of swelling clays in shale hydrocarbon reservoirs, even though it only represents a few percentage of the shale. This is apparently due to the large surface area and continuity of the Smectite clay throughout the shale reservoir. In layman's terms, the above expression refers to the thin sheet of Smectite clay covering the shale surface like a blanket and its infinite spread throughout the formation.

Based on the success of selected fluid at the inhibition of smectite, a final set of fluids were chosen to be tested on the inhibition of Marcellus Shale. 


\section{Conclusion}

After every possible realistic permutation and combination of the chemicals and fluids used for this research, the $1 \% \mathrm{KCl}+0.5 \%$ Diamino Hexane+Aquagel system possessed all the fine attributes required of a perfect drilling fluid. The combination of $\mathrm{KCl}$-Aquagel system with Diamino Hexane improved inhibitive properties of the KCl-Aquagel system even better, making the $1 \% \mathrm{KCl}+0.5 \%$ Diamino Hexane+Aquagel system a competitive candidate for an optimum inhibitive drilling fluid. Low and gentle PV trends, low filtrate loss, acceptable gel strength and low YP makes $1 \% \mathrm{KCl}+0.5 \%$ Diamino Hexane+Aquagel system an even more proper candidate for the inhibition of Marcellus Shale and perhaps other shale formations.

It is evident that $1 \% \mathrm{CaCl}_{2}+0.5 \%$ Diamino Hexane+Aquagel and $1 \% \mathrm{MgOH}_{2}+0.5 \%$ Diamino Hexane+Aquagel systems caused the most inhibition of Smectite and shale (Figure 4.15); however, the $1 \% \mathrm{KCl}+0.5 \%$ Diamino Hexane+Aquagel system exhibited overall better filtration and rheological properties than the other systems. Based on this, the $1 \% \mathrm{KCl}+0.5 \%$ Diamino Hexane+Aquagel system was selected as the inhibition system of choice for reducing formation damage in the Marcellus Shale, reducing incidences of formation damage, stuck pipe, preventing bit balling, heaving and sloughing.

More so, the effect of various Chlorides and Hydroxides of various metals on the rheology and filtration characteristics of bentonite based drilling fluids has been evaluated and documented herein. Some chemicals instigate sharp decrease or increase in rheological properties of the mud while others cause gentle changes in rheological properties of Bentonite based mud. Intriguing 
results were also documented for the effect of Chlorides and Hydroxides of various metals on the filtration characteristics of Bentonite based drilling fluids.

Again, as shown in Figure 3.1, the Smectite content of the Marcellus Shale formation in West Virginia is fairly low and minute shale swelling was recorded while using a very sensitive linear swell meter. The linear swell meter was capable of measuring up to $1000^{\text {th }}$ of an inch; however, very little swelling was measured when the Marcellus Shale samples came into contact with the selected drilling fluid system, proving the fact that Smectite is indeed responsible for the swelling of shale.

However, the true mineral composition of the shale samples used in this research were unknown and it is indeed possible that the shale samples may have contained some Smectite clay within, leading to the minute, but insignificant swelling of the shale.

Furthermore, the linear swell meter, although very sensitive, had a presumed mechanical limitation in the fact that the metal piston may have been slightly too heavy to allow for effective swelling of the shale sample.

It is therefore recommended that a more sensitive and mechanically suitable linear swell meter be used for future experiments regarding the inhibition of shale. 


\section{Recommendations}

This research has achieved a remarkable feat; nevertheless, there are still areas which require further research and evaluation by fellow drilling engineers who wish to pursue research in drilling fluids engineering and science. I solemnly recommend that cost analysis be performed on the inclusion of Diamino Hexane and other Diamino Alkanes into drilling fluids when drilling at various depths of formation. I also recommend the execution of the work contained herein on other shale formations such as Huron, Utica, Antrim, Fayetteville, Haynesville, Woodford, Barnett, Pierre, Bakken, Conasanga, Chattanooga, New Albany etc.

In addition, this research utilized Aquagel clay for the base drilling fluid. Therefore, it is recommended that the work contained herein be executed for other clays such as Attapulgite, Quickgel, Zeogel and etc. There is still work to be done in this unconventional, novel area of shale gas formation.

Finally, it is recommended that Diamino Alkanes be tested on the field to evaluate its field performance. 


\section{References}

Adesoye, Kehinde. "Shale Characterization for Evaluation of Shale-Drilling Fluid Interaction" M.S. Thesis, University of Oklhoma (2009).

Azar, J.J. Lummus, James L. "Drilling Fluids Optimization, A Practical Approach" ISBN: 0878143068, PennWell, Tulsa, OK (1986).

Bernhard, Ronald.P. "Rheological Properties of High Temperature Drilling Fluids" Thesis, Texas Tech University (1981)

Borgoyne A.T., Chenevert M.E., Millheim K.K., Young F.F.: “Applied Drilling Engineering”, SPE Textbook Series, Vol. 2, Richardson, Texas 1986.

Chenevert, M.E. and Osisanya, S.O.: "Shale Swelling at Elevated Temperature and Pressure", presented at the 33rd Symposium in Rock Mechanics, Santa Fe, New Mexico, June 8-10, 1992

Chenevert M.E. and Osisanya S.O.: "Shale/Mud Inhibition Defined with Rig-Site Methods”, SPE Drilling Engineering, September, 1989.

Darley, H.C.H. Gray, R George. "Composition and Properties of Oil Well Drilling Fluids" $4^{\text {th }}$ Edition Elservier, New York, NY (1981).

Devereux, Steve. "Practical Well Planning \& Drilling Manual” PennWell, Tulsa, OK (1998).

EXLOG Staff. "Theory and Application of Drilling Fluid Hydraulics" International Human Resources Development Corporation (1980).

H.Rabia. "Oil Well Drilling Engineering, Principles and Practice" Graham and Trotman, Maryland (1985).

http://www.mapwv.gov/UnconventionalResources/marcellusLithoAndPetroPaper.pdf

http://www.soils.umn.edu

http://www.terragis.bees.unsw.edu.au/terraGIS_soil/sp_cation_exchange_capacity.html

Ismali, Issham. Huang, Ann "The Application of Methyl Gucoside as Shale Inhibitor in Sodium Chloride Mud" Jurnal Teknologi, 50(F) Jun 2009: 53-65 Universiti Teknologi Malaysia. 
Jones F.O Jr.: "New Fast, Accurate Test Measurement of Bentonite in Mud", Oil and Gas Journal, pp 76-78, June 1, 1964.

Serpen, Umran. "Investigation on Geothermal Drilling Muds with high temperature stability" ITÜ, Petroleum and Natural Gas Eng. Dept., Maslak, 80626, Istanbul, Turkey (2006).

www.netl.doe.gov National Energy Technology Laboratory

www.ogj.com Oil and Gas Journal

Z.John, Zhou. David H.S, Law. Alberta Research Council. "Swelling Clays in Hydrocarbon Reservoirs: the Bad, the Less Bad, and the Useful" (1998) No. 1998.057

Zhang, Jianguo. Baker Atlas, Baker Hughes Drilling Fluids et al. "Ion Movement and Laboratory Technique to Control Wellbore Stability Fluids" (2006) AADE-06-DF-HO-37 


\section{Resume}

\section{Ike Eleanya Onuoha}

1133 District Lane, Morgantown, WV, USA 26505

(412)-551-8429 eleanya_ng $a$ yahoo.com

\begin{tabular}{|c|c|c|c|c|}
\hline Objective: & \multicolumn{4}{|c|}{$\begin{array}{l}\text { To work as a Reservoir Engineer, Instructor or Researcher in Reservoir Engineering, EOR, Reservoir Characterization or } \\
\mathrm{CO}_{2} \text { Sequestration. }\end{array}$} \\
\hline Education: & \multicolumn{2}{|c|}{$\begin{array}{l}\text { West Virginia University, Morgantown, West Virginia, USA } \\
\text { Doctor of Philosophy in Petroleum and Natural Gas Engineering } \\
\text { Expected: May, } 2015 \\
\text { Cumulative GPA: } 4.0 \text { Out of } 4.0 \\
\text { West Virginia University, Morgantown, West Virginia, USA } \\
\text { Master of Science in Petroleum and Natural Gas Engineering } \\
\text { Graduated: May, } 2011 \\
\text { Cumulative GPA: } 4.0 \text { Out of } 4.0\end{array}$} & \multicolumn{2}{|c|}{$\begin{array}{l}\text { Arkansas Tech University, Russellville, Arkansas, USA } \\
\text { Bachelor of Science in Mechanical Engineering } \\
\text { Graduated: December } 2008 \\
\text { Cumulative GPA: } 3.29 \text { Out of } 4.0\end{array}$} \\
\hline $\begin{array}{l}\text { Work } \\
\text { Experience: }\end{array}$ & \multicolumn{4}{|c|}{ 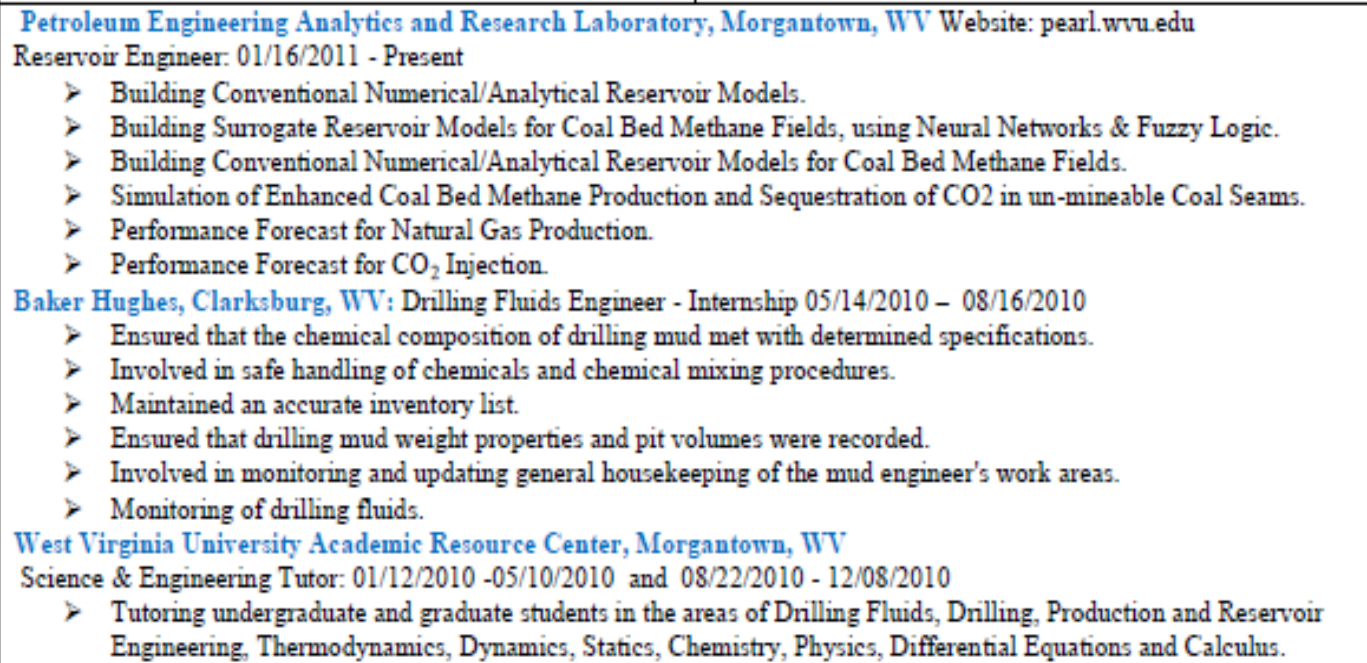 } \\
\hline $\begin{array}{l}\text { Sponsored } \\
\text { Research }\end{array}$ & \multicolumn{4}{|c|}{$\begin{array}{l}\text { Modeling and Simulation of Enhanced Coal Bed Natural Gas Production and Sequestration of } \mathrm{CO}_{2} \text { in Un-minable Coal } \\
\text { Seams. Sponsored by Consol, DOE and NETL. }\end{array}$} \\
\hline $\begin{array}{l}\text { Completed M.S. } \\
\text { Thesis Research }\end{array}$ & \multicolumn{4}{|c|}{$\begin{array}{l}\text { A Study of Additives for Aquagel/Bentonite Based Drilling Fluids in Relation to Filtration and Rheological Properties, } \\
\text { Smectite Inhibition and Their Application to Marcellus Shale. }\end{array}$} \\
\hline Work Permit: & \multicolumn{4}{|c|}{ US Permanent Residence/US Green Card Holder } \\
\hline $\begin{array}{l}\text { Software } \\
\text { Experience: }\end{array}$ & \multicolumn{4}{|c|}{$\begin{array}{l}\text { CMG, ECLIPSE, PETREL, Lone Star Steel, AutoCAD, MATLAB, Microsoft Excel, PowerPoint, Microsoft Word, } \\
\text { Microsoft Office Suite. }\end{array}$} \\
\hline $\begin{array}{l}\text { Operating } \\
\text { Systems: }\end{array}$ & \multicolumn{4}{|c|}{ UNIX, Mac, MS DOS, Windows 95/98/00/XP/Vista } \\
\hline $\begin{array}{l}\text { Programming } \\
\text { Experience: }\end{array}$ & \multicolumn{4}{|l|}{ FORTRAN, HTML, MS Excel Macros } \\
\hline Organizations: & \multicolumn{4}{|c|}{$\begin{array}{l}\text { Society of Petroleum Engineers, American Association of Drilling Engineers, American Society of Mechanical Engineers, } \\
\text { American Society of Heating, Refrigerating and Air-Conditioning Engineers. }\end{array}$} \\
\hline $\begin{array}{l}\text { Honorary } \\
\text { Achievements: }\end{array}$ & \multicolumn{2}{|c|}{$\begin{array}{l}\text { WVU PNGE Outstanding M.S. Graduate Student of the } \\
\text { Year based on Research and Academic Achievement } 2011\end{array}$} & \multicolumn{2}{|c|}{$\begin{array}{l}\text { Arkansas Tech University Honors student 2004, } 2008 \\
\text { Arkansas Tech University Dean's List 2004, 2008 }\end{array}$} \\
\hline References: & $\begin{array}{c}\text { Sam Ameri } \\
\text { Chairperson, Petroleum and Natural Gas } \\
\text { Engineering } \\
\text { Professor, College of Engineering and } \\
\text { Mineral Resources } \\
\text { West Virginia University, Morgantown, } \\
\text { WV } \\
\text { (304) }-293-3949 \\
\text { samuel.ameri } @ \text { mail. wvu.edu }\end{array}$ & $\begin{array}{r}\text { Sinisha } \\
\text { Pro } \\
\text { Natural Gas and } \\
\text { Strategic Center } \\
\text { National Energ: } \\
\text { United States De } \\
\text { Sinisha.Ji }\end{array}$ & $\begin{array}{l}\text { ay) Jilich, } \mathrm{PhD} \\
\text { ct Manager } \\
\text { Oil Project Management } \\
\text { ivision, } \\
\text { or Natural Gas and Oil, } \\
\text { Technology Laboratory, } \\
\text { artment of Energy ( } 304) \\
55-4320\end{array}$ & \begin{tabular}{|c|} 
H. Illin Bilgesu, PhD \\
Associate Professor, Petroleum and \\
Natural Gas Engineering \\
Associate Professor, College of \\
Engineering and Mineral Resources \\
West Virginia University, \\
Morgantown, WV \\
(304)-293-3966 \\
Inkin.Bilgesu@mail.wvu.edu
\end{tabular} \\
\hline
\end{tabular}


APPENDIX A - TABLES 


\begin{tabular}{|c|c|c|c|c|c|c|c|c|c|}
\hline Mud System & Clay Type & Concentration & Gel & 600 RPM & 300 RPM & Density ppg & PV & AV & $\mathrm{YP}$ \\
\hline Aquagel & Aquagel & $5 \%$ Aquagel & 13.5 & 35 & 26 & $\begin{array}{r}8.6 \\
\end{array}$ & 9 & 17.5 & 17 \\
\hline \multirow[t]{4}{*}{$\mathrm{KCl}$-Aquagel } & Aquagel & $5 \%$ Aquagel $+0.5 \% \mathrm{KCl}$ & 12 & 28.5 & 21 & 8.6 & 7.5 & 14.25 & 13.5 \\
\hline & Aquagel & $5 \%$ Aquagel $+1 \% \mathrm{KCl}$ & 12.5 & 32 & 22 & 8.7 & 10 & 16 & 12 \\
\hline & Aquagel & $5 \%$ Aquagel $+2 \% \mathrm{KCl}$ & 14.75 & 43 & 34 & 8.725 & 9 & 21.5 & 25 \\
\hline & Aquagel & $5 \%$ Aquagel $+3 \% \mathrm{KCl}$ & 17 & 54 & 46 & 8.75 & 8 & 27 & 38 \\
\hline \multirow[t]{4}{*}{$\mathrm{MgCl}_{2}$-Aquagel } & Aquagel & $5 \%$ Aquagel $+0.5 \% \mathrm{MgCl}_{2}$ & 5.5 & 15 & 11 & 8.55 & 4 & 7.5 & 7 \\
\hline & Aquagel & $5 \%$ Aquagel $+1 \% \mathrm{MgCl}_{2}$ & 6 & 17.5 & 13.5 & 8.6 & 4 & 8.75 & 9.5 \\
\hline & Aquagel & $5 \%$ Aquagel $+2 \% \mathrm{MgCl}_{2}$ & 6.25 & 18.75 & 15 & 8.675 & 3.75 & 9.375 & 11.25 \\
\hline & Aquagel & $5 \%$ Aquagel $+3 \% \mathrm{MgCl} 2$ & 6.5 & 20 & 16.5 & 8.75 & 3.5 & 10 & 13 \\
\hline \multirow[t]{4}{*}{$\mathrm{MgOH}_{2}$-Aquage } & Aquagel & $5 \%$ Aquagel $+0.5 \% \mathrm{MgOH}_{2}$ & 16 & 35.5 & 27 & 8.55 & 8.5 & 17.75 & 18.5 \\
\hline & Aquagel & $5 \%$ Aquagel $+1 \% \mathrm{MgOH}_{2}$ & 16.5 & 37 & 28.5 & 8.6 & 8.5 & 18.5 & 20 \\
\hline & Aquagel & $5 \%$ Aquagel $+2 \% \mathrm{MgOH}_{2}$ & 18.75 & 39 & 32.25 & 8.675 & 6.75 & 19.5 & 25.5 \\
\hline & Aquagel & $5 \%$ Aquagel $+3 \% \mathrm{MgOH}_{2}$ & 21 & 41 & 36 & 8.75 & 5 & 20.5 & 31 \\
\hline \multirow[t]{4}{*}{$\mathrm{CaCl}_{2}$-Aquagel } & Aquagel & $5 \%$ Aquagel $+0.5 \% \mathrm{CaCl}_{2}$ & 7 & 19.5 & 15.5 & 8.55 & 4 & 9.75 & 11.5 \\
\hline & Aquagel & $5 \%$ Aquagel $+1 \% \mathrm{CaCl}_{2}$ & 7.5 & 21 & 17 & 8.65 & 4 & 10.5 & 13 \\
\hline & Aquagel & $5 \%$ Aquagel $+2 \% \mathrm{CaCl}_{2}$ & 7.65 & 21.25 & 17.6 & 8.7 & 3.65 & 10.63 & 13.95 \\
\hline & Aquagel & $5 \%$ Aquagel $+3 \% \mathrm{CaCl}_{2}$ & 7.8 & 21.5 & 18.2 & 8.75 & 3.3 & 10.75 & 14.9 \\
\hline \multirow[t]{4}{*}{$\mathrm{CaOH}_{2}$-Aquage } & Aquagel & $5 \%$ Aquagel $+0.5 \% \mathrm{CaOH}_{2}$ & 7.5 & 30 & 25.5 & 8.6 & 4.5 & 15 & 21 \\
\hline & Aquagel & $5 \%$ Aquagel $+1 \% \mathrm{CaOH}_{2}$ & 8 & 39.5 & 33 & 8.65 & 6.5 & 19.75 & 26.5 \\
\hline & Aquagel & $5 \%$ Aquagel $+2 \% \mathrm{CaOH}_{2}$ & 10.5 & 43 & 37 & 8.675 & 6 & 21.5 & 31 \\
\hline & Aquagel & $5 \%$ Aquagel $+3 \% \mathrm{CaOH}_{2}$ & 13 & 46.5 & 41 & 8.7 & 5.5 & 23.25 & 35.5 \\
\hline \multirow[t]{4}{*}{ ZnCl-Aquagel } & Aquagel & $5 \%$ Aquagel $+0.5 \% \mathrm{ZnCl}$ & 10 & 35.5 & 32 & 8.55 & 3.5 & 17.75 & 28.5 \\
\hline & Aquagel & $5 \%$ Aquagel $+1 \% \mathrm{ZnCl}$ & 9.5 & 46 & 40 & 8.7 & 6 & 23 & 34 \\
\hline & Aquagel & $5 \%$ Aquagel $+2 \% \mathrm{ZnCl}$ & 9.75 & 49 & 42.5 & 8.8 & 6.5 & 24.5 & 36 \\
\hline & Aquagel & $5 \%$ Aquagel $+3 \% \mathrm{ZnCl}$ & 10 & 52 & 45 & 8.9 & 7 & 26 & 38 \\
\hline \multirow[t]{4}{*}{ LiCl-Aquagel } & Aquagel & $5 \%$ Aquagel+0.5\% LiCl & 11 & 23 & 18.5 & 8.6 & 4.5 & 11.5 & 14 \\
\hline & Aquagel & $5 \%$ Aquagel+1\% LiCl & 10.5 & 25 & 20 & 8.7 & 5 & 12.5 & 15 \\
\hline & Aquagel & $5 \%$ Aquagel $+2 \% \mathrm{LiCl}$ & 10.75 & 24.25 & 19.5 & 8.725 & 4.75 & 12.13 & 14.75 \\
\hline & Aquagel & $5 \%$ Aquagel+3\% LiCl & 11 & 23.5 & 19 & 8.75 & 4.5 & 11.75 & 14.5 \\
\hline \multirow[t]{4}{*}{$\mathrm{NaCl}$-Aquagel } & Aquagel & $5 \%$ Aquagel $+0.5 \% \mathrm{NaCl}$ & 13 & 30.5 & 20.5 & 8.5 & 10 & 15.25 & 10.5 \\
\hline & Aquagel & $5 \%$ Aquagel $+1 \% \mathrm{NaCl}$ & 11.5 & 29.5 & 21.5 & 8.55 & 8 & 14.75 & 13.5 \\
\hline & Aquagel & $5 \%$ Aquagel $+2 \% \mathrm{NaCl}$ & 11.5 & 27.5 & 20.5 & 8.625 & 7 & 13.75 & 13.5 \\
\hline & Aquagel & $5 \%$ Aquagel $+3 \% \mathrm{NaCl}$ & 11.5 & 25.5 & 19.5 & 8.7 & 6 & 12.75 & 13.5 \\
\hline \multirow[t]{4}{*}{ LiOH-Aquagel } & Aquagel & $5 \%$ Aquagel $+0.5 \% \mathrm{LiOH}$ & 17 & 67.5 & 61 & 8.6 & 6.5 & 33.75 & 54.5 \\
\hline & Aquagel & $5 \%$ Aquagel $+1 \% \mathrm{LiOH}$ & 18.5 & 74 & 69 & 8.65 & 5 & \begin{tabular}{|l|}
37 \\
\end{tabular} & 64 \\
\hline & \begin{tabular}{|l|} 
Aquagel \\
\end{tabular} & $5 \%$ Aquagel $+2 \% \mathrm{LiOH}$ & 21.25 & 88 & 78.75 & 8.725 & 9.25 & 44 & 69.5 \\
\hline & Aquagel & $5 \%$ Aquagel $+3 \% \mathrm{LiOH}$ & 24 & 102 & 88.5 & 8.8 & 13.5 & 51 & 75 \\
\hline
\end{tabular}

Table A.1: Rheological Properties of Base Drilling Fluids 


\begin{tabular}{|c|c|c|c|c|c|c|c|c|c|c|c|c|c|c|c|c|c|c|c|c|c|c|c|c|c|c|c|c|c|c|c|c|}
\hline \multirow[b]{2}{*}{ Mud System } & & \multicolumn{31}{|c|}{$\min ^{1 / 2}$} \\
\hline & Mud Cake & & $\begin{array}{ll}0 & 1 \\
\end{array}$ & 1.41 & \begin{tabular}{|l|}
1.73 \\
\end{tabular} & 2 & 2.24 & 2.449 & \begin{tabular}{|l|}
2.65 \\
\end{tabular} & 2.83 & 3 & 3.16 & 3.3 & 3.46 & 3.61 & \begin{tabular}{|l|}
3.74 \\
\end{tabular} & 3.87 & 4 & 4.1 & 4.24 & 4.4 & 4.47 & \begin{tabular}{|l|}
4.6 \\
\end{tabular} & 4.69 & \begin{tabular}{|l|}
4.8 \\
\end{tabular} & 4.9 & & \begin{tabular}{|l|l|}
5 & 5.1 \\
\end{tabular} & 5.2 & 5.3 & \begin{tabular}{|l|}
5.4 \\
\end{tabular} & 5.5 \\
\hline (5\%Aquagel) & $\mathrm{mm}$ & ml & $\mathrm{ml}$ & \begin{tabular}{|l|l}
$\mathrm{ml}$ & $\mathrm{n}$
\end{tabular} & \begin{tabular}{|l|l}
$\mathrm{ml}$ & $\mathrm{n}$ \\
\end{tabular} & \begin{tabular}{|l|l}
$\mathrm{ml}$ & $\mathrm{r}$ \\
\end{tabular} & $\mathrm{ml}$ & $\mathrm{ml}$ & \begin{tabular}{|l|l}
$\mathrm{ml}$ & $\mathrm{n}$
\end{tabular} & ml & $\mathrm{ml}$ & $\mathrm{ml}$ & $\mathrm{ml}$ & \begin{tabular}{|l|l}
$\mathrm{ml}$ & $\mathrm{n}$
\end{tabular} & $\mathrm{ml}$ & \begin{tabular}{|l|l}
$\mathrm{ml}$ & $\mathrm{r}$ \\
\end{tabular} & \begin{tabular}{|l|l}
$\mathrm{ml}$ & $\mathrm{n}$
\end{tabular} & \begin{tabular}{l|l}
$\mathrm{ml}$ & $\mathrm{n}$ \\
\end{tabular} & $\begin{array}{ll}\mathrm{ml} & \mathrm{r}\end{array}$ & $\mathrm{ml}$ & $\mathrm{ml}$ & $\mathrm{ml}$ & \begin{tabular}{|l|l}
$\mathrm{ml}$ & $\mathrm{n}$ \\
\end{tabular} & \begin{tabular}{l|l}
$\mathrm{ml}$ & $\mathrm{r}$
\end{tabular} & $\mathrm{ml}$ & $\mathrm{ml}$ & $\mathrm{ml}$ & $\mathrm{ml}$ & $\mathrm{ml}$ & $\mathrm{ml}$ & \begin{tabular}{|l|l}
$\mathrm{ml}$ & $\mathrm{n}$ \\
\end{tabular} & $\mathrm{ml}$ \\
\hline $5 \% A$ & 0.97 & 1 & $1 \quad 4.5$ & 7 & \begin{tabular}{|l|}
8.5 \\
\end{tabular} & 10 & 11 & 12 & 13 & \begin{tabular}{|l|}
14 \\
\end{tabular} & 15 & 16 & 17 & 17 & 18 & 19 & 19.5 & 20 & 21 & 21 & 22 & 22 & \begin{tabular}{|r|}
23 \\
\end{tabular} & 23 & 24 & 25 & 25 & 25.5 & 26 & 27 & \begin{tabular}{|r|}
28 \\
\end{tabular} & 28 \\
\hline $0.5 \%$ & 84 & 4 & 18 & 25.5 & 31 & 36 & 40 & 44 & | & 52 & 54 & 56 & 60 & 63 & 65 & 68 & 70 & 73 & 75 & 77.5 & 79 & 81 & 83 & 86 & 87 & 89 & 91 & 193 & 94 & 96 & 98 & 100 \\
\hline $1 \% Z$ & 2 & 5 & 18 & 26 & 32 & 38 & 42 & 45 & 50 & 53 & 55 & 60 & 63 & 65 & 69 & 71 & 74 & 76 & 79 & 81 & 83 & 85 & 87 & 89 & 91 & 92 & 95 & 97 & 98.5 & 101 & 102 & 105 \\
\hline $2 \% \mathrm{Zn}$ & 005 & & 19 & 26.5 & 33 & \begin{tabular}{|l|}
38.5 \\
\end{tabular} & 42.5 & 45.5 & 50 & 53.5 & 55.5 & 60.5 & 64 & 66 & 69.5 & 71.5 & 74.5 & 77 & 79 & 81 & 83 & 85.5 & 88 & 89.5 & 91.5 & 93 & 96 & \begin{tabular}{|l|}
57.5 \\
\end{tabular} & 99 & 102 & \begin{tabular}{|l|}
103 \\
\end{tabular} & 105 \\
\hline $3 \% \mathrm{ZnCl}$ & 01 & 5 & 20 & 27 & 34 & 39 & 43 & 46 & 50 & 54 & 56 & 61 & 65 & 67 & 70 & 72 & 75 & 77 & 80 & 81 & 82 & 86 & 88 & 90 & 92 & 94 & 96 & \begin{tabular}{|c|}
6 \\
\end{tabular} & 99.5 & 102 & 103 & 106 \\
\hline $1 \% \mathrm{CaCl}_{2}$ & 81 & 5 & 15 & 22 & 26 & 30 & 34 & 37 & 40 & 42.5 & 45 & 47.5 & 50 & 53 & 55 & 57 & 59 & 62 & 63 & 65 & 67 & 68.5 & 70 & 72 & 73 & 75 & 76 & 78 & 79 & 81 & 82 & 85 \\
\hline $2 \% \mathrm{CaCl}_{2}$ & 77 & 5 & 15 & 21.8 & 26 & 30.3 & 34 & 37 & 40 & 42.5 & 45 & 47.5 & 50 & 53 & 55.5 & 57.5 & 59.5 & 62 & 64 & 65.5 & 67 & 69 & 71 & 72.5 & 73.8 & 76 & 77 & 78.7 & 80 & 82 & 83 & 85 \\
\hline $3 \% \mathrm{Ca}$ & 73 & 5 & 15 & 21.5 & 26 & 30.5 & 34 & 37 & 40 & 42.5 & 45 & 47.5 & 50 & 53 & 56 & 58 & 60 & 62 & 64 & 66 & 68 & 69.5 & 72 & 73 & 74.5 & 77 & 78 & 79.3 & 81 & 83 & 84 & 86 \\
\hline $0.5 \% \mathrm{~L}$ & 39 & 4 & 6 & 8.7 & 11 & \begin{tabular}{|l|}
12.8 \\
\end{tabular} & 14.5 & 15 & 17 & 18 & 19 & 20 & 21 & 22 & 23 & \begin{tabular}{|l|}
23.8 \\
\end{tabular} & 24.5 & 25 & 26 & 27 & 28 & 28.5 & 29 & 30 & 30.5 & 31 & 32 & 32.8 & 33 & 34 & 35 & 35 \\
\hline $1 \%$ Li & 62 & 4.5 & 7 & 9 & 11 & 12.8 & 14 & 15 & 17 & 17.5 & 18.5 & 19 & 21 & 21.5 & 22 & 23 & 24 & 25 & 25 & 26 & 27 & 27.6 & 28 & 29 & 30 & 31 & 31 & 31.5 & 32 & 33 & 33 & 34 \\
\hline $2 \% \mathrm{~L}$ & 1.425 & 4.75 & \begin{tabular}{|l|l|}
5 & 7.25 \\
\end{tabular} & 9.5 & \begin{tabular}{|l|}
11.5 \\
\end{tabular} & \begin{tabular}{|l|}
13.4 \\
\end{tabular} & 14.8 & 16 & 17.5 & 18.5 & 5 & 20.3 & 22 & 22.8 & 23.3 & 24 & 25 & 26 & 27 & 27.5 & 28 & 28.8 & 30 & 30.5 & 31.3 & 32 & 33 & 33 & 33.5 & 34 & 35 & 35 \\
\hline $3 \% \mathrm{Li}$ & 23 & & \begin{tabular}{l|l|}
5 & 7.5 \\
\end{tabular} & 10 & \begin{tabular}{|l|}
12 \\
\end{tabular} & \begin{tabular}{|l|}
14 \\
\end{tabular} & 15.5 & 17 & 18 & 19.5 & 20.5 & 21.5 & 23 & 24 & 24.5 & 25 & 26 & 27 & 28 & 29 & 30 & 30 & 31 & 32 & 32.5 & 33 & 34 & 34.5 & 35 & 36 & 36 & 37 \\
\hline $0.5 \% \mathrm{MgOH}_{2}$ & 73 & 2 & 4 & 5 & 6 & 7 & 7.5 & 8 & 8.9 & 9 & 9.7 & 10 & 10 & 11 & 11.5 & 11.8 & 12 & 13 & 13 & 13.1 & 13 & 13.9 & 14 & 14.5 & 14.9 & 15 & 15 & 15.6 & 15.9 & 16 & 17 & 17 \\
\hline $2 \% \mathrm{Mg}$ & 15 & 3.5 & 5.5 & 7.5 & 9 & \begin{tabular}{|l|}
10.7 \\
\end{tabular} & 11.5 & 12.85 & 14 & 14.6 & 15.25 & 16.3 & 17 & \begin{tabular}{|l|}
17.5 \\
\end{tabular} & 18.3 & 18.8 & 19.6 & 20 & 21 & 21.5 & 22 & 22.5 & 23 & 23.8 & 24.2 & 25 & 25 & 25.5 & 26 & 27 & 27 & 27 \\
\hline $3 \% \mathrm{Mg}$ & 39 & 4 & 6 & 8 & 10 & 11.5 & 12.5 & 13.8 & 15 & 15.7 & 16.5 & 17.5 & 18 & 19 & 19.5 & 20 & 21.1 & 22 & 22 & 22.9 & 24 & 24 & 25 & 25.5 & 26 & 27 & 27 & 27.5 & 28 & 29 & 29 & 30 \\
\hline $0.5 \% \mathrm{~L}$ & 1.19 & 3 & 5.5 & 7 & 9 & 10 & 11 & 12 & 13 & \begin{tabular}{|l|}
14 \\
\end{tabular} & 15 & 16 & 17 & 17 & 18 & \begin{tabular}{|l|}
18.5 \\
\end{tabular} & 19 & 20 & 21 & 21 & 22 & 22 & 22 & 23.5 & 24 & 25 & 25 & 25.4 & 26 & 27 & 27 & 28 \\
\hline 1\%Li & 1.34 & 4 & 6 & 8 & 10 & 11 & 12 & 13.5 & \begin{tabular}{|l|}
14.5 \\
\end{tabular} & 15.2 & 16 & 17 & 18 & 18.9 & 19 & 20 & 20.5 & 21 & 22 & 22 & 23 & 23.5 & 24 & 24.5 & 25 & 26 & 26 & 27 & 27.4 & 28 & 28 & 29 \\
\hline 29 & 1.5 & 4.5 & 6.5 & 8.75 & 10.5 & 12 & 13 & 14.25 & \begin{tabular}{|l|}
15.5 \\
\end{tabular} & 16.2 & 17 & 18 & 19 & 20 & 20.5 & \begin{tabular}{|l|}
21.3 \\
\end{tabular} & 21.8 & 23 & 23 & 23.5 & 25 & 25 & 25 & 26 & 26.5 & 27 & 28 & 28.5 & 29 & 29 & 30 & 30 \\
\hline 3 & 1.66 & 5 & 7 & 9.5 & \begin{tabular}{|l|}
11 \\
\end{tabular} & \begin{tabular}{|l|}
12.9 \\
\end{tabular} & 14 & 15 & 16.4 & 17.2 & 18 & 19 & 20 & 21 & 22 & 22.5 & 23 & 24 & 25 & \begin{tabular}{|l|}
25 \\
\end{tabular} & 26 & 26.5 & 27 & 27.5 & 28 & 29 & 30 & 30 & 30.5 & 31 & 32 & 32 \\
\hline 0. & & 4 & 7 & 9.8 & \begin{tabular}{|l|}
11 \\
\end{tabular} & \begin{tabular}{|l|}
13.8 \\
\end{tabular} & & 17 & \begin{tabular}{|l|}
18 \\
\end{tabular} & 19 & 20.5 & 21.7 & 23 & 23.7 & \begin{tabular}{|l|}
24.7 \\
\end{tabular} & 25.7 & 26.7 & 28 & 29 & 29 & 30 & 31 & 32 & 32.5 & 33 & 34 & 35 & 35 & 35.7 & 36 & 37 & 38 \\
\hline $1 \% \mathrm{~K}$ & & & 7.5 & 10 & \begin{tabular}{|l|}
11.5 \\
\end{tabular} & 14 & 16 & 17.5 & 19 & 20 & 21 & 22 & 23 & 24 & 25 & 26 & 27 & 28 & 29 & 30 & 31 & 31.5 & 32 & 33 & 33.5 & 35 & 35 & 35.5 & 36.5 & 37 & 38 & 39 \\
\hline & 275 & 5.25 & \begin{tabular}{|l|l|}
5 & 12.3 \\
\end{tabular} & 17 & 20.8 & 24 & 26.8 & 29.25 & \begin{tabular}{|l|}
31.5 \\
\end{tabular} & 34 & 35.5 & 38 & 40 & 41.5 & 43 & \begin{tabular}{|l|}
44.8 \\
\end{tabular} & 46.5 & 48 & 50 & 52 & 52 & 53.8 & 55 & 56 & 57.5 & 59 & 60 & 61.3 & 62.5 & 64 & 64 & 66 \\
\hline $3 \% \mathrm{KCl}$ & 385 & \begin{tabular}{|r|}
5.5 \\
\end{tabular} & $5 \quad 17$ & 24 & 30 & 34 & \begin{tabular}{|l|}
37.5 \\
\end{tabular} & 41 & 44 & 48 & 50 & 54 & 57 & 59 & 61 & \begin{tabular}{|l|}
63.6 \\
\end{tabular} & 66 & 68 & 70 & 74 & 74 & 76 & 78 & 79 & 81.5 & 84 & 85 & \begin{tabular}{|l|}
87 \\
\end{tabular} & 88.5 & 90 & 91 & 93 \\
\hline $0.5 \% \mathrm{M}$ & 1.55 & 15 & 21 & 28 & 34 & 39 & 43 & 46 & 50 & 53 & 56 & 59 & 62 & 64.5 & 67 & \begin{tabular}{|l|}
69 \\
\end{tabular} & 71.5 & 73 & 76 & 77.9 & 80 & 82 & 84 & 85 & \begin{tabular}{|r|}
88 \\
\end{tabular} & 89 & 91 & 92.5 & 94 & 96 & 98 & 100 \\
\hline $1 \% \mathrm{Mg}$ & 1.59 & 14 & 20 & 27 & 33 & 37.5 & 39 & 45.5 & \begin{tabular}{|l|}
48.9 \\
\end{tabular} & 53 & 57 & 59 & 62 & 64 & 66.5 & 69 & 71 & 73 & 76 & 77.5 & 80 & 81 & 83 & 85 & \begin{tabular}{|l|}
86.5 \\
\end{tabular} & 89 & 90 & 92 & 93.5 & 95 & 97 & 98 \\
\hline $2 \% \mathrm{MgCl}_{2}$ & 1.6075 & 13.5 & 5 & 26 & 32 & \begin{tabular}{|l|}
36.3 \\
\end{tabular} & 39 & 44 & \begin{tabular}{|l|}
47 \\
\end{tabular} & 50.5 & 54.25 & 58.3 & 60 & 61.8 & 64 & 66.5 & 68.3 & 71 & 73 & 74.8 & 77 & 78.3 & 80 & 82.3 & 83.5 & 86 & 87 & 88.8 & 90.3 & 92 & 94 & 95 \\
\hline $3 \% \mathrm{MgCl}_{2}$ & 1.625 & 13 & 19 & 25 & 31 & 35 & 39 & 42.5 & 45 & 48 & \begin{tabular}{|l|} 
\\
\end{tabular} & 57.5 & 58 & 59.5 & 61.5 & 64 & 65.5 & 69 & 71 & 72 & 74 & 75.5 & 78 & 79.5 & 80.5 & 83 & 84 & 85.5 & 87 & 89 & 90 & 92 \\
\hline $0.5 \% \mathrm{CaOH}_{2}$ & 65 & 30 & 40 & 63 & 71 & 79 & 87 & 95 & 103 & 111 & 119 & 127 & 135 & 143 & 151 & 159 & \begin{tabular}{|l|l|}
167 & 1 \\
\end{tabular} & 173 & 179 & 185 & 191 & 197 & 203 & 209 & 215 & 221 & 227 & 233 & 239 & 243 & 247 & 251 \\
\hline $1 \% \mathrm{CaOH}_{2}$ & 2.81 & 40 & 50 & 67 & 76 & 85 & 94 & 103 & 112 & 121 & 130 & 139 & 148 & 157 & 166 & 175 & \begin{tabular}{l|l|l|}
184 & 1 \\
\end{tabular} & 191 & 198 & 205 & 212 & 219 & 226 & 233 & 240 & 247 & 254 & 261 & 268 & 272 & 275 & 279 \\
\hline $0.5 \%$ & & 4 & 6.5 & 9 & 11 & 13 & 14 & 15 & 16.5 & 17 & 18.5 & 19.5 & 20 & 21 & 22 & 22.5 & 23 & 24 & 25 & 25.5 & 26 & 26.5 & 27 & 28 & 28.5 & 29 & 30 & 30.5 & 31 & 31 & \begin{tabular}{|l|}
32 \\
\end{tabular} & 33 \\
\hline $1 \% \mathrm{Na}$ & & 5 & 7 & 10 & 12 & 14 & 16 & 17 & \begin{tabular}{|l|}
18.5 \\
\end{tabular} & 19.5 & 20 & 21 & 22 & 23 & 24 & 25.5 & 26 & 27 & 28 & 29 & 30 & 31 & 32 & 33.5 & 34 & 35 & 36 & 40 & 41 & 42 & 42 & 43 \\
\hline $2 \% \mathrm{NaCl}$ & 1.4025 & 5.25 & 8.5 & 11.8 & \begin{tabular}{|l|}
14.3 \\
\end{tabular} & \begin{tabular}{|l|}
16.5 \\
\end{tabular} & 18.5 & 19.75 & 21.5 & 22.8 & 23.75 & 25 & 26 & 27.3 & 28.5 & \begin{tabular}{|l|}
29.8 \\
\end{tabular} & 30.5 & 32 & 33 & 33.8 & 35 & 35.5 & 37 & 37.8 & 38.5 & 40 & 40 & 42.9 & 43.8 & 45 & 45 & 46 \\
\hline $3 \% \mathrm{NaCl}$ & 1.465 & 5.5 & 10 & 13.5 & \begin{tabular}{|c|}
16.5 \\
\end{tabular} & \begin{tabular}{|l|}
19 \\
\end{tabular} & 21 & 22.5 & \begin{tabular}{|l|} 
\\
\end{tabular} & \begin{tabular}{|r|}
26 \\
\end{tabular} & 27.5 & 29 & 30 & 31.5 & 33 & \begin{tabular}{|l|}
34 \\
\end{tabular} & 35 & 36 & 37 & 38.5 & 39 & \begin{tabular}{|l|}
40 \\
\end{tabular} & 41 & 42 & \begin{tabular}{|r|} 
\\
\end{tabular} & 44 & 45 & 45.7 & 46.5 & 48 & 48 & 49 \\
\hline
\end{tabular}

Table A.2: Filtration Analysis of Base Drilling Fluids 


\begin{tabular}{|c|c|c|}
\hline $\begin{array}{c}\text { Extreme High Loss } \\
\text { Systems }\end{array}$ & High Loss Systems & Low Loss Systems \\
\hline $0.5 \% \mathrm{CaOH}+5 \%$ Aquagel & $0.5 \% \mathrm{ZnCl}+5 \%$ Aquagel & $1 \% \mathrm{NaCl}-5 \%$ Aquagel \\
\hline $1 \% \mathrm{CaOH}+5 \%$ Aquagel & $1 \% \mathrm{ZnCl}+5 \%$ Aquagel & $1 \% \mathrm{KCl}-5 \%$ Aquagel \\
\hline $3 \% \mathrm{CaOH}+5 \%$ Aquagel & $3 \% \mathrm{ZnCl}+5 \%$ Aquagel & $0.5 \% \mathrm{KCl}-5 \%$ Aquagel \\
\hline $2 \% \mathrm{CaOH}+5 \%$ Aquagel & $0.5 \% \mathrm{CaCl}+5 \%$ Aquagel & $3 \% \mathrm{LiCl}-5 \%$ Aquagel \\
\hline & $1 \% \mathrm{CaCl}+5 \%$ Aquagel & $0.5 \% \mathrm{LiCl}-5 \%$ Aquagel \\
\hline & $3 \% \mathrm{CaCl}+5 \%$ Aquagel & $1 \%$ LiCl-5\% Aquagel \\
\hline & $3 \% \mathrm{KCl}+5 \%$ Aquagel & $0.5 \% \mathrm{NaCl}-5 \%$ Aquagel \\
\hline & $3 \% \mathrm{MgCl}+5 \%$ Aquagel & $3 \% \mathrm{LiOH}-5 \%$ Aquagel \\
\hline & $1 \% \mathrm{MgCl}+5 \%$ Aquagel & $3 \% \mathrm{MgOH}-$ Aquagel \\
\hline & $3 \% \mathrm{MgCl}+5 \%$ Aquagel & $1 \% \mathrm{LiOH}-5 \%$ Aquagel \\
\hline & $2 \% \mathrm{CaCl}+5 \%$ Aquagel & $5 \%$ Aquagel \\
\hline & $2 \% \mathrm{ZnCl}+5 \%$ Aquagel & $0.5 \%$ LiOH-5\%Aquagel \\
\hline & $2 \% \mathrm{KCl}+5 \%$ Aquagel & $1 \% \mathrm{MgOH}-5 \%$ Aquagel \\
\hline & & $0.5 \% \mathrm{MgOH}-5 \%$ Aquagel \\
\hline & & $2 \% \mathrm{LiCl}-5 \%$ Aquagel \\
\hline & & $2 \% \mathrm{MgOH}-5 \%$ Aquagel \\
\hline & & $2 \% \mathrm{LiOH}-5 \%$ Aquagel \\
\hline
\end{tabular}

Table A.3: Classification of Base Drilling Fluids with respect to Filtrate loss. 
APPENDIX B - FIGURES 


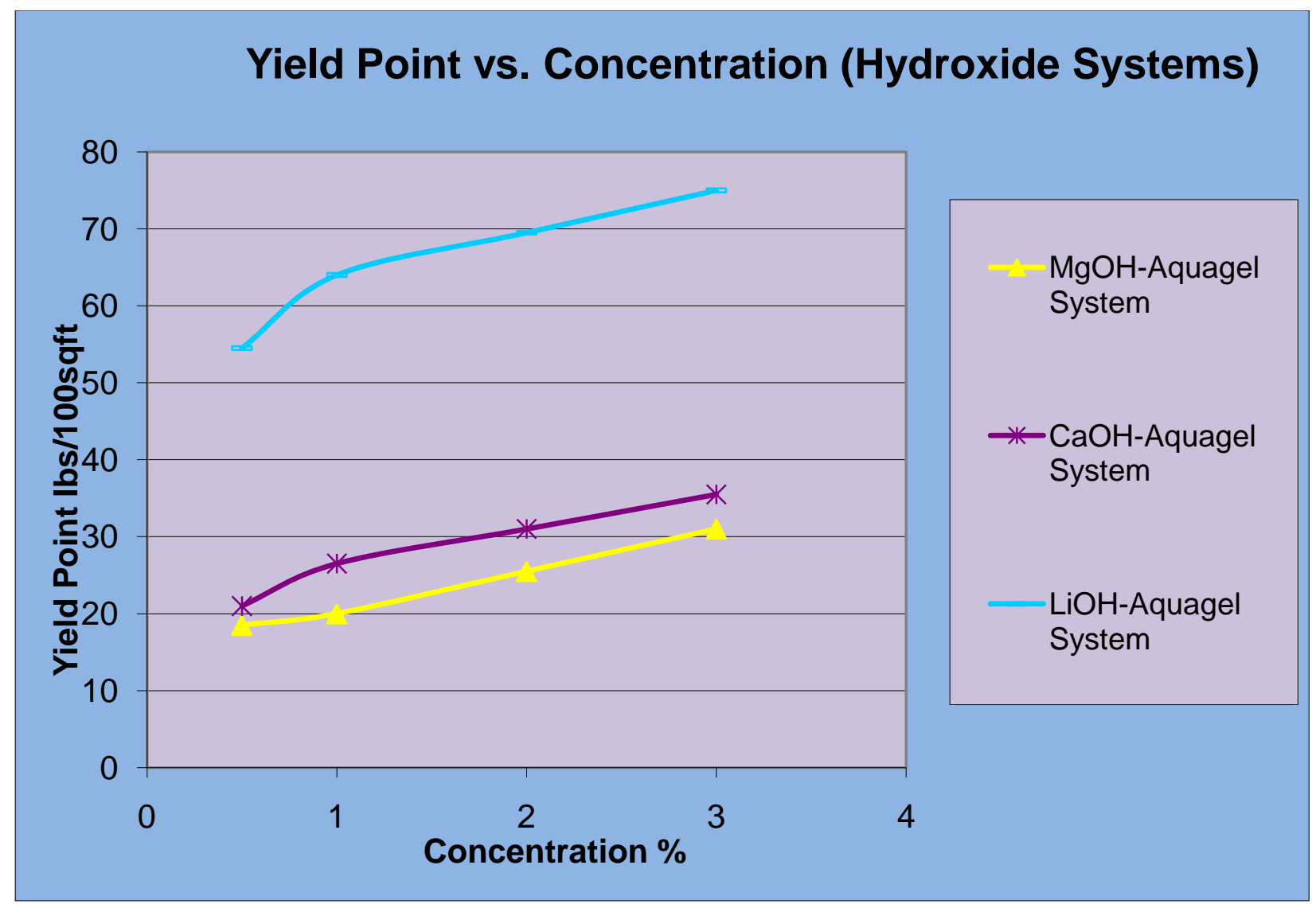

Figure B.1: Variation of Yield Point with Hydroxide concentration for Base Drilling Fluids. 


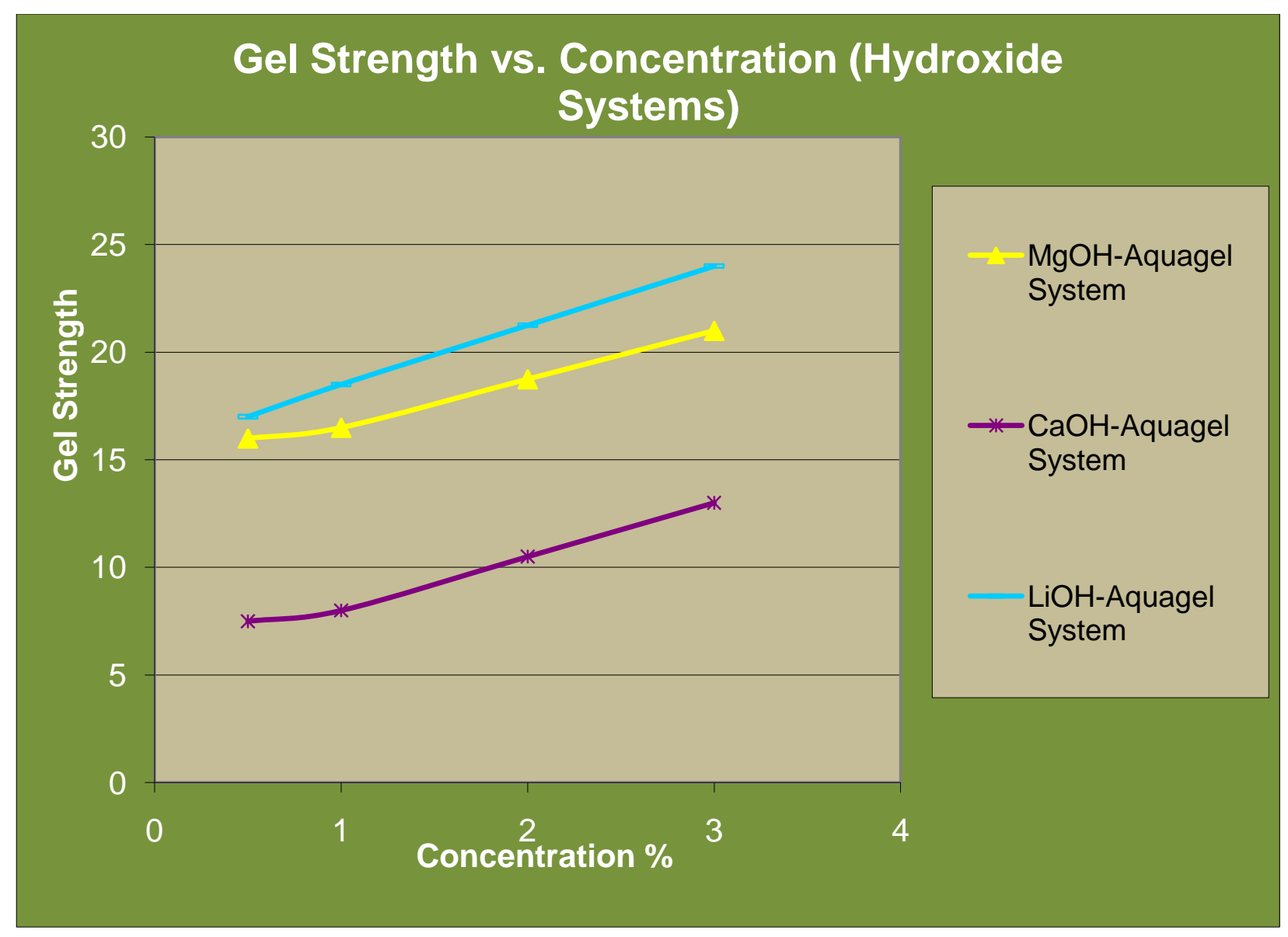

Figure B.2: Variation of Gel Strength with Hydroxide concentration for Base Drilling Fluids. 


\section{Apparent Viscosity vs. Concentration (Hydroxide Systems)}

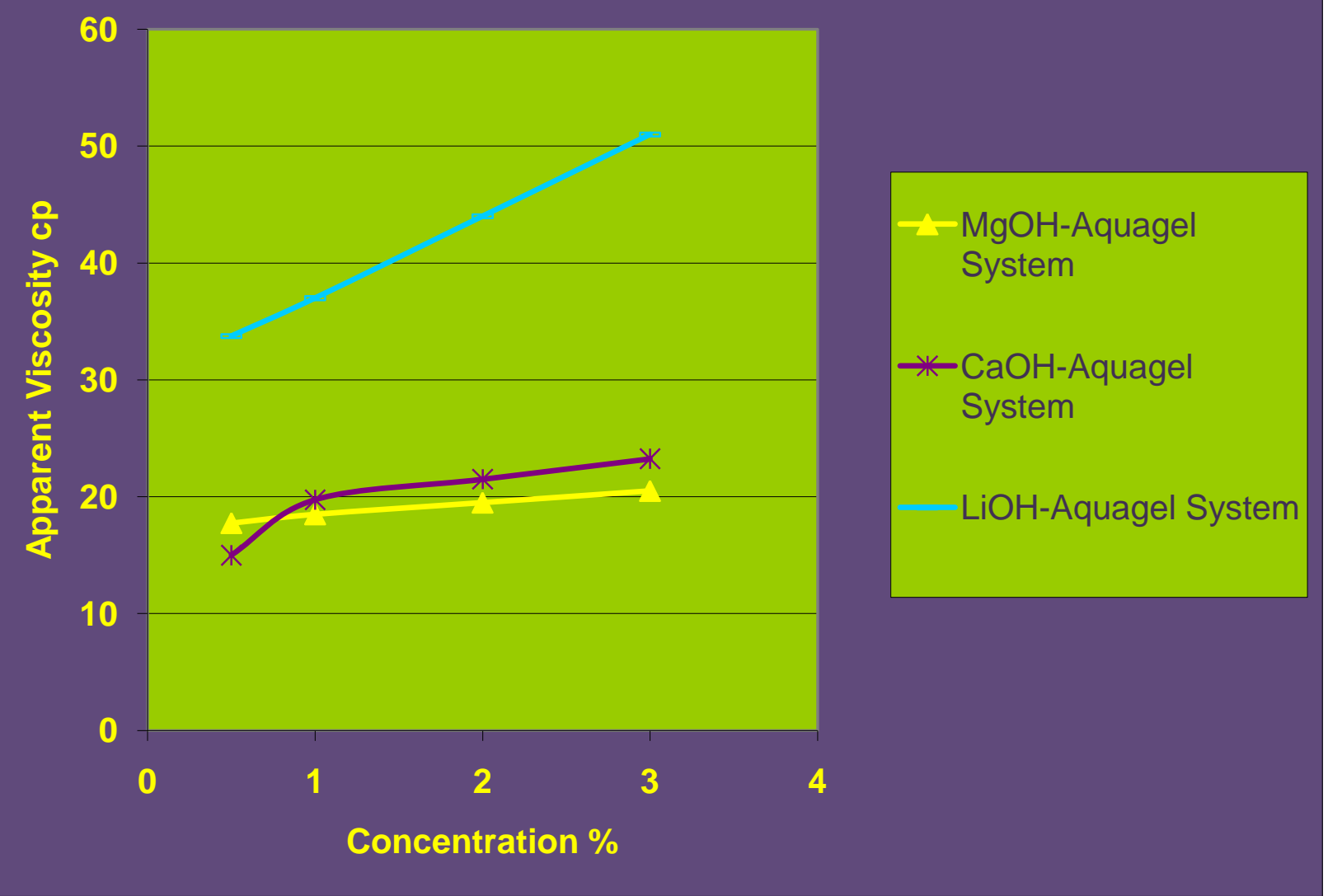

Figure B.3: Variation of Apparent Viscosity with Hydroxide concentration for Base Drilling Fluids. 


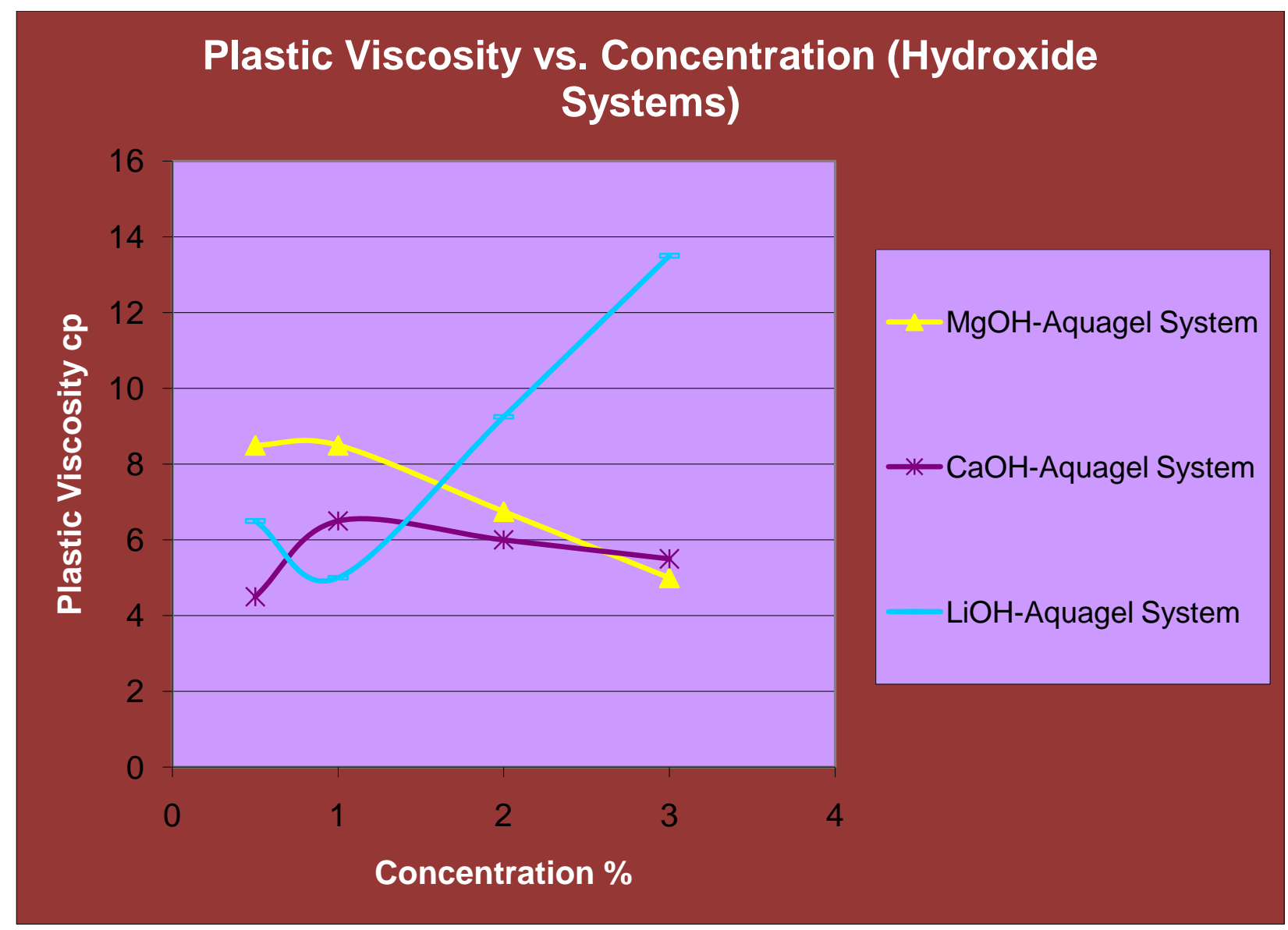

Figure B.4: Variation of Plastic Viscosity with Hydroxide concentration for Base Drilling Fluids. 


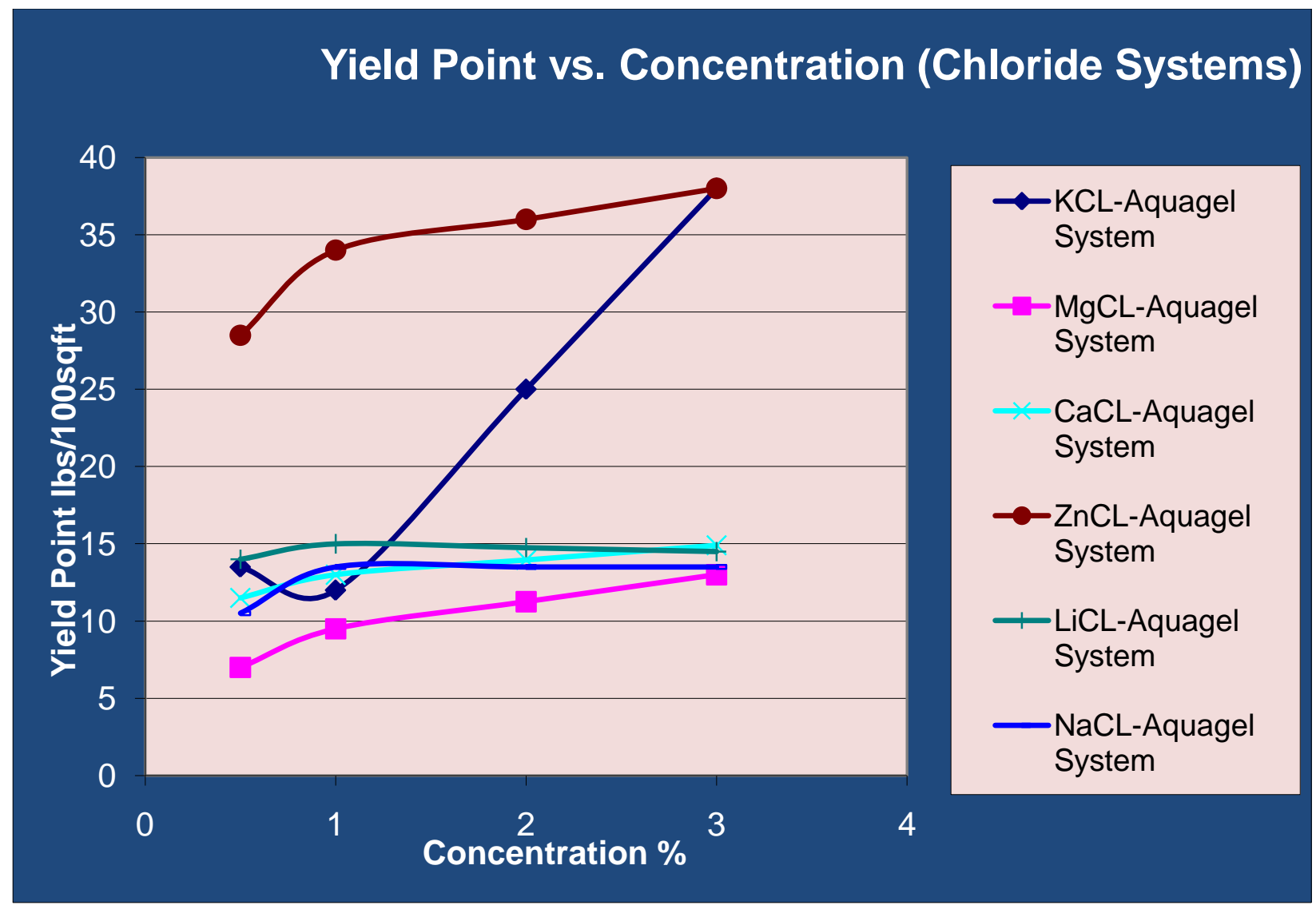

Figure B.5: Variation of Yield Point with Chloride concentration for Base Drilling Fluids. 


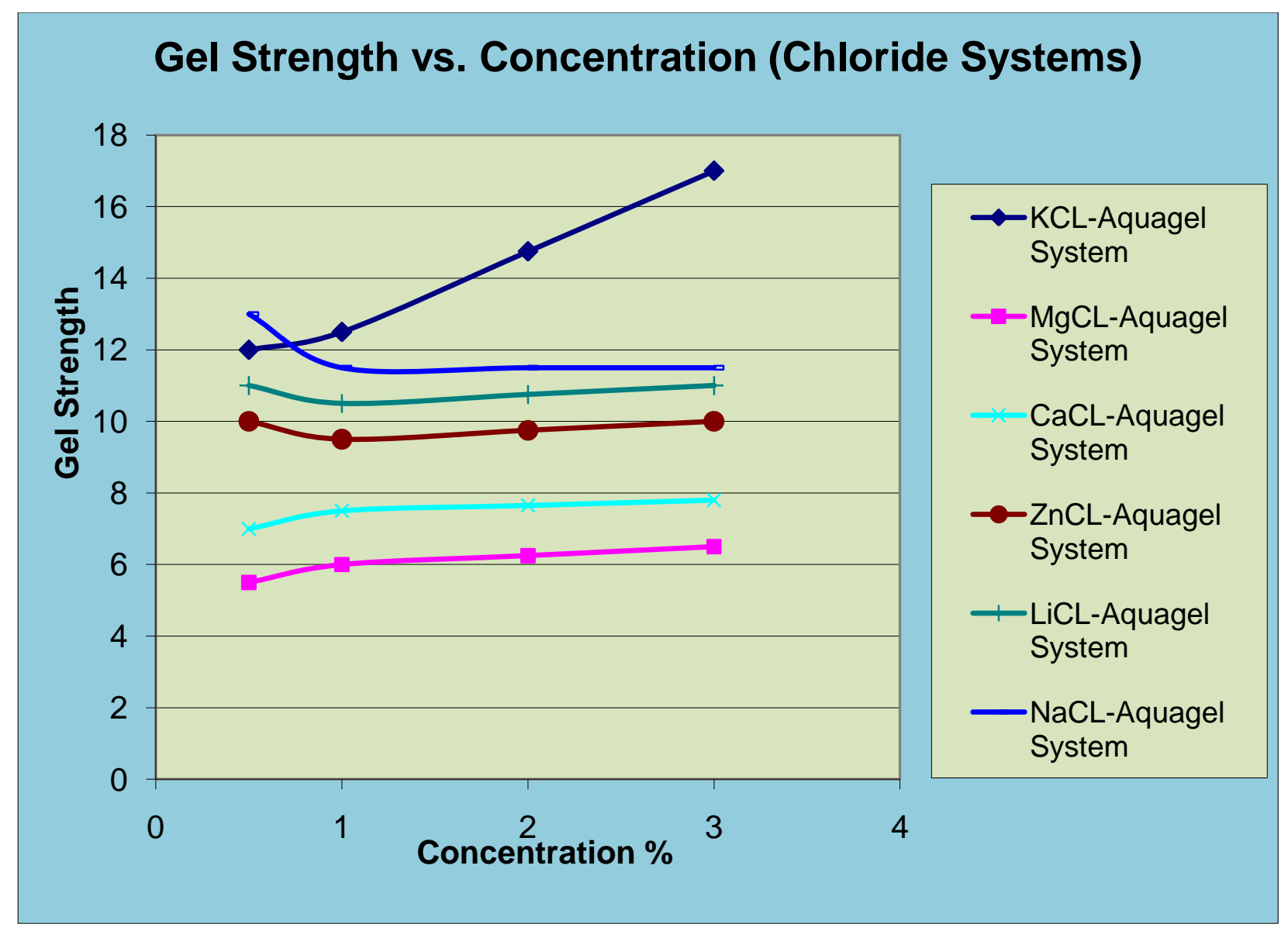

Figure B.6: Variation of Gel Strength with Chloride concentration for Base Drilling Fluids. 


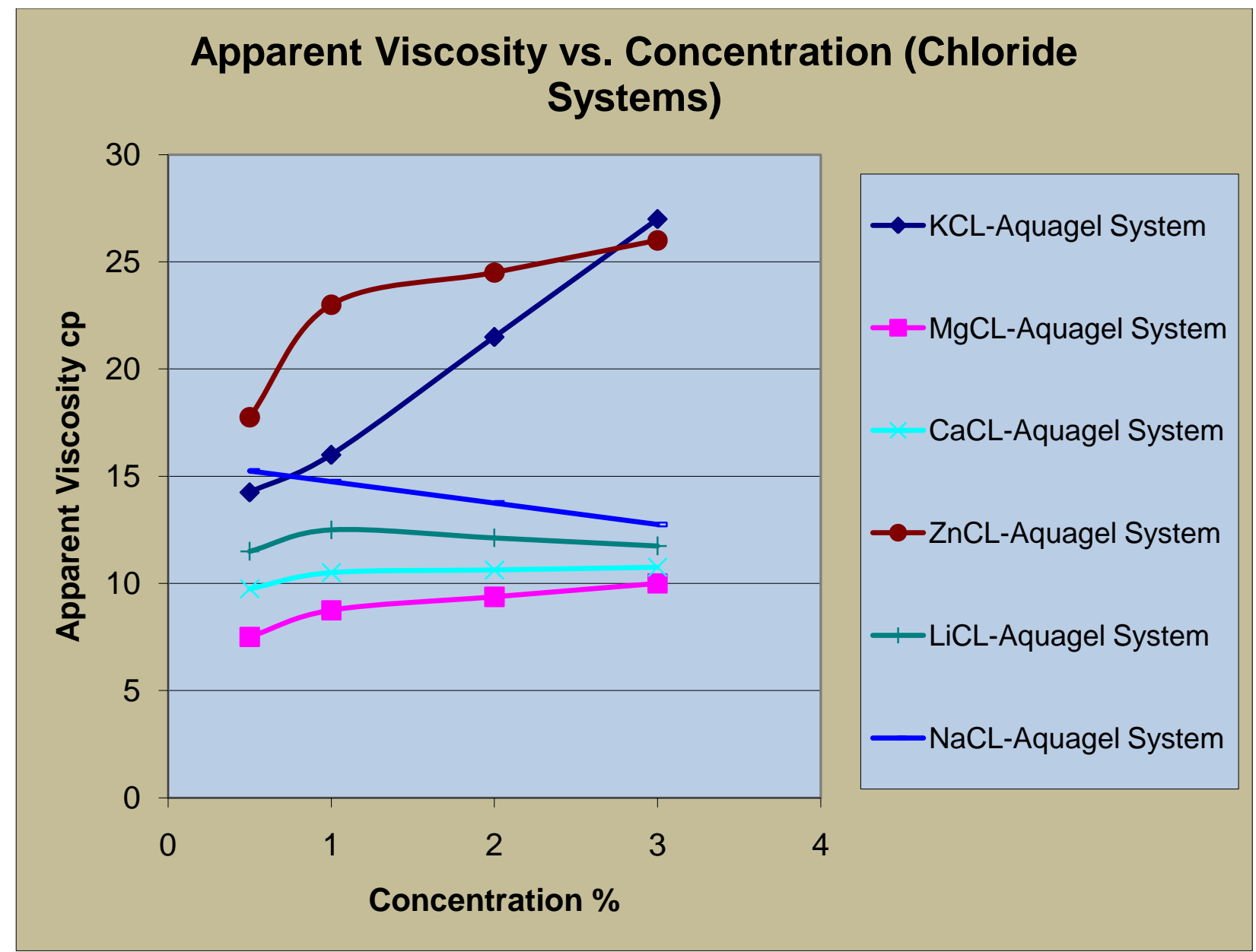

Figure B.7: Variation of Apparent Viscosity with Chloride concentration for Base Drilling Fluids. 


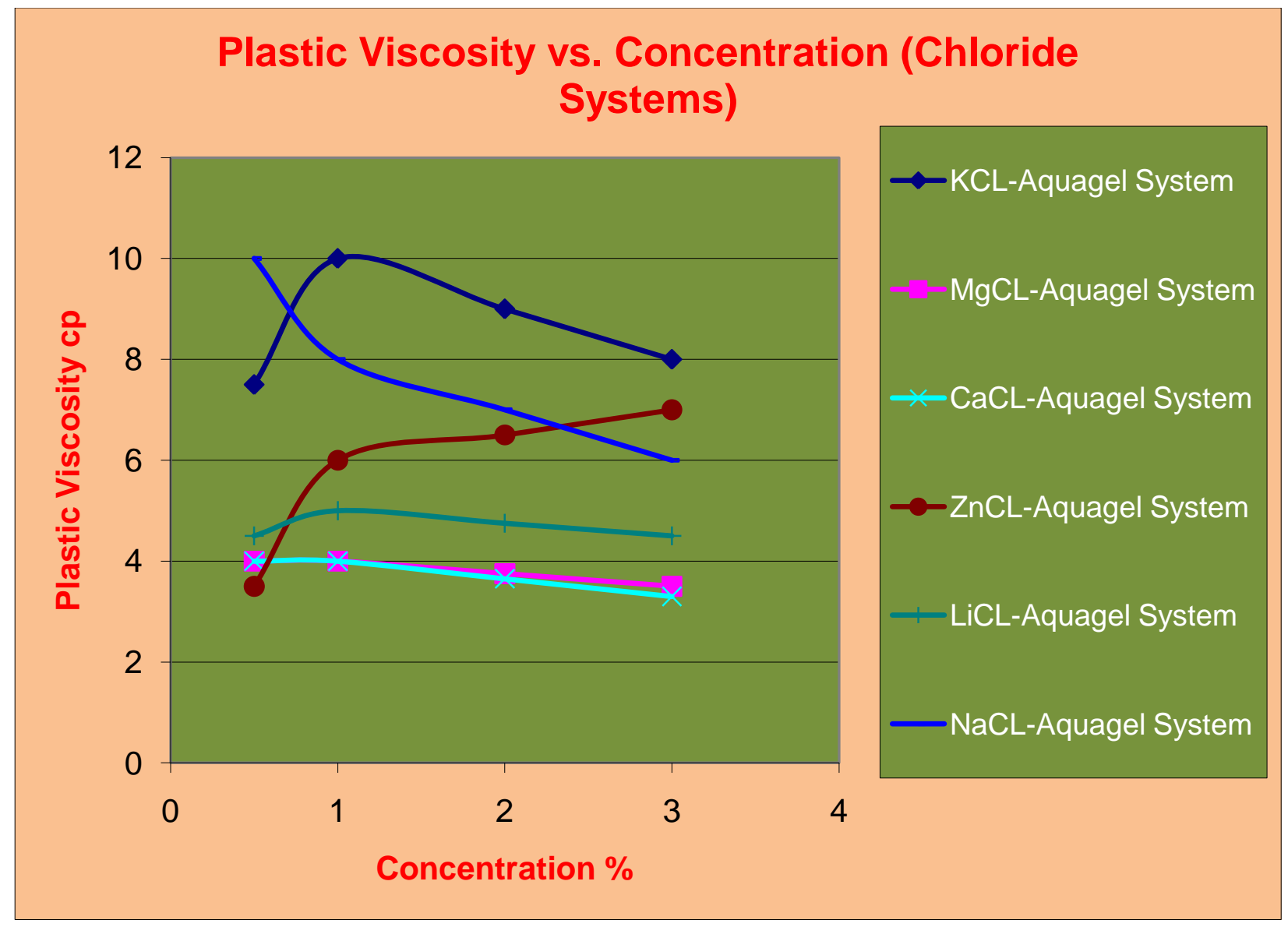

Figure B.8: Variation of Plastic Viscosity with Chloride concentration for Base Drilling Fluids. 


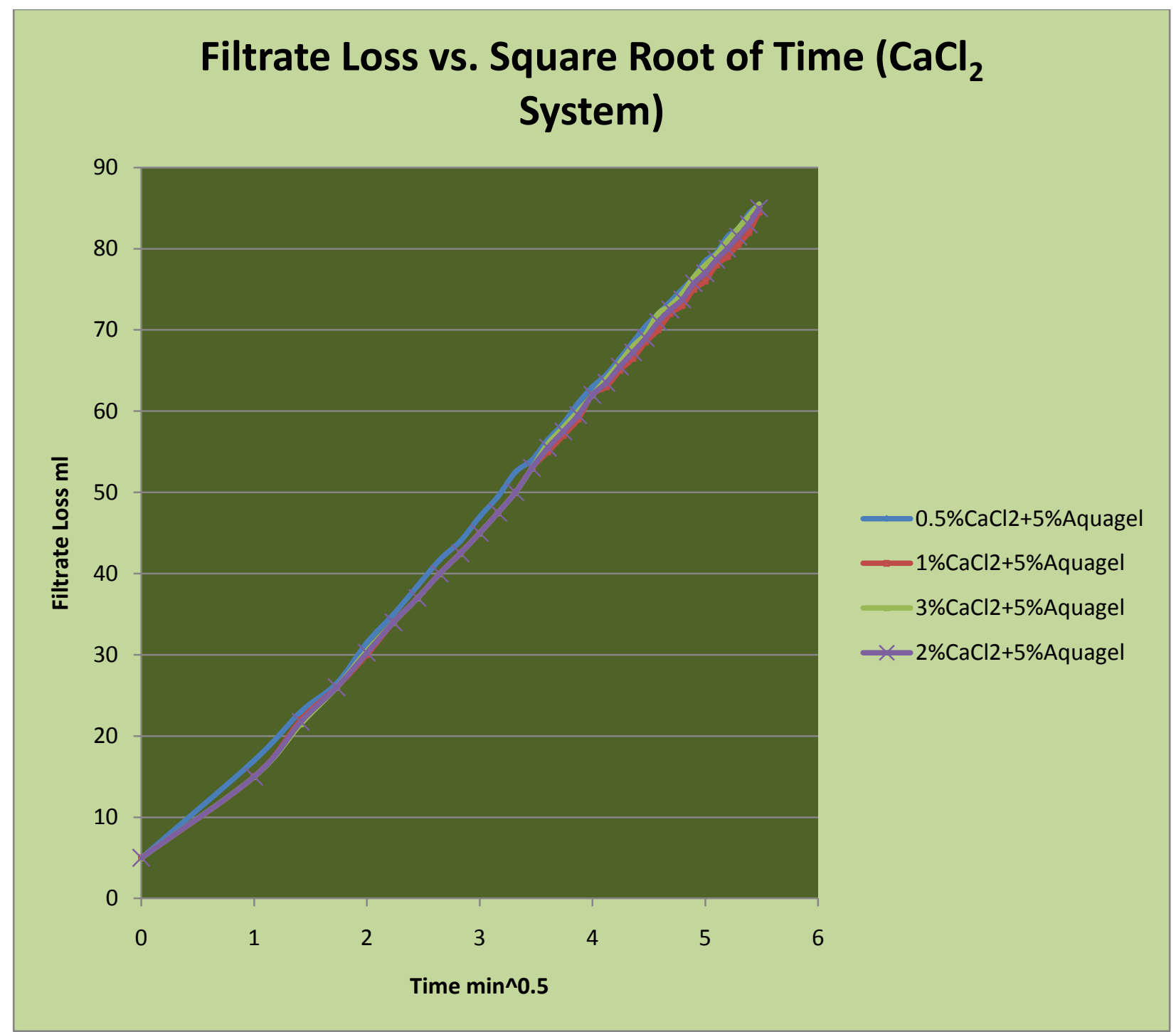

Figure B9: Variation of Filtrate loss with square root of time for $\mathrm{CaCl}_{2}$-Aquagel systems. 


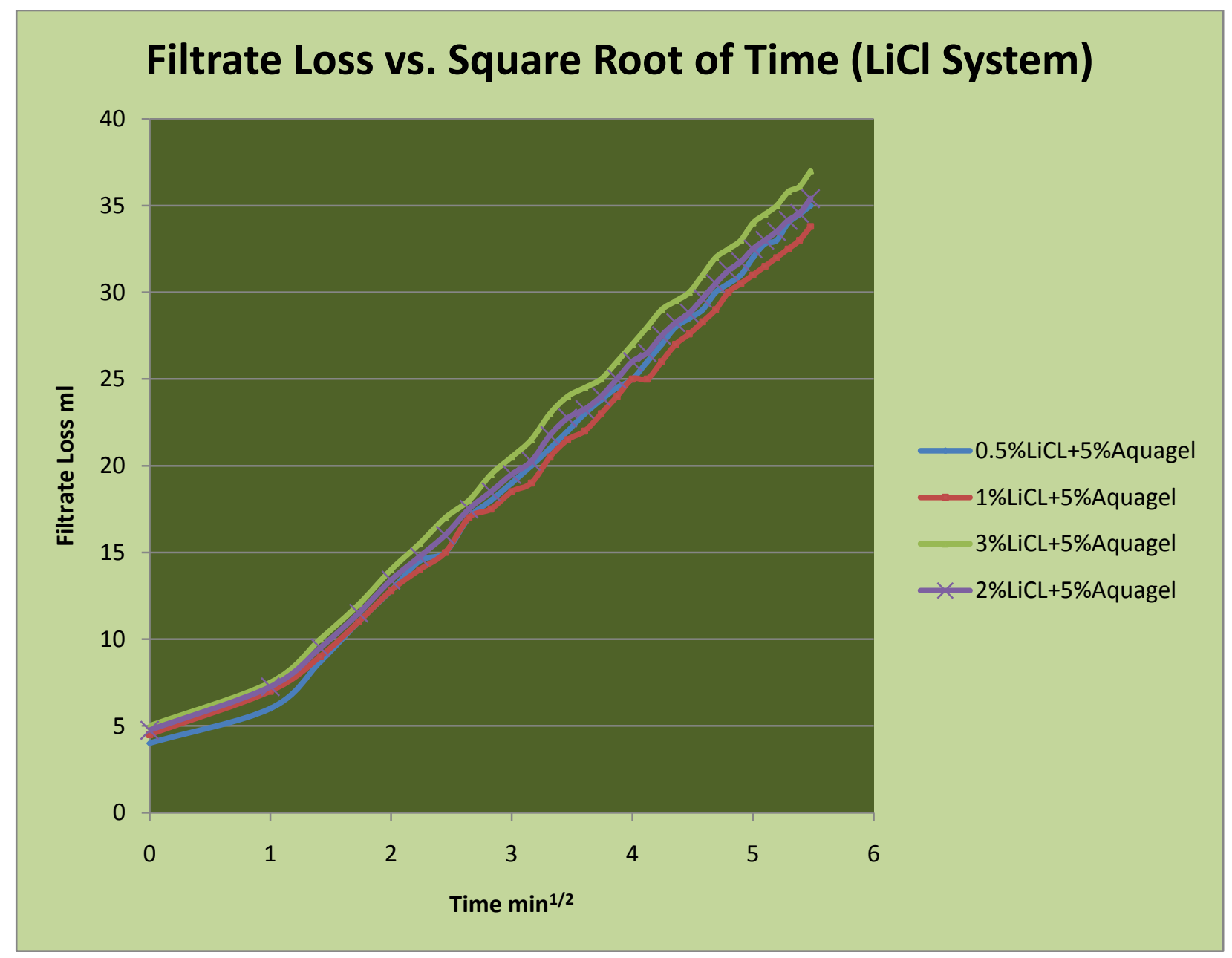

Figure B10: Variation of Filtrate loss with square root of time for LiCl-Aquagel systems. 


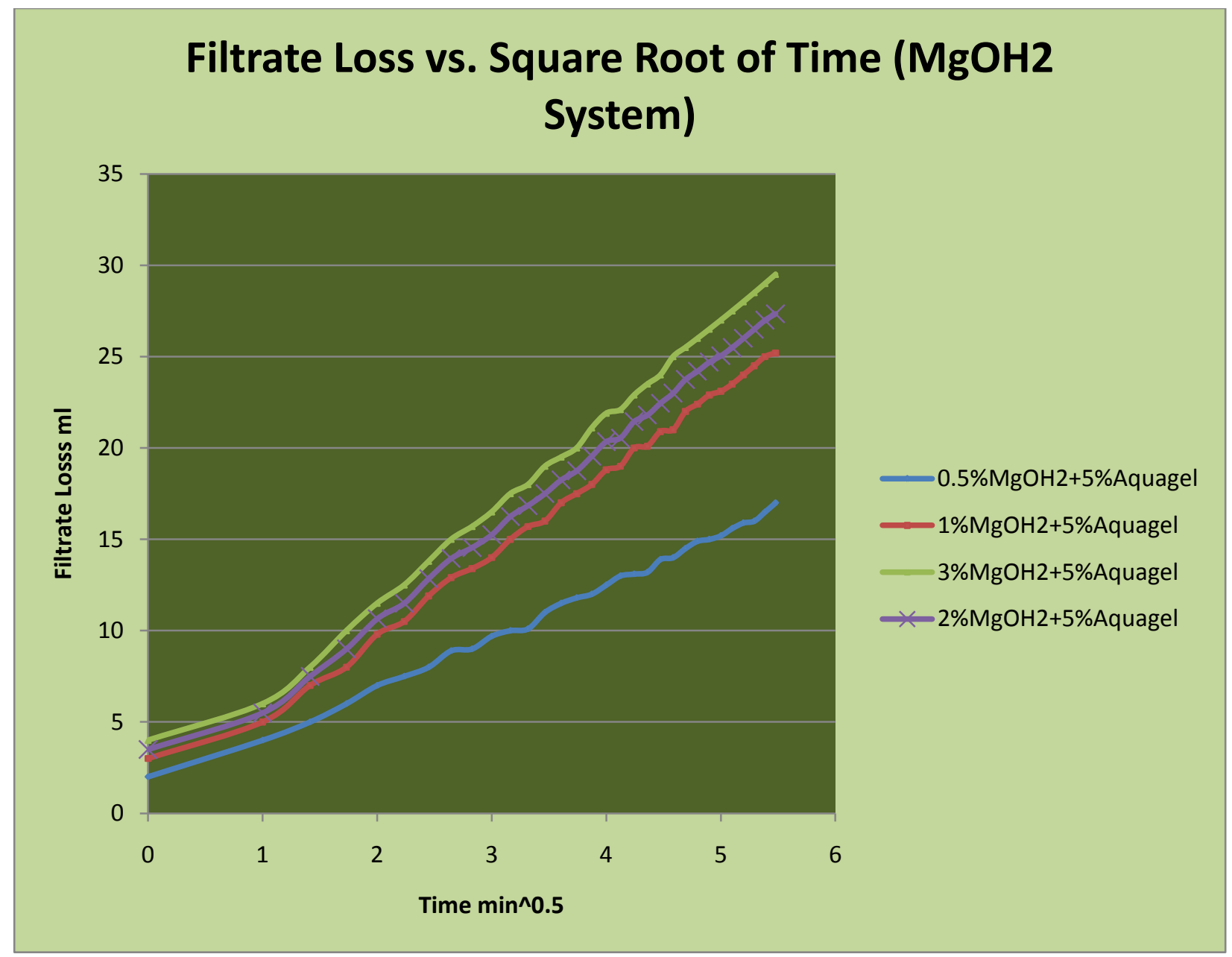

Figure B11: Variation of Filtrate loss with square root of time for $\mathrm{MH}_{2}$-Aquagel systems. 


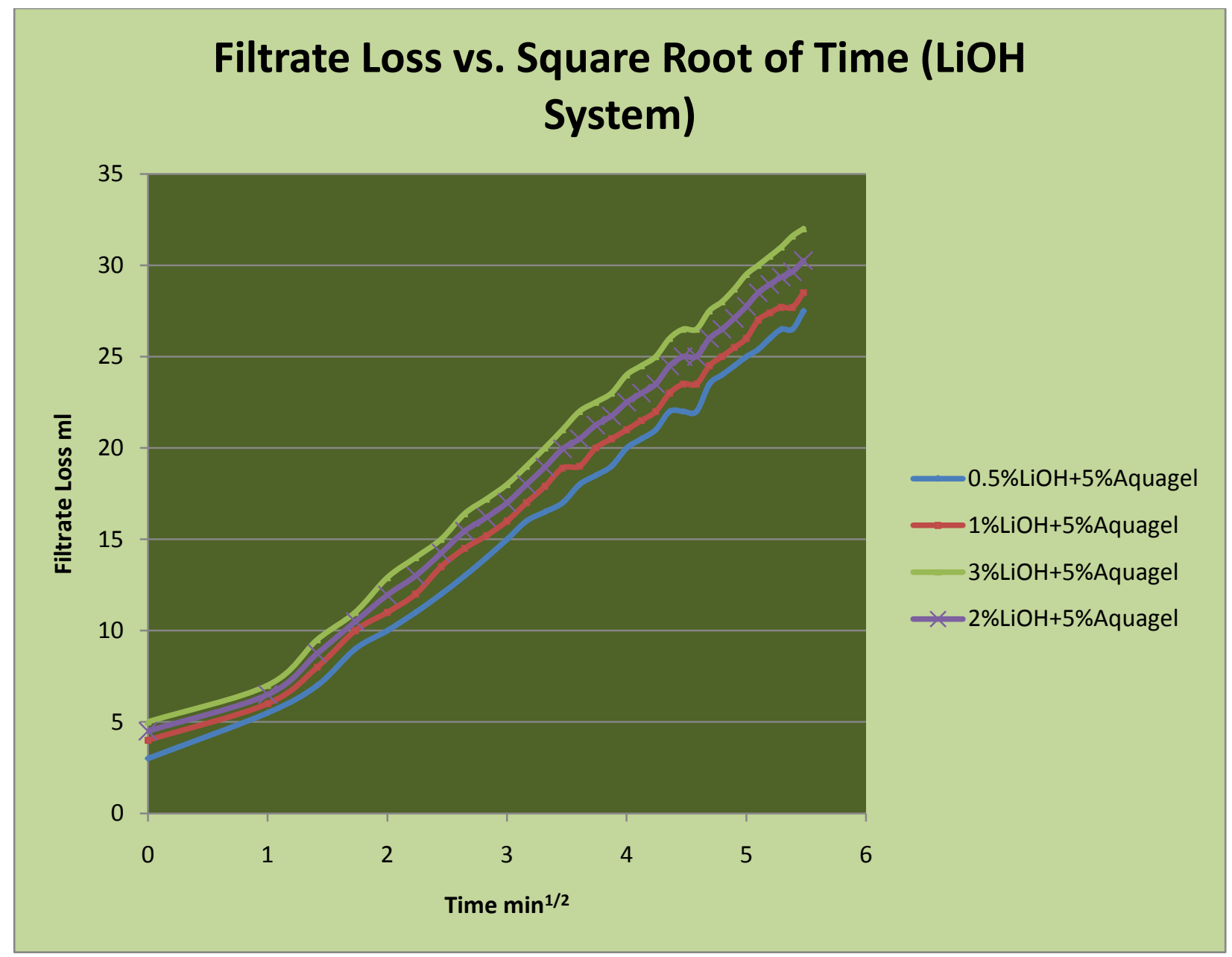

Figure B12: Variation of Filtrate loss with square root of time for LiOH-Aquagel systems. 


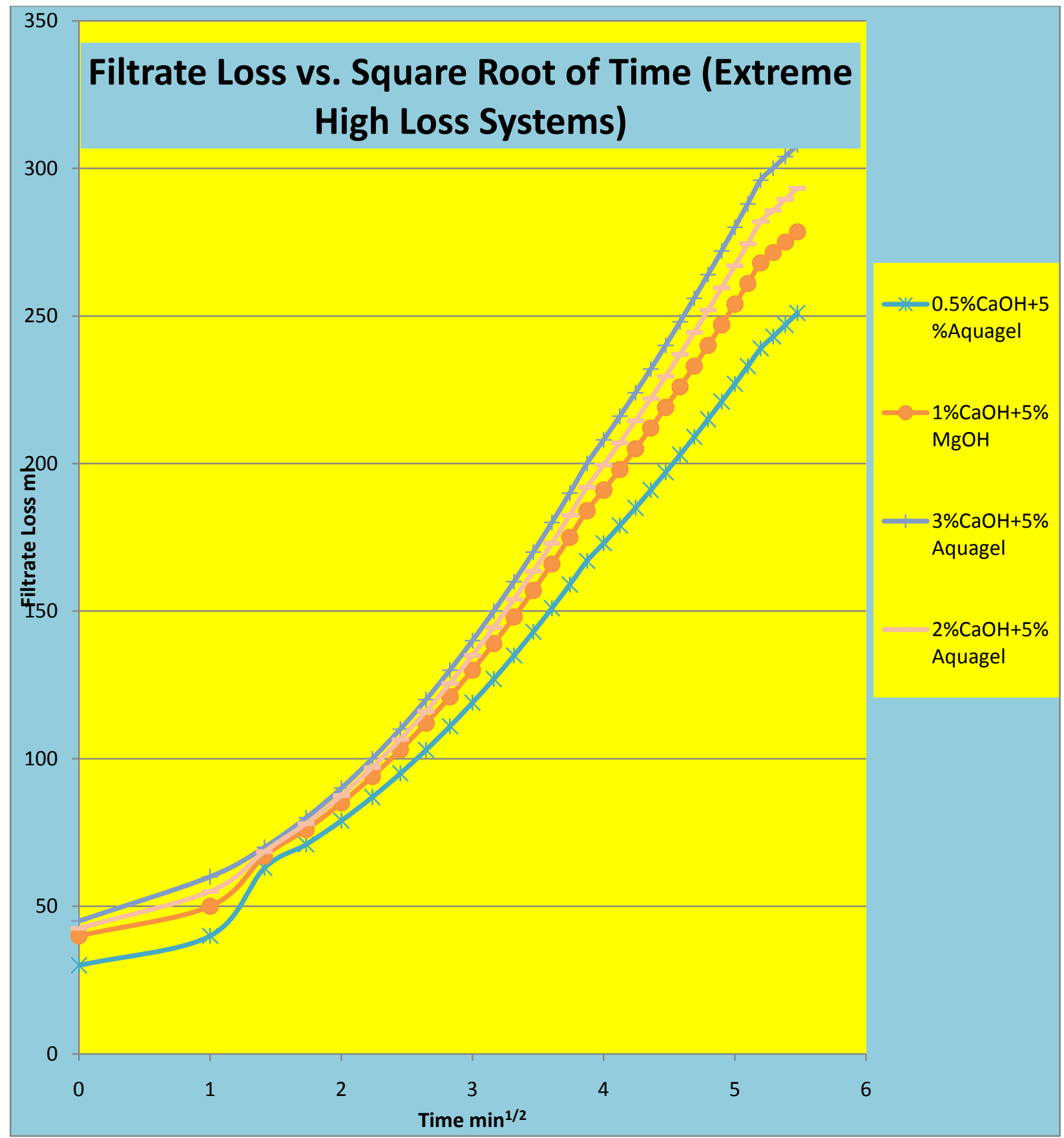

Figure B13: Variation of Filtrate loss with square root of time for Extreme high loss systems. 


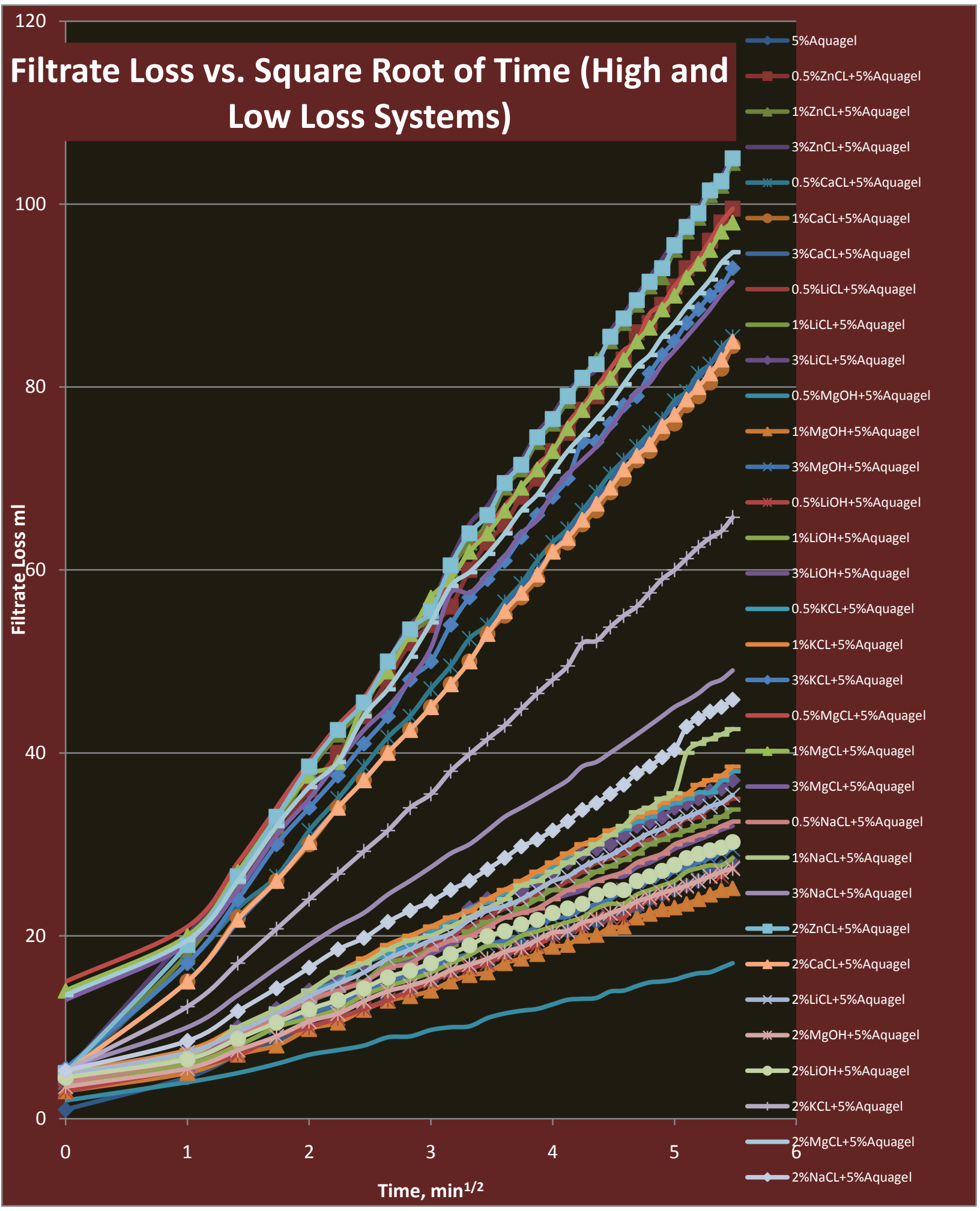

Figure B14: Variation of Filtrate loss with square root of time for High and Low systems. 


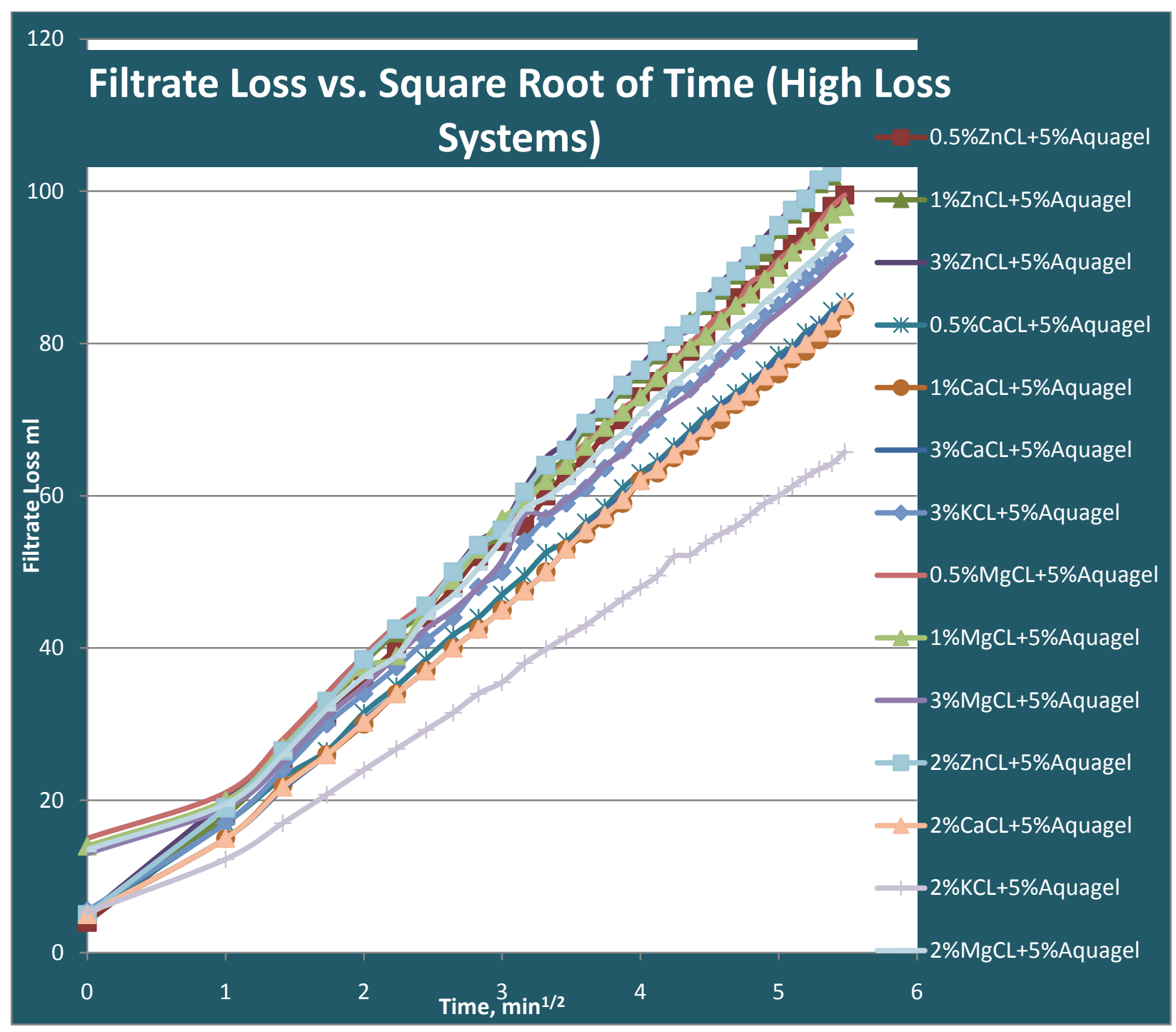

Figure B15: Variation of Filtrate loss with square root of time for High Loss systems. 


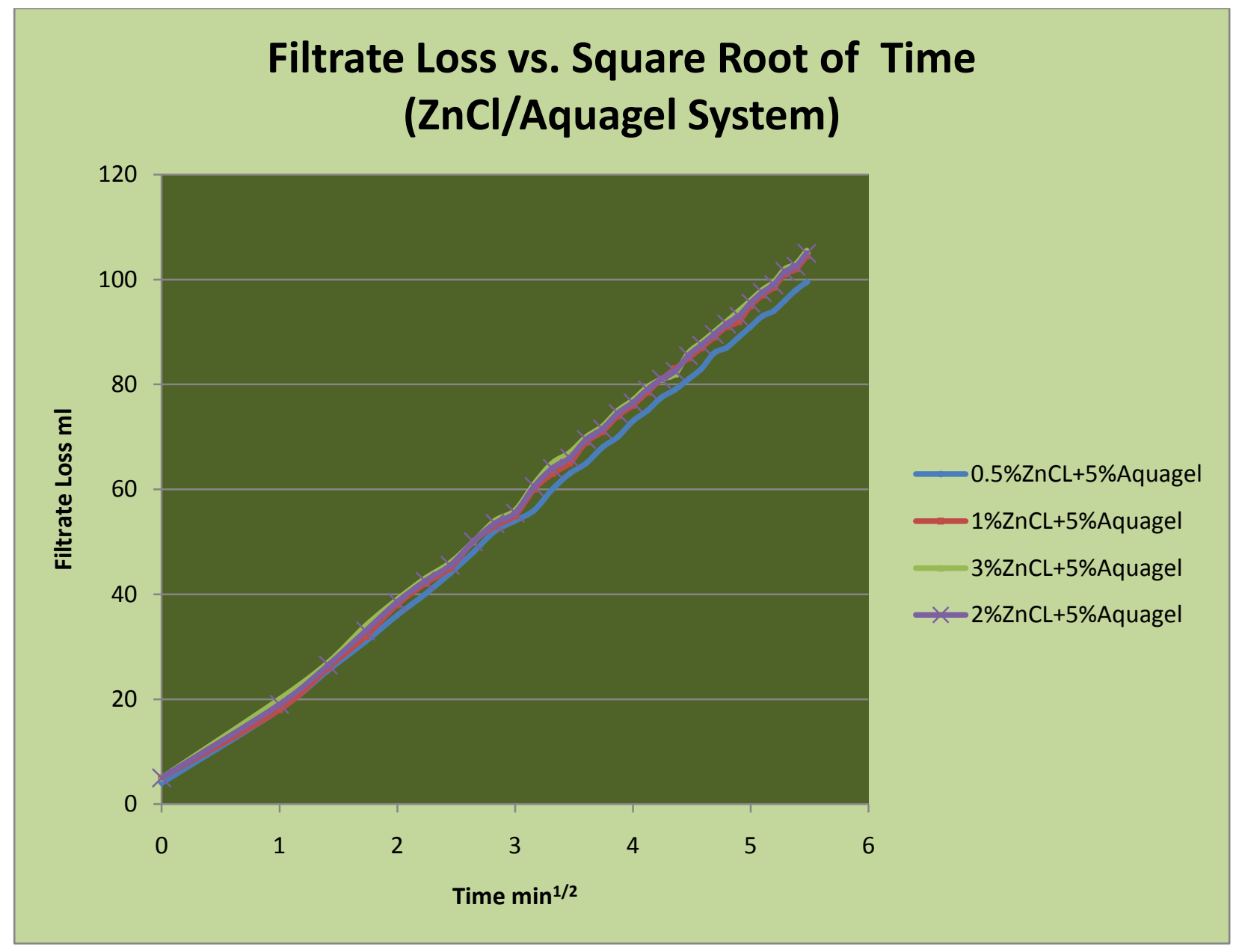

Figure B16: Variation of Filtrate loss with square root of time for ZnCl-Aquagel systems. 


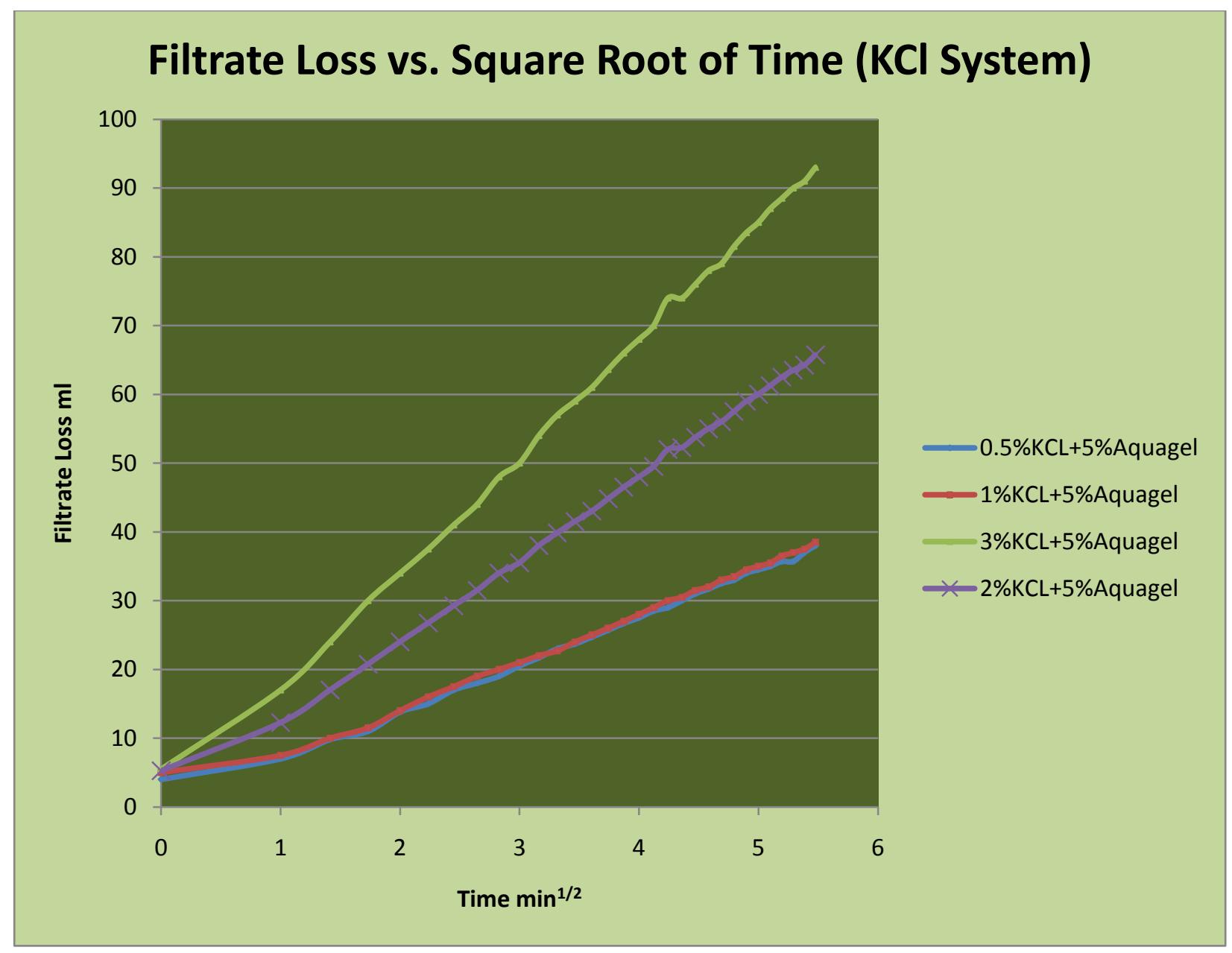

Figure B17: Variation of Filtrate loss with square root of time for KCl-Aquagel systems. 


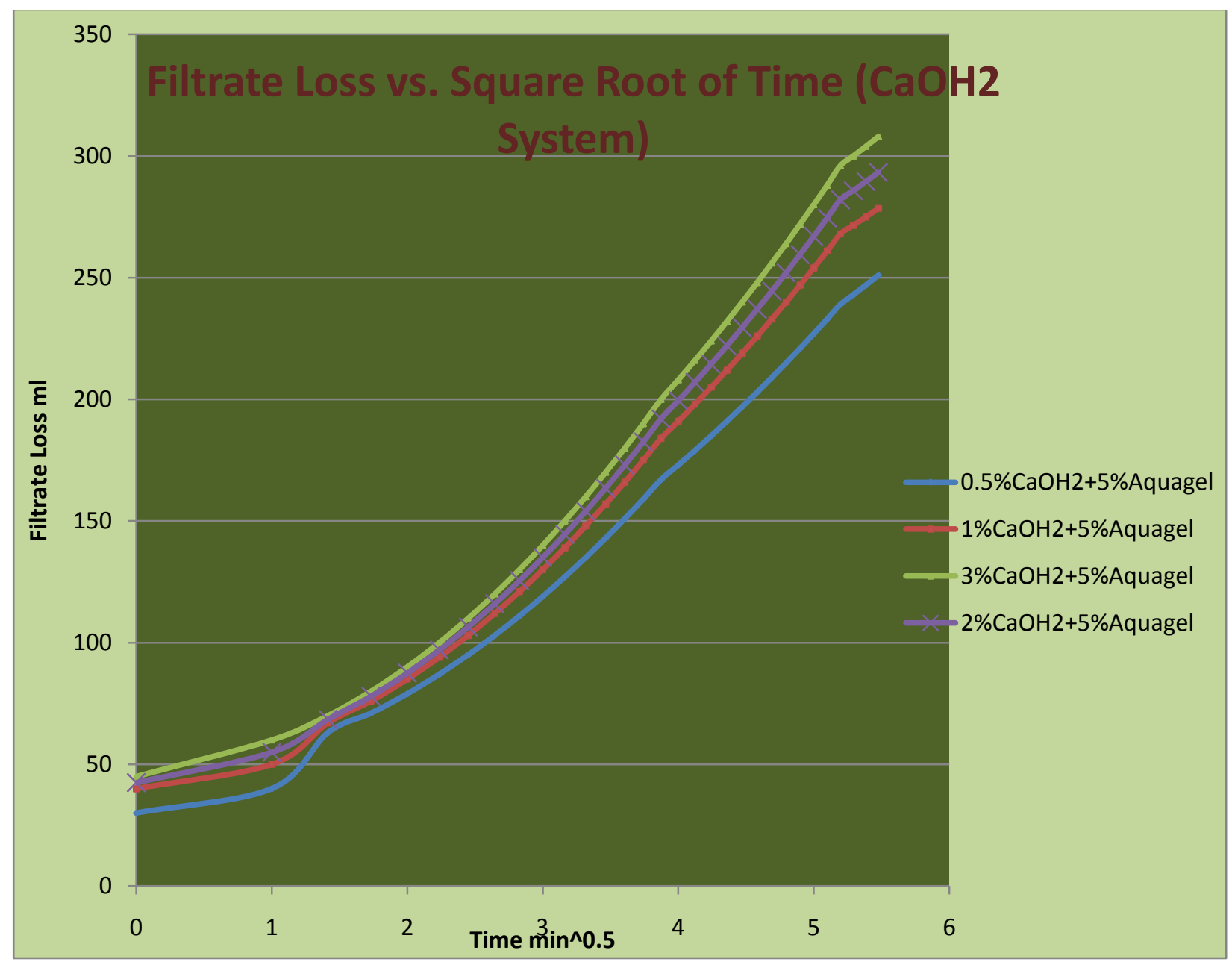

Figure B18: Variation of Filtrate loss with square root of time for $\mathrm{CaOH}_{2}$-Aquagel systems. 


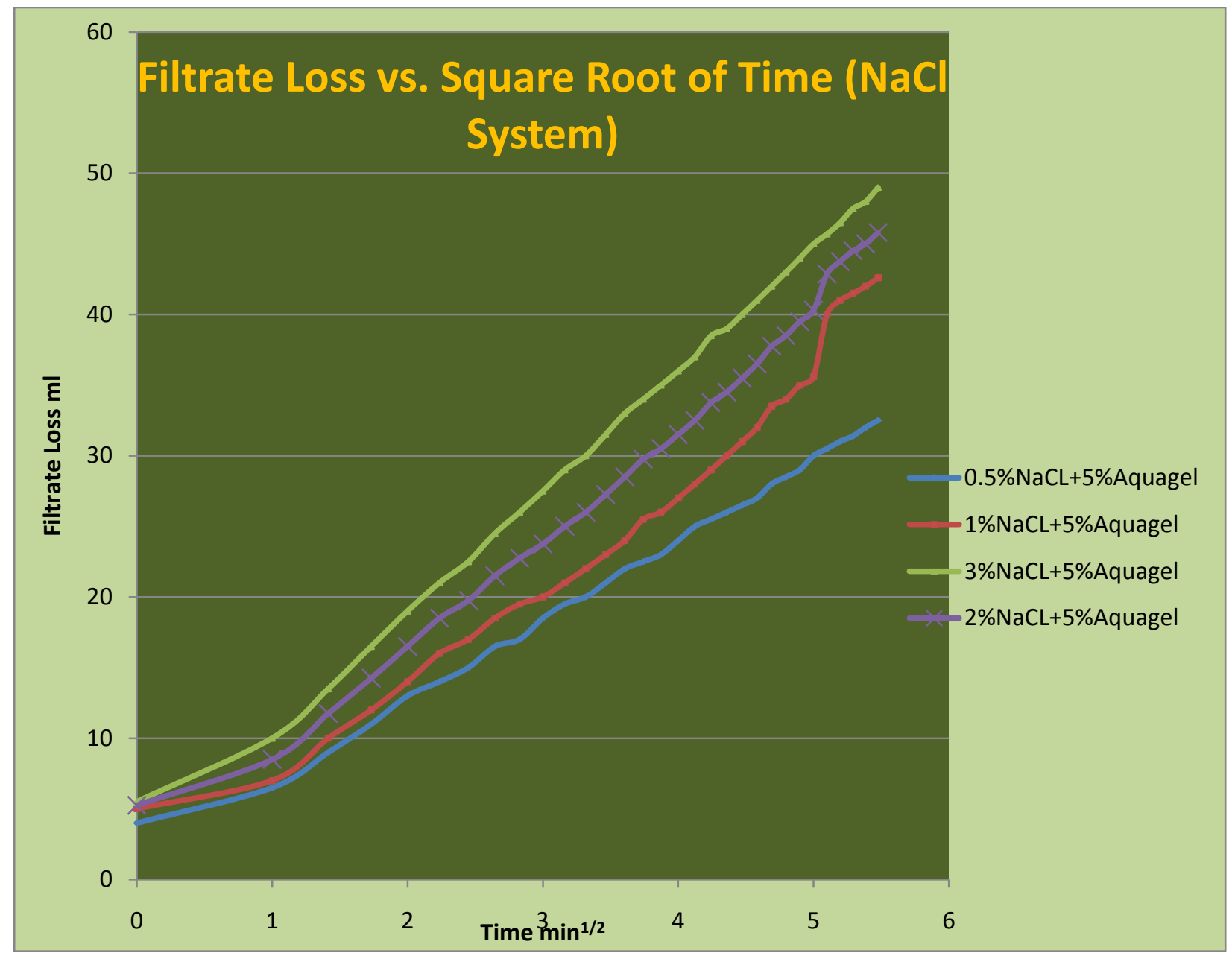

Figure B19: Variation of Filtrate loss with square root of time for NaCl-Aquagel systems. 


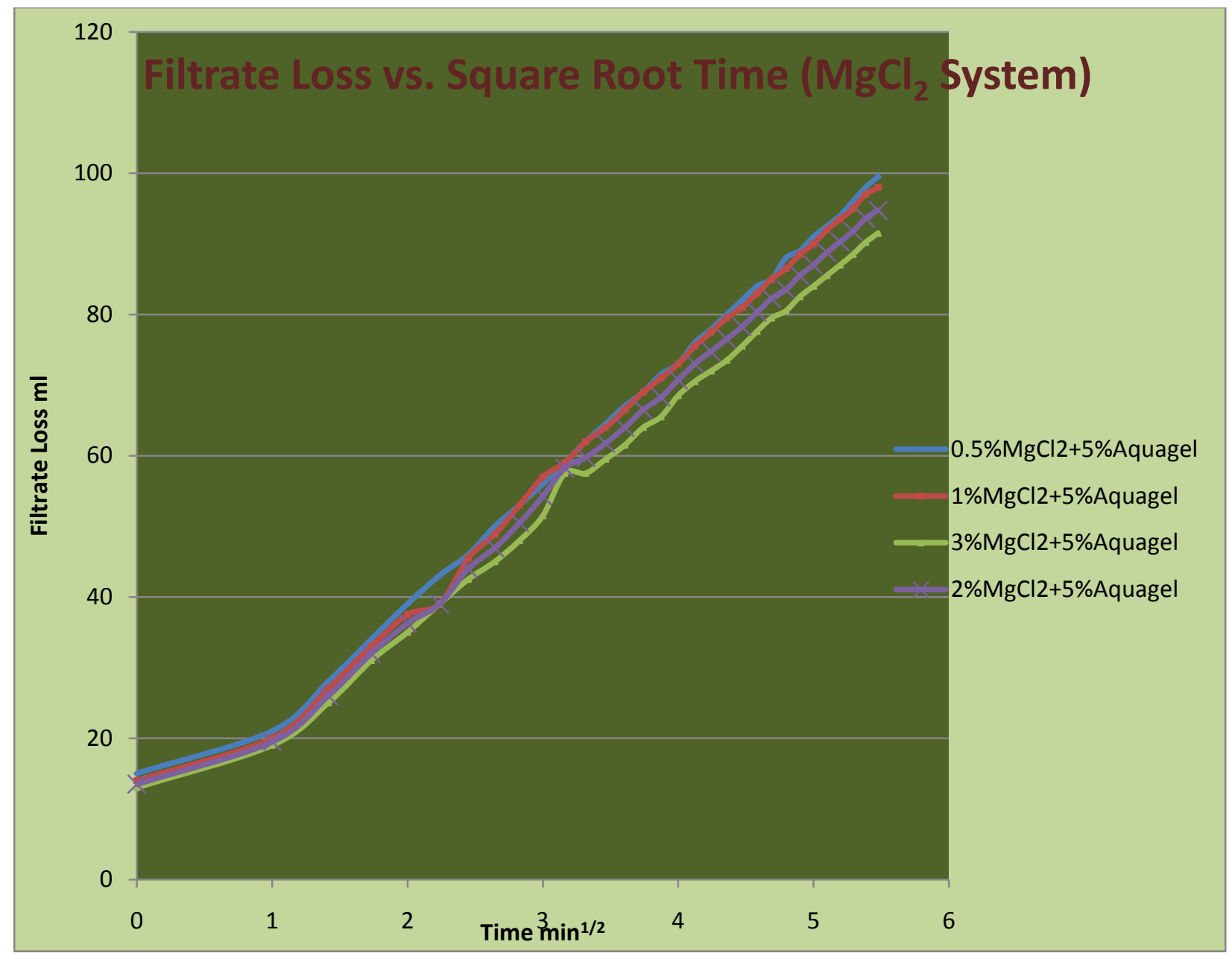

Figure B20: Variation of Filtrate loss with square root of time for $\mathrm{MgCl}_{2}$-Aquagel systems. 


\section{Bibliography}

Ike Eleanya Onuoha obtained his MS in Petroleum and Natural Gas Engineering from West Virginia University and was recently admitted into the PhD. program in Petroleum and Natural Gas Engineering at West Virginia University. His M.S. thesis focused on Drilling Fluid Optimization. He currently works for the Petroleum Engineering Analytics and Research Laboratory on a US DOE sponsored research project on The Simulation and Modeling of Enhanced Coal Bed Methane Production and Sequestration of CO2 in Un-mineable Coal Seams. His main research areas include Reservoir Simulation and Modeling, Unconventional Resources, Reservoir Characterization, Secondary Oil Recovery by Water Flooding, Drilling Fluid Optimization, CO2 Sequestration and the Application of Artificial Neural Networks and Fuzzy Logic to Reservoir Simulation and Modeling.

This research is highly dedicated to the Oil Industry, my research advisor Dr. Ilkin Bilgesu and the Head of the Petroleum Engineering Department at West Virginia University, Prof. Sam Ameri for their unwavering dedication to my academic welfare and research essentials. Again, I sincerely express my gratitude to Dr. Ilkin Bilgesu for his omnipresence during my research. Herein contains a research of the utmost importance to the Oil Industry and to all perspective Drilling Engineers who perhaps are inclined towards drilling fluid formulation and clay inhibition. Nevertheless, this research, in its infinite practicality and majesty, has evaluated several additives, some novel, which can be incorporated into drilling fluids in order to abate the swelling of Smectite clay within Shale formations. 
It is hoped that this research would serve as a cornerstone in augmenting the enthusiasm of perspective Drilling engineers, be it in College or elsewhere. Finally, to all those who are interested in Shale inhibition, please look forward to my first book “An Engineer's Approach to Inhibitive Drilling Fluid Formulation Vol I" which is to be published in the year 2014.

Ike Eleanya Onuoha, M.S. PNGE

West Virginia University 